\title{
Role of infections on intimal hyperplasia : focus on Cytomegalovirus and Chlamydia pneumoniae
}

Citation for published version (APA):

Kloppenburg, G. T. L. (2009). Role of infections on intimal hyperplasia : focus on Cytomegalovirus and Chlamydia pneumoniae. [Doctoral Thesis, Maastricht University]. Maastricht University. https://doi.org/10.26481/dis.20090424gk

Document status and date:

Published: 01/01/2009

DOI:

10.26481/dis.20090424gk

Document Version:

Publisher's PDF, also known as Version of record

\section{Please check the document version of this publication:}

- A submitted manuscript is the version of the article upon submission and before peer-review. There can be important differences between the submitted version and the official published version of record.

People interested in the research are advised to contact the author for the final version of the publication, or visit the DOI to the publisher's website.

- The final author version and the galley proof are versions of the publication after peer review.

- The final published version features the final layout of the paper including the volume, issue and page numbers.

Link to publication

\footnotetext{
General rights rights.

- You may freely distribute the URL identifying the publication in the public portal. please follow below link for the End User Agreement:

www.umlib.nl/taverne-license

Take down policy

If you believe that this document breaches copyright please contact us at:

repository@maastrichtuniversity.nl

providing details and we will investigate your claim.
}

Copyright and moral rights for the publications made accessible in the public portal are retained by the authors and/or other copyright owners and it is a condition of accessing publications that users recognise and abide by the legal requirements associated with these

- Users may download and print one copy of any publication from the public portal for the purpose of private study or research.

- You may not further distribute the material or use it for any profit-making activity or commercial gain

If the publication is distributed under the terms of Article $25 \mathrm{fa}$ of the Dutch Copyright Act, indicated by the "Taverne" license above, 


\section{Role of infections on intimal hyperplasia}

Focus on Cytomegalovirus and

Chlamydia pneumoniae

Geoffrey T. L. Kloppenburg 


\title{
Role of infections on intimal hyperplasia
}

\section{Focus on Cytomegalovirus and}

\section{Chlamydia pneumoniae}

\author{
PROEFSCHRIFT \\ ter verkrijging van de graad van doctor aan de Universiteit Maastricht, \\ op gezag van de Rector Magnificus, Prof.mr. G.P.M.F. Mols \\ volgens het besluit van het College van Decanen, \\ in het openbaar te verdedigen op \\ vrijdag 24 april 2009 om 14.00 uur
}

Cover: Hester Graeler

Lay out:Legatron Electronic Publishing, Rotterdam

door

Printed by: Ipskamp, Enschede (www.ppi.nl)

Geoffrey T. L. Kloppenburg

ISBN: $x x x-x x-x x x x x x x-x$

Copyright $\odot 2009$ G.T.L. Kloppenburg

Geboren te Oss op 9 augustus 1979

All rights reserved. No part of this book may be reproduced or transmitted in any

form or by any means, without prior written permission of the author. 


\section{Promotor:}

Prof.dr. C.A. Bruggeman

\section{Copromotor:}

Dr. F.R.M. Stassen

\section{Beoordelingscommissie:}

Prof.dr. J.G. Maessen (voorzitter)

Prof.dr. H.J.G.M. Crijns

Prof.dr. J.P. van Hooff

Dr. W.J. Morshuis (Cardiothoracale Chirurgie St. Antonius Ziekenhuis, Nieuwegein)

Prof.dr. J.F.M. Smits

\section{Contents}

Preface

Chapter 1 General introduction

1. Cytomegalovirus 10

2 Chlamydia pneumoniae 17

3 Cytomegalovirus and Chlamydia pneumoniae in 20 arterial restenosis

4 Cytomegalovirus and Chlamydia pneumoniae in venous 22 bypass failure

5 Cytomegalovirus and Chlamydia pneumoniae in 26 transplantation arteriosclerosis 26

6 Therapeutic approach: Activin A and venous bypass failure 32

Aims and outline of the thesis

Chapter 2 Cytomegalovirus aggravates intimal hyperplasia in rats

\section{by stimulating smooth muscle cell proliferation}

Chapter 3 FK778 attenuates cytomegalovirus-enhanced vein graft intimal hyperplasia in a rat model

Chapter 4 Chlamydia pneumoniae aggravates vein graft intimal hyperplasia in a rat model

Chapter 5 Chlamydia pneumoniae infection is not associated with chronic transplant dysfunction in a rat aortic allograft model

Chapter 6 Adenoviral activin A expression prevents vein graft intimal hyperplasia in a rat model 
Chapter 7 General discussion

Summary

Samenvatting

Dankbetuigingen

About the author

List of scientific papers

Color figures

\section{Preface}

Atherosclerotic disease is the most common origin of cardiovascular disorders giving rise to the leading cause of death of adults living in the western world. Atherosclerosis is a complex ongoing disease starting early in the twenties and involving many risk factors ultimately leading to unstable atherosclerotic plaques, ischemia, infarction and eventually death. Treatment options are generally available and include drug therapy to influence features like hypercholesterolemia, diabetes and hypertension as well as prevention of thrombus formation. Interventions are also possible with percutaneus revascularization techniques or more invasively with bypass grafting of coronary or peripheral arteries. End stage atherosclerotic disease leading to permanent damaged solid organs as seen after massive myocardial infarction may require organ transplantation.

Unfortunately the long term results of these interventions are compromised by renewed narrowing of either the former dilated lesion after percutaneus angioplasty (restenosis), the venous bypass graft (graft failure) or the smaller arteries in the solid grafts (transplantation arteriosclerosis). The linking factor between these different modalities is neointimal hyperplasia which is the major cause of restenosis, graft failure and transplantation arteriosclerosis. Although subject of study for several years the exact factors influencing neointimal hyperplasia are still not completely elucidated. Recent epidemiological associations and pathological evidence have suggested a role for micro-organisms like Cytomegalovirus and Chlamydia pneumoniae on the process of intimal hyperplasia.

Whether these pathogens play a causal role or are just present as an innocent bystander has remained rather unclear and is subject of this thesis. In addition we investigated a novel therapeutic gene based approach of preventing intimal hyperplasia. 


\section{Chapter 1}

General introduction 


\section{Cytomegalovirus}

\subsection{Characteristics of cytomegalovirus}

The human herpesvirus family consists of nine members: herpes simplex virus types 1 (HSV-1) and 2 (HSV-2), varicella-zoster virus (VZV), Epstein-Barr virus (EBV), cytomegalovirus (CMV), human herpesvirus 6 (variants $A$ and $B$ ), human herpesvirus 7, and Kaposi's sarcoma virus or human herpesvirus 8. CMV belongs to the betaherpesvirinae together with alphaherpesvirinae and gammaherpesvirinae one of the three subfamilies within the family of herpesviridae. The alphaherpesvirinae, HSV-1, HSV-2 and VZV are characterized by an extremely short reproductive cycle (hours), prompt destruction of the host cell, and the ability to replicate in a wide variety of host tissues. They characteristically establish latent infection in sensory nerve ganglia. The betaherpesvirinae, CMV and HHV-6 and HHV-7 have a restricted host range. Their reproductive life cycle is long (days), with infection progressing slowly in cell culture systems. A characteristic of these viruses is their ability to form enlarged cells, as exemplified by CMV. These viruses can establish latent infection in secretory glands, cells of the reticuloendothelial system, and the kidneys. The gammaherpesvirinae, EBV and HHV-8 have the most limited host range. They replicate in lymphoblastoid cells in vitro and can cause lytic infections in certain target cells. Latent virus has been demonstrated in lymphoid tissue (Roizmann 1992).

\subsection{Structure and replication of cytomegalovirus}

The virus has a unique four-layered structure: a core containing the large linear double-stranded DNA genome of $229 \mathrm{~kb}$ with a molecular weight of $150-155 \times 10^{6} \mathrm{Da}$. The genome contains two unique segments, US (short) and UL (long), one internal repeat and two terminal repeat sequences enclosed by an icosapentahedral symmetric capsid with a diameter of $100-110 \mathrm{~nm}$ which is composed of 162 capsomers. The capsid is tightly surrounded by an amorphous protein coat called the tegument. Loosely surrounding the capsid and tegument is a glycoprotein-bearing lipid bilayer envelope derived from host cell membranes. Several host proteins have been found in the envelope, among them annexin and beta-2 microglobulin (Wright 1995, Grundy 1987).

CMV encodes for many proteins that are non-essential for virus replication but are important to establish life long persistence in its host (Chee 1990, Mocarski 2001 Griffiths 1997).During CMV infection virtally all cells of the body can be infected including: fibroblasts, endothelial cells, monocytes/macrophages, epithelial cells and smooth muscle cells. The virus behaves differently in different cell types. In some cells such as fibroblasts a fully permissive replication with production of infectious virus occurs while in other cells such as monocytes the infection is restricted to early events and no infectious virus is produced. Since it is known that fibroblasts are fully permissive cells for CMV replication these cells have been used as model to study the entry and replication of the virus. The virus enters these cells by attachment to extracellular heparan sulfate. When the viral envelope fuses with the host cell membrane, the nucleocapsid and the tegument proteins are released into the cytoplasm of the cell. The tegument contains proteins capable of transactivating viral genes. Transcription, genome replication, and capsid assembly occur in the host cell nucleus. In a productive infection genes are replicated in a specific order: (1) immediate-early (IE) genes, which encode regulatory proteins and act as trans-activators for many cellular promoters and (2) early $(E)$, genes which encode enzymes for replicating viral DNA and in turn activate (3) late (L) genes, which encode structural proteins and proteins which play a role in the assembly of the virus. Assembly of the viral core and capsid takes place within the nucleus. The tegument and envelope are acquired as the virion buds out at the nuclear membrane and during transport out of the nucleus through the endoplasmic reticulum and the Golgi complex. Glycosylation of the viral membrane occurs in the Golgi apparatus. Mature virions are transported to the outer membrane of the host cell inside vesicles. Release of progeny virus is accompanied by cell lyses (Compton 1993, Mocarski 2001, Mettenleiter 2002, Homman-Loudiyi 2003).

A unique characteristic of the herpesviridae is their ability to persist in the host in a quiescent state or so called latent infection. Viral latency is defined as the persistence of the viral genome in the absence of production of infectious virions, but with the ability of the viral genome to reactivate under specific stimuli. All herpesviruses have the potential to establish latency in specific host cells, and the latent viral genome may be either extra-chromosomal or integrated into host cell DNA. HSV-1, HSV-2 and VZV all establish latency in the dorsal root ganglia. EBV virus can maintain latency within B lymphocytes and salivary glands, while CMV, HHV-6 and HHV-7 have relatively unknown sites of latency. Monocytes are responsible for dissemination of the virus and are also thought to be the predominant cell for latency (Taylor-Wiedema 1991). The precise cellular sites in which CMV is carried and the mechanisms regulating its latency and reactivation remain poorly understood. CMV can be transmitted by blood transfusion and leucocyte depletion reduces the risk of infection suggesting strongly 
that one site of carriage of this virus was in the peripheral-blood compartment (Adler 1983, de Graan-Hentzen 1989). By using highly sensitive polymerase chain reaction (PCR) strategies, a number of laboratories have demonstrated the presence of CMV DNA in the peripheral blood leukocytes of healthy individuals and it has now become clear that especially peripheral blood monocytes are a major site of of CMV carried in a true latent state, with little or no accompanying viral IE expression (Prosch 1999, Taylor-Wiedema 1991, Söderberg 1993). Wether there are other sites of latency or long term-carriage of CMV is still matter of debate. Especially vascular cells such as smooth muscle cells and endothelial cells have been suggested to be a reservoir of latent virus, perhaps providing support to the evidence that has linked CMV infection to atherosclerosis (Jarvis 2002, Hendrix 1990).

\subsection{Epidemiology and clinical presentation of cytomegalovirus infection} CMV is found universally throughout all geographic locations, and seroepi-demiological studies have demonstrated a high prevalence of antibodies against HCMV up to $50 \%$ till $85 \%$ of all individuals. The seroprevalence depends on socioeconomic state and in western countries the seroprevalence increases with $10 \%$ every decade resulting in a total prevalance of $85 \%$ by the age of 75 (Staras 2006).

In adults transmission of $\mathrm{CMV}$ occurs from person to person mainly during sexual interplay or by contact with young children. Infection requires close, intimate contact with a person excreting the virus in saliva, urine, or other body fluids. CMV can be sexually transmitted and can also be transmitted via breast milk, transplanted organs and by blood transfusions. The immune status of the host is an important determinant in the clinical course of CMV infection. Most infections in immunocompetent individuals are subclinical although some persons may experience symptoms resembling infectious mononucleosis, with prolonged fever, nausea, fatigue, pharyngitis, mild hepatitis and occasionaly rash. Suggestive laboratory findings include atypical lymfocytosis, abnormal liver functions and thrombocytopenia (Klemola 1973, Jordan 1973).

Although CMV is not associated with clinical apparent disease in non immunosuppressed hosts it may cause severe symptoms in immunosuppressed patients. In newborns severe infections with clinical findings as hepatitis, splenic enlargement and central nervous systems disease are reported. Infection of the developing fetus in utero (congenital infection) is characterized by high levels of replicating virus in many organs (Boppana 1997, Boppana 1992).
CMV infection is the most common congenital infection in humans. Between 1 and $2 \%$ of the infants born are infected in utero and an additional 8 to $60 \%$ of the newborns become infected in the first months after birth mainly due to infection occurring during labor or breastfeeding. Infants and children who get CMV infection after birth have few, if any, symptoms or complications. When symptoms do appear, they are generally mild and include lung problems, poor weight gain, swollen glands, rash and jaundice. In rare cases newborns can have a life-threatening infection mostly acquired in utero during primary infection of the mother. Up to $30 \%$ of these infants become infected in utero if the mother is found to be CMV IgM seropositive or if IgG seroconversion is present. In this group 5 to $18 \%$ is symptomatic at birth resulting in a severe congenital CMV disease characterized by hepato-splenomegaly, prolonged jaundice, petechia and pneumonitis. Other consequences of intrauterine CMV infection are fetal growth retardation, pre-term birth and intra-uterine death resulting in a mortality of almost $30 \%$. Survivors are confronted with a high morbidity of $80 \%$ and may suffer from severe neurological impairments including microencephalopathy, cerebral palsy, mental retardation, delayed psychomotor development and often sensor neural hearing loss. Many of these children require custodial care for life, with significant public health implications (Stagno 1982, Stagno 1983, Revello 2004).

CMV disease is a well-known cause of morbidity and mortality in people with weakened immune system as seen for example in solid organ and bone marrow transplant recipients and in patients with AIDS. The pathogenesis of CMV infections in these immunosuppressed hosts is related to the level of virus replication in several organs (Emery 1999, Gewurz 2001).

The manifestation of CMV infection is not only dependent on the viral burden but a lot of variables, such as severity of immune suppression, past experience of the host with the virus (primary infection, donor seropositivity and recipient seronegativity), play a role in the pathogenesis. In transplant recipients the degree of major histocompatibility complex mismatch has also an influence on pathology of CMV disease. In general primary infection results more often in severe symptomatic CMV disease compared to re-infection. Symptoms also tend to be more pronounced in heart, liver and lung recipients compared to kidney transplant recipients, in whom immunosuppressive regimens are less rigorous. In addition to symptomatic CMV infections, CMV may predispose the transplant recipients to bacterial and fungal infections (Rubin 1990). CMV infections also play an important role in allogenic bone marrow transplant recipients. The loss of immune response in these patients has been 
shown to lead to uncontrolled virus replication leading to massive and widespread viral dissemination. Especially the loss of T-cell reactivity is responsible for reactivation of CMV and for the development of disease (Reusser 1997). Reactivation of CMV in already seropositive recipients is common occurring in up to $65 \%$ of those patients (Miller 1986). In contrast to the high prevalence of CMV infection the frequency of serious CMV disease has been reported to be considerably lower, generally occurring in about 2 to $8 \%$ in bone marrow transplant recipients. Immunotherapy with CMV-specific CD8 T-cells provided passive protection in these patients (Walter 1995, Boeckh 2003). The most severe manifestations of CMV disease after bone marrow transplantation are interstitial pneumonia and less common gastrointestinal involvement leading to gastrointestinal haemorrhage and CMV hepatitis which may result in a high mortality rate of $80 \%$ despite antiviral treatment (Konoplev 2001, Enright 1993).

Virtually every HIV infected adult is CMV seropositive and shedding of infectious virus is common. Generalized infection with viraemia occurs frequently at low CD4 T-cell numbers but the clinical presentation of CMV infection in immunosuppressed individuals differs between organ transplant recipients and AIDS patients. In the latter CMV commonly infects the retina of the eye (CMV retinitis) and cause blindness, but also gastrointestinal involvement, encephalitis and polyradiculopathy are frequently reported in these patients. Occurrence of CMV pneumonia results in a high fatality rate and is often complicated by other opportunistic pathogens, in particular Pneumocystis carinii, however the incidence of CMV disease seems to be declining since the introduction of highly active antiretroviral therapy (HAART) that include protease inhibitors (Accorinti 2006, Gross 1990, Schooley 1990).

Over the years an increasing amount of evidence emerged linking CMV to cardiovascular pathologies especially atherosclerosis. In 1987 a study was published showing a higher incidence of CMV antibodies in patients with severe atherosclerosis needing a surgical revascularisation than in control patients (Adem 1987). A more causal role of cytomegalovirus and atherosclerosis was suggested by Nieto and co-workers who showed in a cohort study a relation between the development of an aggraveted intimal-medial hyperplasia in the carotid artery and the presence of a higher amount of CMV antibodies 15 years earlier (Nieto 1996). Besides its role in atherosclerosis CMV is a significant post-allograft pathogen and contributes to more frequent rejection episodes, increased transplant related arteriosclerosis, and subsequent graft loss after cardiac transplantation (Grattan 1989).

CMV has been also frequently associated with inflammatory bowel disease (IBD) especially in steroid treatment resistent cases (Adani 2001). In some cases, CMV infection is associated with a poor outcome but it is not clear which patients are more likely to be affected and in which stage of the disease. The use of anti-viral therapy in IBD may be benificial but still is controversial and an empirical study with controls is lacking (Kishore 2004, Kandiel 2006).

\subsection{Treatment of Cytomegalovirus infection}

No treatment is generally necessary for $\mathrm{CMV}$ infection in the healthy individual since the majority of infections resolve on their own. Before the introduction of specific antiviral drugs against CMV hyperimmune globulin was used to prevent CMV disease in transplant recipients. However CMV hyperimmune globulin has been found by some investigators to be ineffective in the treatment of $C M V$ disease in solid-organ transplant recipients (Burdelski 1987).

Nowadays ganciclovir treatment is the drug of choice used for patients with depressed immunity who have either sight-related or life-threatening illnesses. The orally applicable valine ester of ganciclovir: valganciclover is also frequently used (Curran 2001, Baldanti 1996, Matthews 1988). It is a prodrug which is phosphorylated to ganciclovir 5'-monophosphate by a protein encoded by the UL97 open reading frame of human CMV and then to the di- and triphosphate forms by host cellular kinases. The active drug inhibits viral replication by competing with deoxyguanosine triphosphate as a substrate for the enzyme DNA polymerase. The incorporation of ganciclovir triphosphate into the growing chain of viral DNA slows extension, thus inhibiting viral replication. Adverse effects of ganciclovir when administered to solid-organ transplant patients are less frequent than in bone marrow transplant recipients and AIDS patients. They include leukopenia, thrombocytopenia, anaemia, eosinophilia, bone marrow hypoplasia, haemolysis, nausea, infusion site reactions, diarrhoea, renal toxicity, seizures, mental status changes, fever, rash, and hepatocellular dysfunction (Buhles 1988, Pava 2004, European/Australian comparative study of efficacy and safety in the prevention of cytomegalovirus retinitis recurrence in patients with AIDS, 1995).

Other anti CMV drugs are foscarnet and cidofovir. They do not require a viral function for activity. Foscarnet or cidofovir can be given in patients with CMV resistant to ganciclovir, though foscarnet is not as well tolerated as ganciclovir. Foscarnet is an inorganic pyrophosphate analogue that does not need to be phosphorylated into an active form by viral or host cell enzymes. It selectively inhibits viral DNA polymerase and is virostatic (Ringden 1986, Baldanti 2004). 
Cidofovir, (S)-1-[3-hydroxy-2-(phosphonylmethoxy)propyl]cytosine, a nucleotide analogue of dCMP, is a novel agent that has been introduced to the antiviral pharmacopoeia (De Clercq 1987). Unlike ganciclovir, cidofovir does not require viral enzymes for activation. It is used almost exclusively for the treatment of CMV infection in patients with AIDS. A major drawback of cidofovir is its associated nephrotoxicity; this can be partially averted by the concurrent administration of probenecid. Neutropenia and constitutional reactions to probenecid may be encountered.

Novel antiviral compounds such as benzimidazole, adefovir, and lobucavir might further improve the management of CMV infection (Zhou et al. 1997, Xiong et al. 1997, Tenny et al. 1997). Moreover, antisense oligonucleotides complementary to RNA transcripts of IE genes provide a novel mechanism of inhibition for viral replication (Anderson 2004).

Ultimately, control of CMV infection, particularly the devastating sequelae of congenital CMV disease, depends on immunization. The major target population for a CMV vaccine is women of childbearing age, in addition a vaccine can also be useful in controlling CMV disease in organ transplant recipients. A live attenuated vaccine, the Towne vaccine, showed promising results for prevention of CMV disease in studies involving renal transplant recipients. However, the Towne strain of CMV is poorly immunogenic, probably because it has been attenuated during the process of tissue culture passage (Plotkin 1994, Plotkin 2004). Newer technologies using recombinant chimeric viruses that represent genetic hybrids between Towne virus and a lowpassage clinical isolate, the Toledo strain, are currently under investigation as the next generation of live-virus CMV vaccines. Subunit vaccine approaches are also being explored. In these vaccines molecularly cloned eucaryotically expressed forms of the major immunogenic CMV envelope protein are used. Another approach is the vectored vaccine approach in a genetically engineered poxvirus vector, canarypox, is also under evaluation. In addition to gB, this approach targets the major CTL target, the UL83 gene product (Gonzol 2001, Berencsi 1996, Pass 1999). Although there is no doubt about the importance to have a CMV vaccine a lot of work has still to be done before a vaccine will be available.

\section{Chlamydia pneumoniae}

\subsection{Characteristics of Chlamydia pneumoniae}

Since 1989 Chlamydia pneumoniae (C. pneumoniae) has been recognized as the third species in the genus Chlamydia. C. pneumoniae was first isolated from the conjunctiva of a child in Taiwan in 1965 and was established as a major respiratory pathogen in 1983 when it was isolated from the throat of a college student at the University of Washington (Grayston 1986). The family Chlamydiaceae consists of genus Chlamydia (C. trachomatis, C. suis and C. muridarum) and genus Chlamydia (C. pneumoniae, C. psittaci, C. abortus, C. caviae, C. felis and C. pecorum) (Everett 1999). Three of these species are known to infect humans. $C$. trachomatis, which can cause urogenital infections, trachoma, conjunctivitis, pneumonia and lymphogranuloma venereum, $C$. psittaci, which can cause pneumonia (psittacosis) and C. pneumoniae. C. pneumoniae causes approximately $10 \%$ of community-acquired pneumonia and $5 \%$ of pharyngitis, bronchitis, and sinusitis. Most infections caused by C. pneumoniae however are subclinical or are characterized by mild flu-like symptoms (Hammerschlag 2002, Kuo 1995).

\subsection{Structure and replication of Chlamydia pneumoniae}

Chlamydiae are small obligate intracellular pathogens and were once considered to be viruses. However, they contain DNA, RNA and ribosomes and make their own proteins and nucleic acids and are now considered to be true bacteria. They possess an inner and outer membrane similar to those of gram-negative bacteria (Cook 1994).

The development of Chlamydia occurs in the cytoplasm of the cell. Chlamydia exists in two forms: a small (0.3-0.4 $\mu \mathrm{m})$ transmissible form called elementary body (EB) and a larger intra-cellular metabolic form called reticulate body (RB) (Ward 1988). The EB is metabolically inert and exists outside of cells. The ultrastructure of Chlamydiae is characterized by a peer-shaped EB. Chlamydiae do not contain a cell wall, but the outer membrane of the EB contains a number of cysteine containing proteins that are heavily cross-linked by disulfide bonds. This stabilizes its outer surface and enables it to survive outside a host. The genome of an EB is densely packed. This is facilitated by histone-like proteins that bind to the DNA and cause it to aggregate inside the EB. Infection of the host cells occurs by attachment of the peershaped EB to the cell's membrane, followed by invagination and endocytosis (Kuo 1988). Inside the host cell the EB differentiates to a metabolic active RB which is the replicative form. In the RB, DNA is not bound to histones, and many more ribosomes, 
mRNA and proteins are found. After two to four days RB mature into EB and cell lyses occurs giving rise to free EB able to infect other cells. C. pneumoniae is able to infect a diversity of cell types like macrophages, endothelial and smooth muscle cells (Gaydos 1996).

\subsection{Epidemiology and clinical presentation of Chlamydia pneumoniae infection}

Transmission occurs from person-to-person by respiratory secretions. All ages are at risk. Seroprevalence of antibodies is common and increases with age (Grayston 1992). Antibodies against $C$. pneumoniae are rare in children under the age of 5 , but common in school-age children. At the ages of 7 and 8 years already $10 \%$ of the children have $C$. pneumoniae antibodies often without a history of clinical respiratory infections (Volanan 2003). In the United States, about $50 \%$ of adults have antibodies against $C$. pneumoniae Antibody prevalence continues to increase slowly to $70 \%$ to $80 \%$ at ages 60 to 70 (Grayston 1986). Recurrent C. pneumoniae disease is common and may result from either repeated infections or persistence of the organism after unresolved infections. However the high incidence of $C$. pneumoniae infections and transient immunity observed after infection posses difficulties in differentiating between persistent infection and re-infection (Patnode 1990).

C. pneumoniae is a well known cause of community acquired respiratory tract infections (Grayston 1993). The clinical symptoms of C. pneumoniae pulmonary infections are similar to those caused by most other respiratory pathogens; the main difference is the ability of $C$. pneumoniae to cause chronic complications. The spectrum of illness can range from asymptomatic infection to severe disease wherein subacute onset and pharyngitis are common. In young children $C$. pneumoniae is associated with upper respiratory tract infections like rhinitis, sinusitis and acute tonsillopharyngitis which left untreated may predispose to lower respiratory tract infections (Norman 1998, Esposito 2006). A biphasic pattern of disease is observed in adults, with pharyngitis resolving before bronchitis or pneumonia develops. Cough is very common and prolonged. Pneumonia is often relatively mild, although approximately 50,000 individuals are hospitalized with this illness in the U.S. every year. Recovery is often slow, even with antibiotic therapy and cough and malaise may persist for many weeks (Kauppinen 1995).

In addition to these acute infections, C. pneumoniae is also associated with a range of chronic diseases that are characterized by persistent inflammation and scarring and may result in significant damage to the host. Here, $C$. pneumoniae seems to be present in a persistent state. Persistence is characterized by modified bacterial metabolism and morphology, as well as a reversible arrest of chlamydial development until reactivation takes place (Beatty 1994). In particular peripheral blood monocytes are able to harbour persistent $C$. pneumoniae which renders it relatively refractory to antibiotic treatment (Gieffers 2001). In cell culture, this persistent state can be induced by gamma interferon. C. pneumoniae is able to cause long-lasting changes in the expression of genes involved in anti-apoptosis, cell cycle control, and host cell metabolism in gamma interferon induced persistence (Eickhoff 2007).

Unresolved respiratory $C$. pneumoniae infection or persistent chronic infection may contribute to the pathogenesis of several chronic inflammatory lung diseases, such as asthma and chronic obstructive pulmonary disease (Gencay 2001, Blasi 1993). In addition to pulmonary consequences, $C$. pneumoniae can also disseminate from the site of initial infection and has been associated with cardiovascular diseases like atherosclerosis myocarditis, vasculitis and myocardial infarction (Tong 1995, Ljungstrom 1997, Kuo 2003, Saikku 1988). Moreover presence of $C$. pneumoniae was detected in atherosclerotic lesions of coronary arteries as well as carotid arteries and lesion progression could be reduced with antibiotic treatment (Kuo 1993, Sander 2002).

Besides cardiovascular diseases chronic $C$. pneumoniae infection has also been linked to late-onset Alzheimer's disease and other clinical syndromes like erythema nodosum, sarcoidosis, multiple sclerosis and reactive arthritis (Balin1998, Yucescan 2001, Hannu et al. 1999, Stratton 2006, Gaede 2002, Erntell 1989).

\subsection{Treatment of Chlamydia pneumonia infection}

C. pneumoniae infections are susceptible to antibiotics that inhibit protein synthesis such as tetracyclines, macrolides and quinolones. Doxycycline is the treatment of choice except in children younger than 9 years and pregnant women. Treatment should be continued for at least 10-14 days after defervescence. If symptoms persist, a second course with a different class of antibiotics is usually effective. Alternatives include erythromycin and newer macrolides such as azithromycin and clarithromycin. Newer macrolides are better tolerated than erythromycin. Shorter courses of the newer macrolides appear to be effective. Telithromycin is the first antibiotic in a new class called ketolides and is approved for C. pneumoniae pneumonia. Fluoroquinolones, including levofloxacin and more recent ones as gemifloxacin and moxifloxacin also have some activity, although less than that of tetracyclines or macrolides (Kauppinen 1995, Hammerschlag 1992, Miyashita 2002, Riog 2006). In 
addition vaccines are curently under development and have been shown effective in animal models (Thorpe 2007).

\section{Cytomegalovirus and Chlamydia pneumoniae in arterial restenosis}

\subsection{Arterial restenosis}

Coronary artery stenosis, resulting from advanced atherosclerosis, is commonly treated with percutaneous transluminal coronary angioplasty (PTCA) and stenting. Unfortunately, the initially high success rate is in $30-50 \%$ of all cases compromised in the long run by the problem of restenosis, a renewed narrowing of the formerly dilated vessel (Glagov 1994). Despite intensive investigation, the exact underlying pathological mechanisms and causal factors still have to be elucidated. Pathological processes underlying atherosclerosis and restenosis resemble but are not identical. In contrast to atherosclerosis, which is considered as an ongoing chronic inflammatory disease that develops over decades, restenosis is initiated by an acute mechanical injury to the vessel wall resulting in luminal narrowing within a period of several weeks to months (Schwartz 2002). Neointimal hyperplasia is a major factor in the restenosis problem, although other factors might be equally important (Tanaka 1995). Additional factors include thrombus formation, intimal and medial dissections and elastic recoil of the arterial wall. Recent epidemiological studies indicated that infectious agents, like Helicobacter pylori, C. pneumoniae and CMV may increase the risk of restenosis after PTCA, although reported results have not always been consistent (Horne 2002, Anderson 1995, Patel 1995). Below, we will briefly discuss this possible role of both $\mathrm{CMV}$ and $\mathrm{Cpn}$ in restenosis.

\subsection{Cytomegalovirus and arterial restenosis}

In 1996, it was Epstein and co-workers who first reported that prior infection with CMV might be a strong independent risk factor for restenosis after coronary atherectomy (Zhou 1996). Additional evidence has been provided by Blum et al. who demonstrated that high antibody titers against CMV correlated with the prevalence of coronary artery disease and predicted post PTCA restenosis (Blum 1998). Even after aggressive ballooning with coronary stenting, patients with prior $\mathrm{CMV}$ infection had a smaller permissive lumen and a higher restenosis rate at six month after intervention (Mueller 2003). However, not always was CMV IgG seropositivity found to carry an increased risk of restenosis after stenting (Neumann, 2001, Schiele 2001).
Concerning the underlying mechanisms, it has been speculated that angioplastyinduced injury to the vessel wall reactivates latent CMV (Guetta 1997). Then, once reactivated, the virus causes excessive accumulation of SMCs in the developing neointima and thereby contributes to restenosis. Molecular mechanisms involved in this process may include including inhibition of p53 function (which could enhance SMC proliferation or inhibit apoptosis), an increase in cytokine expression and coagulability of CMV-infected endothelial cells with an increased platelet and monocyte adhesion or the substantial up-regulation of the beta-receptor of plateletderived growth factor in SMC with an increased proliferative activity following stimulation (Tanaka 1999, Speir 1994, Span 1991, Reinhardt 2005). Also the marked degradation of the extra-cellular matrix due to a reduction in collagen type I and fibronectin synthesis as well as the enhanced MMP-2 protein production and activity following CMV infection of SMC might be a factor in the augmented response to injury following eg balloon angioplasty (Reinhardt 2006). Importantly, the latter may facilitate migration of SMC to the lesion site which is interesting in view of the observation that the US28 gene product, a chemokine receptor encoded by CMV, is also able to stimulate SMC migration (Streblow 1999).

However, the importance of these predominantly in vitro findings may be limited for our knowledge regarding the underlying mechanisms of CMV-enhanced restenosis in vivo. Yet, in contrast to findings in atherosclerotic specimens, CMV DNA could not be demonstrated unequivocally in endarterectomy material from patients suffering from either coronary restenosis or progressive allograft coronary artery disease (Gulizia 1995, Kol 1995). This suggests that the presence of the virus in the vascular wall may not be a prerequisite as inflammatory and immune responses to chronic persistent $C M V$ infection may be more important for the exaggerated response to vascular injury in CMV seropositives (Stassen 2006, 2008). This is supported by findings in animal models showing that $\mathrm{CMV}$ infection of immunocompetent adult rats increases the neointimal response to vascular injury despite the absence of virus in the vascular wall (Zhou 1999, 2000).

\subsection{Chlamydia pneumoniae and arterial restenosis}

In contrast to its role in atherosclerosis, the effect of $C$. pneumoniae on restenosis has been less well established. Sero-epidemiological evidence has been provided by Hayashida et al., who showed the presence of anti C. pneumoniae IgG antibodies to be a strong independent risk factor for restenosis after percutaneous intervention (Hayashida 2002). These findings have been confirmed by others who demonstrated 
pre-procedural seropositivity of anti C. pneumoniae IgA antibodies to be related with re-intervention, need for coronary artery bypass grafting, myocardial infarction, death and angina pectoris after the intervention, even when stents were used to prevent coronary intimal hyperplasia (Rahel 2004, Tanaka 2001). In addition, in patients with high $C$. pneumoniae antibody titres, roxithromycin reduced the rate of restenosis after coronary stent placement (Neumann 2001).

As already mentioned for $\mathrm{CMV}$, the association between restenosis and the presence of $C$. pneumoniae in the vascular wall is scant. Although $C$. pneumoniae could be detected in $32 \%$ of all endatherectomy specimens taken from patients undergoing coronary artery bypass grafting, no associations with secondary lesions could be demonstrated (Radke 2001). Likewise, C. pneumoniae was also found in carotids plaques obtained from patients undergoing carotid endarterectomy. Yet, during a four year follow-up period no causal role for C. pneumoniae in restenosis or progression of carotid disease or mortality was seen in this patient group (Jahromi 2003). Therefore, more detailed studies regarding the possible role of $C$. pneumoniae in restenosis and intima hyperplasia are required. Unfortunately, until now no experimental studies are available investigating a possible causal relationship between $C$. pneumoniae and restenosis.

\section{Cytomegalovirus and Chlamydia pneumoniae in venous bypass failure}

\subsection{Venous bypass failure}

Autologus saphenous vein grafts are commonly used for treatment of severe atherosclerosis via coronary artery bypass grafting (CABG) and infrainguinal bypass procedures in patients with critical limb ischemia. Although the initial results of these procedures are successful, the symptoms tend to recur due to degeneration and occlusion of the graft giving rise to $15-30 \%$ graft failure within one year and up to $50 \%$ of all grafts being occluded 10 years after surgery (Fitzgibbon 1996).

The main causes of venous graft failure are surgical trauma, intraoperative ischemia reperfusion injury, and implantation of a vein into the arterial circulation. In addition to surgical sequels, patients' characteristics like insulin dependent diabetes, impaired left ventricular function and target vessel diameter have also been shown to negatively influence long term graft patency (Cho 2006, Cataldo 1993, graft failure occurs within the first months after surgery and is predominantly caused by thrombotic events often due to mechanical trauma during vein harvesting and is thought to be responsible for $20 \%$ of all failed grafts. Late graft failure tends to occur after several years and is caused by accelerated atherosclerosis (Paz 1993). These causes may be treated with currently available antiplatelet and lipid lowering drug therapy which has been proven to be successful in several clinical studies (Christenson 2001). Intermediate failure of saphenous vein grafts is due to neointimal hyperplasia $(\mathrm{IH})$, defined as the accumulation of smooth muscle cells (SMC) and extra-cellular matrix in the intimal component of the vein which is most prominent in the first year after surgery but can occur up to three years after CABG (Barboriak 1978). This process of graft occlusion involves the migration of medial vascular smooth muscle cells to the lumen of the graft were they transform into a more synthetic phenotype. Then, these cells will start proliferating as well as secreting extra-cellular matrix proteins. These processes will ultimately result in the formation of a neointima. It has been strongly suggested that $\mathrm{IH}$ is associated with extensive endothelial denudation and destruction of venous grafts, resembling to the response to injury as seen after PTCA often leading to restenosis of the denuded artery (Logerfo 1983).

\subsection{Cytomegalovirus and venous bypass failure}

Whether the unresolved problem of venous coronary artery bypass graft occlusion is related to infection with $C$. pneumoniae and/or CMV has not been addressed extensively. Although multiple studies demonstrated a role for infectious agents, and in particular CMV, in atherosclerosis, restenosis and certainly in transplantation related vasculopathy, a possible contribution of $\mathrm{CMV}$ in venous bypass failure received only very limited attention so far and results have been inconclusive.

Bartels et al. demonstrated IgG CMV antibody titers, indicating prior CMV infection, to be present in $58.3 \%$ of the patients undergoing primary or repeated CABG. However, elevated IgM titers were not present and no CMV DNA could be detected by quantitative PCR in coronary desobliterated (dissecting the atherosclerotic cylinder from the adventitial layer of the coronary artery) samples or occluded aorto-coronary venous grafts obtained during re-operation (Bartels 2000). In addition, they failed to detect presence of CMV DNA in native saphenous veins used for CABG (Bartels 1999). Experimental studies could have addressed the question whether infections contribute to venous bypass failure in a more detailed way. However, to our knowledge studies focusing on a relationship between $\mathrm{CMV}$ and venous bypass failure in an experimental model are missing. They are important to further elucidate a possible involvement of a pathogen in the process of restenosis. 


\subsection{Chlamydia pneumoniae and venous bypass failure}

In contrast to $\mathrm{CMV}$ the relationship between $C$. pneumoniae and venous graft failure has been more a subject of study. Bartels et al. were able to detect $C$. pneumoniae DNA in $25 \%$ of occluded vein grafts obtained from patients undergoing re-operations although they observed no differences regarding histopathological changes or proliferation rate of neointimal smooth muscle comparing $C$. pneumoniae positive and negative occluded vein grafts (Bartels 1999). Additionally they observed a strong correlation between elevated $C$. pneumoniae IgG titers and the presence of $C$. pneumoniae in occluded vein grafts (Bartels 2000). Similar data were shown by Zorc et al., suggesting an etiological role for $C$. pneumoniae in arterial bypass failure (Zorc 2005). Whether presence of $C$. pneumoniae in patients undergoing cardiac surgery increases changes of clinical sequela remains disputable. Zamorano et al. were unable to show a significant increased risk of subsequent death, recurrent intervention and myocardial infarction in patients with unstable angina who harboured $C$. pneumoniae in the coronary artery atherosclerotic plaques prior to CABG (Zamaro 2003).

Although presence of $C$. pneumoniae antibodies in patients with venous bypass failure has been reported in literature, again no experimental studies have been published yet shedding light on a possible causal relationship. One could however speculate that mechanisms resembling those previously discussed in the interplay between $C$. pneumoniae and restenosis may play a similar role in venous bypass failure. In vitro $C$. pneumoniae is able to infect endothelial cells, SMC, and macrophages. Infection in all these cell types can be persistent giving rise to a continuous state of activation (Gaydos 1996). For example C. pneumoniae is able to induce a permanent state of activation in SMC leading to induction of secretion of interleukin 6, tumor necrosis factor alpha (TNFa), interleukin-1-beta (IL-1B) and basic fibroblast growth factor (Rödel 2000). These pro-inflammatory cytokines play an important role in the process of atherosclerosis but may also be of importance in venous bypass failure. Indeed in a prospective study involving 99 patients raised preoperative IL-6 levels have been shown to be associated with both early graft occlusion and late cardiovascular events after CABG (Hedman 2007). Furthermore, IL-6 is able to induce the production of C-reactive protein (CRP), which is able to stimulate endothelial and smooth muscle cell proliferation thereby providing a pathway for $C$. pneumoniae to aggravate vein graft failure (Cirillo 2005). Indeed, increased levels of CRP are independent predictors of late all-cause mortality after primary on-pump CABG (Kangasniemi 2006). C. pneumoniae is also able to stimulate SMC activation and proliferation through a wide range of soluble growth factors secreted from infected neighboring endothelial cells, representing an important paracrine mechanism stimulating intimal hyperplasia (Coombes 1999, 2001).

Besides activation and proliferation the invasion of SMC as facilitated by matrix metalloproteinases (MMP's) is an important event in the development of intimal hyperplasia in saphenous vein bypass grafts. Inhibition of MMP's has been shown to reduce neointimal hyperplasia in human saphenous veins (Porter 1999, George 1998). Several studies delineate a relation between $C$. pneumoniae and MMP's. For example presence of $C$. pneumoniae in coronary artery atherosclerotic lesions correlates with MMP-9 expression and infection of monocytes by $C$. pneumoniae directly induces MMP activity (Arno 2005, Schmidt 2006).

Additionally Kol et al. have shown that chlamydial heat shock protein- 60 stimulates MMP-2 and MMP-9 production in atherosclerotic lesions hereby contributing to the breakdown of extracellular matrix and stimulating migration of SMC providing an additionally mechanism by which $C$. pneumoniae may be able to aggravate venous bypass graft failure in a similar fashion (Kol 1998).

If $C$. pneumoniae indeed contributes to venous graft failure it would be tempting to intervene with antibiotic treatment trying to improve clinical outcome after bypass grafting. Several small clinical trials have indicated that antibiotic treatment of $C$. pneumoniae infection is associated with a better outcome in patients with coronary artery disease. However evidence available from large meta-analysis to date does not demonstrate an overall benefit of antibiotic therapy in reducing mortality or cardiovascular events (O'Conner 2003, Gupta 1997, Sinisalo 2002, Andrews 2005). Nonetheless antibiotic treatment prior to coronary artery bypass grafting could be an interesting therapeutic option clinical studies focusing on antibiotic treatment and primary prevention of vein graft failure as determined by visualization with intra vascular ultrasound, computer tomography or angiography are still lacking. However Berg et al. treated patients scheduled for CABG surgery with clarithromycin demonstrating no differences focusing on secondary endpoints as recurrence of cardiovascular events or mortality (Berg 2005). Although in this study antibiotic treatment prior to coronary artery bypass grafting did not seem to influence secondary endpoints it is questionable whether this therapeutic regime was effective in eradicating $C$. pneumoniae from the vascular tissue. In a study published by the same group they tested the presence of $C$. pneumoniae in vascular tissue specimens by immunohistochemistry after treatment with clarithromycin in a group of patients with coronary artery disease waiting for CABG. They found no differences in the presence of $C$. pneumoniae major outer membrane protein antigen in the specimens 
from the group treated with clarithromycin in comparison with the specimens from the placebo-treated control group (Berg 2005).

Summarizing, there is evidence that $C$. pneumoniae is present in occluded saphenous vein grafts but until now it is unclear whether $C$. pneumoniae substantially contributes to graft failure in the long run. Therefore, experimental (animal) studies are mandatory to shed light on the possible causal relationship between $C$. pneumoniae infection and vein graft failure.

\section{Cytomegalovirus and Chlamydia pneumoniae in transplantation arteriosclerosis}

\subsection{Transplantation arteriosclerosis}

Organ transplantation has become an increasingly successful medical treatment for patients with end-stage organ failure. However, despite improvements in immunosuppressive drug therapy and treatment of acute rejection, long-term survival of solid-organ transplants is limited as a result of chronic transplant dysfunction (CTD).

The leading causes of death in the first year following cardiac transplantation include infection, rejection, and graft failure. After the first year, CTD is the second leading cause of death following cardiac transplantation and the incidence of CTD increases in the next years. This is illustrated by the International Society of Heart and Lung Transplantation registry, in which CTD is reported in only $7.0 \%$ of survivors at 1 year but in $32 \%$ and $46 \%$ of survivors at 5 and 8 years, respectively (International Society of Heart and Lung Transplantation (ISHLT) registry. http://www.ishlt.org/ registries). Furthermore, with the availability of intravascular ultrasonography, a sensitive imaging modality which allows excellent examination of the entire coronary arterial wall, it has become clear that up to $75 \%$ of all transplant patients have some form of transplantation arteriosclerosis already at 1 year post transplantation (Yeung 1995).

Cardiac allograft vasculopathy is thought to result from an initial injury to the endothelium of the allograft ensuing in a chronic inflammatory state. In the majority of organs and predominantly in the heart, this ultimately results in a persistent perivascular inflammation, diffuse multifocal myointimal hyperplasia and inadequate vascular remodeling with intimal narrowing of all the vessels in the graft, also named transplantation arteriosclerosis (TA) (Pethig 1998). In addition to the conventional risk factors for atherosclerosis, such as hyperlipidemia, hypertension and diabetes, determinants contributing to this inflammation include preservation injury, the frequency and intensity of acute rejection episodes, alloimmune response (cellular and humoral rejection), and cytomegalovirus infection (Cramer 1989, Tesi 1993, Winters 1990).

\subsection{Cytomegalovirus and transplantation arteriosclerosis}

Evidence linking infections and acute or chronic solid organ transplant rejection was first presented in the early 1970s and primarily refers to the role of herpes viruses and cytomegalovirus in particular (Lopez 1974). Cytomegalovirus infection in solid organ transplant recipients mostly occurs through reactivation of latent virus from either the infected graft (primary infection) or the recipient and epidemiological data revealed that CMV infections occur in $30 \%-65 \%$ of transplantation recipients, of which $18 \%-40 \%$ developed a symptomatic infection mostly within 1 to 3 months after transplantation (Reischig 2006). In a prospective study of 218 liver transplant recipients Paya and coworkers showed that $55 \%$ of patients developed CMV infection during the 1st year post-transplantation. Of the 62 episodes of documented organ involvement, liver was the major site (38 episodes), followed by lung, gastrointestinal tract and retina (Paya 1993). In another study, Lautenschlager et al. showed that there was at least one episode of rejection early after transplantation in ten liver transplants whose graft was lost due to histologically confirmed chronic rejection. All patients had a history of CMV infection usually following acute rejection. Persistent CMV-DNA was found in all of those grafts examined by DNA-hybridization in situ, CMVDNA was strongly expressed in the remaining bile ducts and moderately expressed in endothelial cells of the vascular structures. Persistent CMV genome was found in those structures that were the major targets of chronic rejection process in the liver (Lautenschlager 1997, Arnold 1992). Besides, a study concerning the relation between cytomegalovirus infection status and first-year mortality among orthotopic liver transplantation recipients showed that donor and recipient CMV serologic status is a significant pre-transplantation determinant for death in liver transplant recipients (Falagas 1997). In addition, CMV infection in heart transplant recipients has been shown to augment plaque progression as determined by quantitative intra-coronary ultrasound. The CMV-positive group showed more advanced, calcified lesions and the maximal plaque thickness was significantly enhanced compared to the CMV-negative group. Thus CMV seropositivity is a predictor for the progression of CTD independent of other cardiovascular risk factors while a positive PCR test for CMV even further increases the risk for accelerated transplant arteriosclerosis and consecutively transplant failure (Fateh-Moghadam 2003). 
The critical role of CMV infection in TA has also been demonstrated in experimental models. Compelling evidence for enhancing effect of CMV on transplantation arteriosclerosis comes from various transplantation models in rats using aortic, cardiac, kidney and liver allografts as well as a trachea model. Infection of the immune-competent recipients resulted in an early inflammatory response with an increased influx of monocytes/macrophages and T-lymphocytes in the aortic and cardiac allograft vascular adventitia and intima and in the airway wall of tracheal allografts (Koskinen 1994, Li 1996). This early inflammatory response leads to enhanced intimal thickness in vascular and cardiac allografts and enhanced luminal occlusion of tracheal allografts (Lemström 1993, 1995, 1996). Similar findings were reported using a rat kidney allograft in which CMV infection prolonged and increased graft inflammation and accelerated chronic rejection of renal allografts (Lautenschlager 1997). The role of CMV in TA is further corroborated by data demonstrating that antiviral drug treatment entirely abolished the enhanced intimal response and luminal occlusion in allografts (Lemström 1997, 1994, Tikkanan 2001).

Several mechanisms have been suggested to explain the association between CMV and transplant rejection. The findings in the studies mentioned before could partially be explained by the direct effects of CMV infection on the inflammatory response leading to the development of transplant arteriosclerosis and allograft rejection. CMV infection triggers an immune response by inducing MHC antigens and adhesion molecules on the cell surface making the cells a target for immunological attack. Indeed, CMV immediate early proteins (IE-1 and IE-2) increase the constitutive expression of several cell surface molecules by CMV-infected endothelial cells that are involved in the adhesion of leukocytes, such as intracellular adhesion molecule1 (ICAM-1), vascular adhesion molecule-1 (VCAM-1), vascular adhesion protein-1 (VAP-1), E-selectin and MHC class I antigens (van Dorp 1989, Kloover 2000, Martelius 2000). Also, a cross-reaction between the viral protein and MHC molecules cannot be excluded because $C M V$ has been shown to encode a protein homologous to MHC class I antigen, and a CMV IE-2 protein has been found to share an epitope with the HLA-DRB chain (Beck 1988, Fujinami 1988). Furthermore, CMV infection has been shown to induce the production of chemokines, like CCL5 (earlier called Regulated upon Activation, Normal $T$-cell Expressed, and Secreted or RANTES) and monocyte chemotactic protein-1 (MCP-1), which subsequently induce the migration of the inflammatory cells to the sites of the chemokine production. It has been suggested that this results from generation of reactive oxygen species (ROS) following CMV infection of for example smooth muscle cells (SMC). This ROS production may subsequently result in the production of chemokines as well as pro-inflammatory cytokines (Speir 1998). Apart from its effects of host chemokine production it has been demonstrated that CMV encodes several viral chemokines, like as US28, which have been implicated in vascular disease because of their ability to induce SMC migration (Streblow 1999). It has also been reported that immediate early gene products of HCMV increase SMC proliferation possibly by augmenting platelet derived growth factor- $B$ (PDGF- $B$ ) receptor expression and enhancing migration of cells towards the PDGF- $B$ receptor (Zhou 1999). Additionally, CMV might induce proliferation of SMC in the vascular wall by altering the SMC metabolism due to the production of an immediate early gene product of CMV, IE2-84, which has been shown to bind to and inactivate the tumor suppressor gene p53 (Speir 1994). CMV may also interfere with the endothelial nitric oxide system. This is supported by recent data showing that CMV infection accelerates CTD through its ability to diminish the vascular protective effects of the endotheliumderived nitric oxide system (eNOS) (Speir 1998, Weis 2004). The importance of the eNOS system for TA has recently been demonstrated in eNOS deficient mice, in which aortic allograft failure was significantly accelerated (Lee 2000). Furthermore, gene delivery of eNOS to cardiac allografts at the time of transplantation, extended graft survival, and inhibited NFKB activation, adhesion molecule expression and leukocyte infiltration (Iwata 2001).

Most of the molecular mechanisms mentioned above require infection of specific cells like SMC. However, although several studies have shown a stimulating effect of cytomegalovirus infection on CTD, in the rat aortic allograft model only a few RCMV-positive cells in allografts could be detected at any time point and the infected cells mainly appeared to be mononuclear inflammatory cells and not SMC (Lemström 1993). This suggests that aside from its effects in causing local disease, CMV is also recognized to have indirect effects, consistent with the induction of a pro-coagulant and pro-inflammatory state. Indeed, CMV is able to induce a procoagulant environment on endothelial surfaces. This probably occurs because CMV surface molecules contain pro-coagulant phospholipids that promote the assembly of a complex between factors $\mathrm{Xa}$ and cofactor Va. Also, CMV has the ability to form prothrombinase leading to thrombin generation (van Dam-Mieras 1992, Pryzdia 1994).

In addition to its potential role in chronic allograft dysfunction, CMV is a marked risk factor for acute allograft rejection episodes and has been shown to actively boost the alloimmune response (Potena 2006, Lemström 1995). The latter is supported by earlier data demonstrating the efficacy of triple drug immunosuppression on RCMVinduced allograft arteriosclerosis suggesting that CMV aggravates SMC proliferation 
and CTD indirectly by stimulating the immune response (Lemström 1994). Nevertheless, there might be two sides on the coin of anti-rejection therapy, as it might also suppress CMV specific cytotoxic T-cell responses and result in prolonged viraemia, which in turn could cause a prolonged alloreactive cytotoxic response increasing the risk of allograft rejection and vascular disease (Tu 2006). Interesting in this respect would be the combination of an immunosuppressive drug with antiviral properties like the recently introduced synthetic malononitrilamide FK778 (Evers 2005). Taking all this in consideration, prophylaxis might be beneficial in preventing direct and indirect effects of CMV infection in transplant recipients, affecting both allograft and patient survival. If CMV infection is really an etiological factor for CTD, antiviral therapy would also be effective in decreasing incidence of the chronic rejection in clinical studies; indeed, this has been demonstrated in patients who underwent heart transplantation. In a prospective cohort study of 66 heart transplant recipients, aggressive CMV prophylaxis with CMV hyperimmune globulin and four weeks of intravenous ganciclovir followed by two months of valganciclovir was compared with the standard prophylaxis of four weeks intravenous ganciclovir. Aggressively treated patients had a lower incidence of CMV infection and reduced risk for acute rejection. Additionally they also showed a slower progression of CTD, in terms of coronary artery lumen loss at one year follow up (Potena 2006).

\subsection{Chlamydia pneumoniae and transplantation arteriosclerosis}

Since the original observation by Saikku and colleagues, demonstrating an increased incidence of myocardial infarction among $C$. pneumoniae positive coronary heart disease patients, the role of $C$. pneumoniae on the progress of atherosclerosis and coronary artery disease has been suggested by many others. The presence of $C$. pneumoniae DNA, C. pneumoniae antigen and viable $C$. pneumoniae in the vesse wall has further contributed to the mounting evidence of $C$. pneumoniae involvement in atherosclerosis (Saikku 1988, Ramirez 1996, Campbell 1995). This is supported by experimental studies which showed an acceleration of lesion development in several experimental animal models of mice and rabbits although an atherogenic diet seems to play a pivotal role for the $C$. pneumoniae induced effects in these models (Ezzahir 2002, Fong 1999).

Several mechanisms are held responsible for the $C$. pneumoniae accelerated atherosclerotic lesions so has $C$. pneumoniae been held responsible for impairing endothelial function and inducing a wide variety of pro-inflammatory cytokines such as IL-1B, IL-3, IL-4, IL-6, IL-8, IFN- $\gamma$ and TNF- $\alpha$. In addition after infection of human vascular endothelial cells an up-regulation of various adhesion molecules (VCAM-1, ICAM-1, P-selectin and E-selectin) has been reported (Liuba 2000, Quin 1999, Burian 2003, Summersgill 2000).

Interestingly, most of the suggested mechanisms by which $C$. pneumoniae may affect atherosclerosis highly resemble those by which $\mathrm{CMV}$ has been suggested to affect the disease. Therefore, it is plausible that C. pneumoniae, similar to CMV, is also involved in other cardiovascular pathologies like CTD. This is supported by previous findings that chronic C. pneumoniae infection as evidenced by anti-IgG antibody titers has a significant effect on the development of cardiac allografts arteriosclerosis, which is considered as the most important indicator for a worsened long term prognosis after heart transplantation (Subramanian 2002).

The impact of $C$. pneumoniae seropositivity on survival after transplantation has been confirmed by Pienazek et al. They found that $C$. peumoniae infection, as expressed through high IgA levels, seems to have adverse impact on the survival rate during one-year follow-up after heart transplantation. Although others were only able to demonstrate a significant trend toward lower actuarial freedom from transplant arteriosclerosis in patients with elevated IgA titers against $C$. pneumoniae after the period of 14 months postoperative (Pieniazek 2003, Wittwer 2000). Likewise, an association between the occurrence of $C$. pneumoniae detected by PCR and the presence of foam cell arteriopathy in liver transplant patients with chronic rejection has been suggested (Lotz 2004). Also in lung transplant complications C. pneumoniae might be involved. A common late complication in lung transplant recipients is bronchiolitis obliterans syndrome (BOS), a fibrotic process resulting in progressive narrowing of bronchiolar lumens and airflow obstruction, which is a manifestation of chronic allograft rejection. Based on the observation that BOS occurs more frequent and earlier in $C$. pneumoniae seropositive recipients it has been suggested that the presence of $C$. pneumoniae IgG antibodies in the lung transplant recipient is an independent risk factor for the development of BOS (Kotsimbos 2005). Similar results were published by Glanville et al. who showed an association between persistent infection with $C$. pneumoniae confirmed by nested PCR and deterioration of pulmonary allograft functioning, graft rejection and BOS (Glanville 2005). Along the same line, it has been shown previously that the presence of $C$. pneumoniae in peripheral blood leukocytes increased the risk of chronic kidney allograft rejection. Additionally seropositivity for IgG and IgA antibodies to $C$. pneumoniae was found to be associated with increased mortality as the result of cardiovascular disease in renal transplant recipients (Haubitz 2004, Kwiatkowski 2006). Nonetheless, not all 
studies have confirmed a decrease in survival rate after heart transplantation of $C$. pneumoniae positive recipients. Also in a retrospective study involving 115 kidney transplant patients no correlation between CRP levels or C. pneumoniae seropositivity with respect to rejection rates or graft failure was found. However increased CRP levels were associated with all-cause and cardiovascular mortality indicating an inflammation mediated effect (Fang 1998, Varagunam 2004).

Summarizing, although there is some evidence that chronic infections with $C$. pneumoniae seem to be associated with post-transplant allograft vasculopathy, experimental evidence for this hypothesis is fairly absent. Also, no clinical trials of empiric antibiotic therapy for $C$. pneumoniae in transplant recipients have been performed so far. Therefore, one of the main topics of this thesis is to address the potential role of $C$. pneumoniae in TA in a rat aortic allograft model and an animal model of vein graft failure.

\section{Therapeutic approach: Activin A and venous bypass failure}

\subsection{Gene therapy and venous bypass failure}

Even with optimal pharmacotherapy, some forms of cardiovascular disease may be refractory to treatment and prognosis remains poor for a significant number of patients. Also, pharmacotherapy often requires long-term administration while rarely addressing the underlying pathophysiology. Alternatively, with the identification of a number of genes, which are key to neointimal formation, gene therapy aiming to alter their relative expression has been recognised as having the potential to be added to the therapeutic armamentarium available to treat patients after intervention thereby providing secondary prevention (Baker 2002). In particular, those genes involved in smooth muscle cell proliferation might be of special interest. For example, in the carotid artery model of balloon angioplasty, enhancing the local expression of inhibitors of cell cycle progression, like p21 protein, ribozymes against c-myb mRNA, light-type caldesmon or retinoblastoma significantly inhibited experimental neointimal hyperplasia (Chang 1995, Macejak 1999, Yokouchi 2006, Chen 1997). An ideal target for cell-cycle blockade would be E2F, a transcription factor that leads to up-regulation of 12 cell-cycle genes. Recently, a strategy has been developed to block E2F using a double stranded decoy oligodeoxynucleotide that bears the consensus E2F-binding site, and this approach has proven to be effective in reducing neointima hyperplasia in different experimental animal models (Morishita 1995, Ehsan 2001, Cho 2005).
Yet, as already mentioned above, intimal hyperplasia is not only seen after balloon dilatation but also in venous graft failure and targeting similar genes may eventually preserve vein graft patency. However, until now no data have been presented regarding interference with genes associated with cell cycle progression in vein graft failure. Alternatively, West et al. demonstrated that adenoviral-mediated overexpression of neuronal NOS (nNOS) decreased SMC proliferation and intimal hyperplasia in a rabbit model of jugular vein to ipsilateral carotid artery grafting (West 2001). Furthermore, overexpression of nNOS during the early phase of vein graft remodelling resulted in intimal SMC with a more differentiated phenotype and reduced SMC-related superoxide production, thus protecting the vein graft from damage by reactive oxygen species. The importance of reactive oxygen species in modulating intima hyperplasia has recently been emphasized as $\mathrm{N}$-acetylcysteine, a strong scavenger of oxygen-free radicals, significantly reduced the amount of intimal hyperplasia in rat venous graft model (de Graaf manuscript in preparation).

Besides inhibition of SMC proliferation, gene therapy offers other therapeutic approaches like modulation of SMC migration and regulation of SMC apoptosis. For example, over-expression of p53 has been shown to inhibit migration of SMC and to inhibit intimal thickening in an ex vivo human saphenous vein model (George 2001). Similar results were obtained in a porcine venous interposition graft model were induction of SMC apoptosis by transient p53 over-expression reduced neointimal proliferation by $28 \%$ resulting in a $68 \%$ less thicker neointima with a significant increase in lumen size (Wan 2004). Likewise, neointimal hyperplasia was also diminished by stimulating SMC apoptosis through Fas ligand gene transfer to the vessel wall (Sata 1998). Furthermore, decreased SMC migration has been achieved by preventing matrix degradation through over-expression of tissue inhibitors of matrix metalloproteinase's (TIMP). Several studies demonstrated the effectiveness of TIMP-1 and TIMP-2 overexpression in reducing neointimal hyperplasia in a rat balloon injury model and ex vivo culture models of human saphenous veins (Dollery 1999, George 1998). Additionally, over-expression of TIMP-3, an extracellular matrix-associated MMP inhibitor which uniquely promotes apoptosis of isolated vascular smooth muscle cells, reduced neointima formation by $84 \%$ in human organ cultures and by $58 \%$ in pig vein grafts. The latter was confirmed by Akowauh et al. using the same model but in combination with a non-viral delivery system demonstrating that TIMP-3 is able to influence venous remodelling by increasing lumen size and total vessel area (Baker 1998, George 2000, Akowuah 2005). Other approaches include successful attempts to downregulate the expression of chemotactic and mitogenic factors in the graft or to inhibit the signalling cascade responsible for neointimal hyperplasia (Wolff 2005) 
Direct access to the vein during surgery offers a major potential benefit as a target for gene therapy. The vein graft can be manipulated and therapeutic genes, which may prevent subsequent graft failure, can be applied ex vivo. Yet, only a few clinical studies have addressed this subject so far. In the single-centre, prospective, randomised controlled PREVENT phase I trial ("PRoject of Ex-vivo Vein graft ENgineering via Transfection”) E2F decoy oligodeoxynucleotides were applied ex-vivo to the saphenous vein graft resulting in a promising $24 \%$ decrease in early 30 day graft occlusion (Mann 1999). However, subsequent studies were less positive including recently published results of the PREVENT III phase 3, multicentre, randomised double-blinded, placebo-controlled trial including 1404 patients undergoing surgical bypass of peripheral arterial occlusive disease with autologous vein grafts. Unfortunately, in this large trial a protective role E2F decoy oligodeoxynucleotides in preserving graft patency rates at one year after surgery could not be confirmed (Conte 2006). Furthermore in a phase 3 randomized, double-blind, placebo-controlled trial of 3014 patients undergoing primary CABG, the PREVENT IV trial showed that E2F decoy oligodeoxynucleotide had no effect on angiographically determined vein graft failure compared to the placebo-treated group during a 12 to 18 month follow up period (Alexander 2005).

\subsection{Activin $A$ and vein graft failure}

Experimental studies delineated above have mainly focused on adenovirus-mediated inhibition of neointimal hyperplasia through induction of cell cycle arrest or apoptosis of the activated SMC rather than on preventing the phenotypical change of SMC from quiescent to proliferating stage. Activin $A$, a member of the transforming growth factor- $B$ super family, does enhance the expression level of SMC-specific alpha-actin markers, indicating that it promotes the contractile phenotype of these cells (Engelse 1999). Based on these observations Engelse et al. hypothesized that activin A might reduce neointima formation by preventing phenotypic modulation of vascular SMC. Indeed, they demonstrated in a femoral artery cuff mouse model that systemically induced elevated levels of activin A resulted in a $77 \%$ reduction of neointima formation. Similar results were obtained with local adenoviral expression of activin A in a human saphenous vein organ culture model (Engelse 2002). In this thesis we will address a similar approach - maintenance of the contractile phenotype of SMC through activin A overexpression - to prevent intimal hyperplasia in venous graft failure.

\section{Aims and outline of the thesis}

Intimal hyperplasia is considered to be the major determining factor limiting long term success after PTCA, venous bypass grafting and solid organ transplantation. Although the underlying cause is generally considered to be multifactorial, infections with C. pneumoniae and CMV have been proposed as pathogenic factors possibly aggravating intimal hyperplasia.

However sero-epidemiological studies describing an association between $C$. pneumoniae, CMV and restenosis, venous graft failure and transplantation arteriosclerosis show conflicting results. Moreover animal models shedding light on a more causal relationship between these two pathogens and intimal hyperplasia if any are scarce and do not point in the same direction, thereby generating the need for additional evidence.

In this thesis we tried to shed a light and unravel the mechanisms of interplay between $C$. pneumoniae, CMV and intimal hyperplasia using different animal models.

First we studied the effect of CMV infection on the process of restenosis (Chapter 2). Hereby we tried to show the relationship between the time point of CMV infection and its effect on SMC proliferation using a well described animal model of photochemically induced endothelial denudation leading to intimal hyperplasia. As CMV showed to aggravate intimal hyperplasia as seen in the process of restenosis we hypothesized that similar effects might be present in intimal hyperplasia leading to venous bypass failure. In a study using an epigastric vein-to-common femoral artery interposition graft we evaluated the effect of CMV infection. Additionally we studied the potential effect of a new immunosuppressive, anti-viral and anti-proliferative agent FK778 to prevent intimal hyperplasia and its ability to diminish the CMV induced effects (Chapter 3). Today it is generally acknowledged that atherosclerosis can be considered as an inflammatory disease. Common chronic infections caused by viruses and bacteria may contribute to this inflammatory process and interact with classic cardiovascular risk factors. Most convincing evidence comes from data regarding the intracellular pathogen $C$. pneumoniae. We hypothesized that $C$. pneumoniae besides in atherosclerosis may also be involved in venous bypass failure. Using the epigastric vein-to-common femoral artery interposition graft rat model we studied the effect of C. pneumoniae infection on intimal hyperplasia in venous bypass failure. Additionally we studied the role of $\mathrm{C}$-reactive protein and heat shock protein 60 in this process (Chapter 4). 
Given the well established relationship between CMV and transplantation arteriosclerosis we hypothesized that other pathogens like $C$. pneumoniae may also play a role in similarity with observations seen in the field of atherosclerosis. Using a well established rat allograft model of orthotopic abdominal aorta transplantations we studied the effect of $C$. pneumoniae infection on transplantation arteriosclerosis

\section{(Chapter 5).}

Even with optimal pharmacotherapy some forms of cardiovascular disease may be refractory to treatment and prognosis remains poor for many patients. Gene therapy aiming at preventing intimal hyperplasia has been recognised as having the potential to add to the therapeutic armamentarium by treating patients during or after intervention providing secondary prevention. Maintaining the contractile SMC phenotype could prevent intimal hyperplasia and would represent a novel strategy to prevent venous graft failure (chapter 6 ).

Finally, in Chapter 7 the observations as presented in this thesis are discussed and related to the hypothesis that the pathogens $C$. pneumoniae and CMV contribute to intimal hyperplasia thereby compromising the long term results of intervention techniques used for salvation of atherosclerotic induced pathology.

\section{References}

Adani GL, Avital I, Ferraresso C, Aoki T. CMV infection in severe refractory ulcerative and Crohn's colitis. Am J Gastroenterol. 2001 Dec;96(12):3464-5.

Adler S.P. Transfusion-associated cytomegalovirus infections. Rev Infect Dis. 1983 NovDec;5(6):977-93.

Accorinti M, Pirraglia MP, Corradi R, Corsi C, Fabiani C, Pivetti-Pezzi P. Changing patterns of ocular manifestations in HIV seropositive patients treated with HAART. Eur J Ophthalmol. $2006 \mathrm{Sep}$ Oct;16(5):728-32.

Adam E, Melnick JL, Probtsfield JL, Petrie BL, Burek J, Bailey KR, McCollum CH, Debakey ME. High levels of cytomegalovirus antibody in patients requiring vascular surgery for atherosclerosis. Lancet. 1987 Aug 8;2(8554):291-3.

Akowuah EF, Gray C, Lawrie A, Sheridan PJ, Su CH, Bettinger T, Brisken AF, Gunn J, Crossman DC, FrancisSE, Baker AH, Newman CM. Ultrasound-mediated delivery of TIMP-3 plasmid DNA into saphenous vein leads to increased lumen size in a porcine interposition graft model. Gene Ther. 2005 Jul;12(14):1154-7.

Alexander JH, Hafley G, Harrington RA, Peterson ED, Ferguson TB Jr, Lorenz TJ, Goyal A, Gibson M, Mack MJ, Gennevois D, Califf RM, Kouchoukos NT. Efficacy and safety of edifoligide, an E2F transcription factor decoy, for prevention of vein graft failure following coronary artery bypass graft surgery: PREVENT IV: a randomized controlled trial. JAMA. 2005 Nov 16;294(19):2446-54.

Anderson, J.L., et al., Evaluation of C-reactive protein, an inflammatory marker, and infectious serology as risk factors for coronary artery disease and myocardial infarction. J Am Coll Cardiol, 1998. 32(1): p. 35-41.

Anderson, K. P., M. C. Fox, V. Brown-Driver, M. J. Martin, and R. F. Azad. 1996. Inhibition of human cytomegalovirus immediate-early gene expression by an antisense oligonucleotide complementary to immediate-early RNA. Antimicrob. Agents Chemother. 40:2004-2011.

Andraws R, Berger JS, Brown DL. Effects of antibiotic therapy on outcomes of patients with coronary artery disease: a meta-analysis of randomized controlled trials. JAMA. 2005 Jun 1;293(21):2641-7.

Arno G, Kaski JC, Smith DA, Akiyu JP, Hughes SE, Baboonian C. Matrix metalloproteinase-9 expression is associated with the presence of Chlamydia pneumoniae in human coronary atherosclerotic plaques. Heart. $2005 \mathrm{Apr} ; 91(4): 521-5$.

Arnold JC, Portmann BC, O'Grady JG, Naoumov NV, Alexander GJ, Williams R. Cytomegalovirus infection persists in the liver graft in the vanishing bile duct syndrome. Hepatology 1992; $16: 285$ 292.

Baker AH. Development and use of gene transfer for treatment of cardiovascular disease. J Card Surg. 2002 Nov-Dec;17(6):543-8.

Baker AH, Zaltsman AB, George SJ, Newby AC. Divergent effects of tissue inhibitor of metalloproteinase-1, -2, or -3 overexpression on rat vascular smooth muscle cell invasion, proliferation, and death in vitro. TIMP-3 promotes apoptosis. J Clin Invest. 1998 Mar 15;101(6):1478-87.

Baldanti F, Lurain N, Gerna G. Clinical and biologic aspects of human cytomegalovirus resistance to antiviral drugs. Hum. Immunol.2004: 65:403.

Balin BJ, Gérard HC, Arking EJ, et al. Identification and localization of Chlamydia pneumoniae in the Alzheimer's brain. Med Microbiol Immunol 1998;187:23-42.

Barboriak JJ, Pintar K, Van Horn DL, et al. Pathologic findings in the aortocoronary vein grafts. A scanning electron microscope study. Atherosclerosis. 1978 Jan;29(1):69-80. 
Bartels C, Maass M, Bein G, Malisius R, Brill N, Bechtel JF, Sayk F, Feller AC, Sievers HH. Detection of Chlamydia pneumoniae but not cytomegalovirus in occluded saphenous vein coronary artery bypas grafts. Circulation. $1999 \mathrm{Feb} 23 ; 99(7): 879-82$

Bartels C, Maass M, Bein G, Brill N, Bechtel JF, Leyh R, Sievers HH. Association of serology with the endovascular presence of Chlamydia pneumoniae and cytomegalovirus in coronary artery and vein graft disease. Circulation. 2000 Jan 18;101(2):137-41.

Beatty WL, Morrison RP, Byrne GI. Persistent chlamydiae: from cell culture to a paradigm for chlamydial pathogenesis. Microbiol Rev. 1994 Dec;58(4):686-99.

Beck S, Barrell BG. Human cytomegalovirus encodes a glycoprotein homologous to MHC class antigens. Nature 1988; 331: 269-272.

Berencsi, K, Gonczol E, Endresz V, Kough J, Takeda S, Gyulay Z, Plotkin SA, Rando RF. The $\mathrm{N}$-terminal 303 amino acids of the human cytomegalovirus envelope glycoprotein (UL55) and the exon 4 region of the major immediate-early protein 1 (UL123) induce a cytotoxic T-cell response. Vaccine 1996;14:369-374.

Berg HF, Maraha B, Scheffer GJ, Quarles-van Ufford M, Vandenbroucke-Grauls CM, Peeters MF, Kluytmans JA. Treatment with clarithromycin prior to coronary artery bypass graft surgery does not prevent subsequent cardiac events. Clin Infect Dis. 2005 Feb 1;40(3):358-65.

Berg HF, Maraha B, van der Zee A, Gielis SK, Roholl PJ, Scheffer GJ, Peeters MF, Kluytmans JA. Effect of clarithromycin treatment on Chlamydia pneumoniae in vascular tissue of patients with coronary artery disease: a randomized, double-blind, placebo-controlled trial. J Clin Microbiol. 2005 Mar;43(3):1325-9.

Blasi, F., D. Legnani, V. M. Lombardo, G. G. Negretto, E. Magliano, R. Pozzoli, F. Chiodo, A. Fasoli, and L. Allegra. 1993. Chlamydia pneumoniae infection in acute exacerbations of COPD. Eur. Respir. J. 6:19-22.

Blum A, Giladi M, Weinberg M, Kaplan G, Pasternack H, Laniado S, Miller H. High anticytomegalovirus (CMV) lgG antibody titer is associated with coronary artery disease and may predict post-coronary balloon angioplasty restenosis. Am J Cardiol. 1998 Apr 1;81 (7):866-8.

Boeckh M, Leisenring W, Riddell SR, Bowden RA, Huang ML, Myerson D, Stevens-Ayers T, Flowers ME, Cunningham T, Corey L. Late cytomegalovirus disease and mortality in recipients of allogeneic hematopoietic stem cell transplants: importance of viral load and T-cell immunity. Blood 2003;101:407-414.

Boppana SB, Pass RF, Britt WJ, Stagno S, Alford CA. Symptomatic congenital cytomegalovirus infection: neonatal morbidity and mortality. Pediatr. Infect. Dis. 1992;11;93-99.

Boppana SB, Fowler KB, Vaid Y, Hedland G, Stagno S, Britt WJ, Pass RF. Neuroradiographic findings in the newborn period and long-term outcome in children with symptomatic congenital cytomegalovirus infection. Pediatrics 1997;99:409-414.

Buhles, W. C., B. J. Mastre, A. J. Tinker, V. Strand, and S. H. Koretz. Ganciclovir treatment of life- or sight-threatening cytomegalovirus infection: experience in 314 immunocompromised patients. Rev. Infect. Dis. 1988 106:S495-S506.

Burdelski, M., K. Schmidt, P. F. Hoyer, U. Bernsau, R. Galaske, J. Brodehl, B. Ringe, W. Lauchart, K. Wonigeit, and R. Pichlmayr. 1987. Liver transplantation in children: the Hanover experience. Transplant. Proc. 19:3277-3281.

Burián K, Hegyesi H, Buzás E, Endrész V, Kis Z, Falus A, Gönczöl E. Chlamydophila (Chlamydia) pneumoniae induces histidine decarboxylase production in the mouse lung. Immunol Lett. 2003 Oct 31;89(2-3):229-36.

Campbell LA, O'Brien ER, Cappuccio AL, Kuo CC, Wang SP, Stewart D, Patton DL, Cummings PK, Grayston JT. Detection of Chlamydia pneumoniae TWAR in human coronary atherectomy tissues. Infect Dis. 1995 Aug;172(2):585-8.
Cataldo G, Braga M, Pirotta N, Lavezzari M, Rovelli F, Marubini E. Factors influencing 1-year patency of coronary artery saphenous vein grafts. Studio Indobufene nel Bypass Aortocoronarico (SINBA). Circulation. $1993 \mathrm{Nov} ; 88(5 \mathrm{Pt}$ 2):1193-8

Chang MW, Barr E, Lu MM, Barton K, Leiden JM. Adenovirus-mediated over-expression of the cyclin/cyclin-dependent kinase inhibitor, p21 inhibits vascular smooth muscle cell proliferation and neointimaformation in the rat carotid artery model of balloon angioplasty. J Clin Invest. 1995 Nov; $96(5): 2260-8$.

Chang MW, Barr E, Seltzer J, Jiang YQ, Nabel GJ, Nabel EG, Parmacek MS, Leiden JM. Cytostatic gene therapy for vascular proliferative disorders with a constitutively active form of the retinoblastoma gene product. Science. 1995 Jan 27;267(5197):518-22.

Chee MS, Bankier AT, Beck S, Bohni R, Brown CM, Cerny R, Horsnell T, Hutschinson CA $3^{\text {rd }}$, Kouzarides T, Martignetti JA and et al. Analysis of the protein-coding content of the sequence of human cytomegalovirus strain AD 169. Curr Top Microbiol Immunol 1990:154-125.

Chen D, Krasinski K, Sylvester A, Chen J, Nisen PD, Andrés V. Downregulation of cyclin-dependent kinase 2 activity and cyclin A promoter activity in vascular smooth muscle cells by p27(KIP1), an inhibitor of neointima formation in the rat carotid artery. J Clin Invest. 1997 May 15;99(10):2334-41.

Cho WH, Lee SO, Kim HT, Ahn JD, Lee IK. E2F decoy oligodeoxynucleotides on neointimal hyperplasia in canine vein graft. Transplant Proc. 2005 Jan-Feb;37(1):77-9.

Cho KR, Kim JS, Choi JS, Kim KB. Serial angiographic follow-up of grafts one year and five years after coronary artery bypass surgery. Eur J Cardiothorac Surg. 2006 Apr;29(4):511-6.

Christenson JT. Preoperative lipid control with simvastatin reduces the risk for graft failure already 1 year after myocardial revascularization. Cardiovasc Surg. $2001 \mathrm{Feb}$;9(1):33-43.

Conte MS, Bandyk DF, Clowes AW, Moneta GL, Seely L, Lorenz TJ, Namini H, Hamdan AD, Roddy SP, Belkin M, Berceli SA, DeMasi RJ, Samson RH, Berman SS. Results of PREVENT Ill: a multicenter, randomized trial of edifoligide for the prevention of vein graft failure in lower extremity bypass surgery. J Vasc Surg. 2006 Apr;43(4):742-751.

Coombes BK, Mahony JB. Chlamydia pneumoniae infection of human endothelial cells induces proliferation of smooth muscle cells via an endothelial cell-derived soluble factor(s). Infect Immun. 1999 Jun;67(6):2909-15.

Coombes BK, Mahony JB. CDNA array analysis of altered gene expression in human endothelial cells in response to Chlamydia pneumoniae infection. Infect Immun. 2001 Mar;69(3):1420-7.

Cirillo P, Golino P, Calabro P, Cali G, Ragni M, De Rosa S, Cimmino G, Pacileo M, De Palma R, Forte , Gargiulo A, Corigliano FG, Angri V, Spagnuolo R, Nitsch L, Chiariello M. C-reactive protein induces tissue factor expression and promotes smooth muscle and endothelial cell proliferation. Cardiovasc Res. 2005 Oct 1;68(1):47-55.

de Clerqe E, Sakuma T, Baba M, Pauwels R, Balzarini J. Rosenberg I, Holy A. Antiviral activity of phosphonylmethoxyalkyl derivatives of purine and pyrimidines. Antiviral Res. 1987;8:261-272.

Compton T, Nowlin DM, Cooper NR. Initiation of human cytomegalovirus glycoprotein complex designated gC-II is a major heparin-binding component of the envelope. 1993 ; J. Virol. 66: 1761.

Cook PJ, Honeybourne D. Chlamydia pneumoniae. J Antimicrob Chemother. 1994 Dec;34(6):859-73.

Cramer, D.V., Oian, S.Q., Harnaha, J., et al., Cardiac transplantation in the rat. I. The effect of histocompatibility differences on graft arteriosclerosis. Transplantation, 1989. 47(3): p. 414-9.

Crumpacker, C. S. Ganciclovir. N. Engl. J. Med. 1996 335:721-729.

Curran M, Noble S. Valganciclovir. Drugs 2001:61:1145-1150.

van Dam-MierasMC, MullerAD, van HinsberghVW, MullersWJ, BomansPH, BruggemanCA. The procoagulant response of cytomegalovirus infected endothelial cells. Thromb Haemost 1992; 68: 364. 
Dollery CM, Humphries SE, McClelland A, Latchman DS, McEwan JR. Expression of tissue inhibitor of matrix metalloproteinases 1 by use of an adenoviral vector inhibits smooth muscle cell migration and reducesneointimal hyperplasia in the rat model of vascular balloon injury. Circulation. 1999 Ju 22;99(24):3199-205.

van DorpWT, JongesE, BruggemanCA, DahaMR, van EsLA, van Der WoudeFJ. Direct induction of MHC class I, but not class II, expression on endothelial cells by cytomegalovirus infection. Transplantation 1989;48: 469 .

Eickhoff M, Thalmann J, Hess S, Martin M, Laue T, Kruppa J, Brandes G, Klos A. Host cell responsesto Chlamydia pneumoniae in gamma interferon-induced persistence overlap those of productive infection and are linked to genes involved in apoptosis, cell cycle, and metabolism. Infect Immun. 2007 Jun;75(6):2853-63.

Ehsan A, Mann MJ, Dell'Acqua G, Dzau VJ. Long-term stabilization of vein graft wall architecture and prolonged resistance to experimental atherosclerosis after E2F decoy oligonucleotide gen therapy. J Thorac Cardiovasc Surg. 2001 Apr;121(4):714-22.

Emery VC. Viral dynamics during active cytomegalovirus infection and pathology. Intervirology 1999;42:405-411.

Engelse MA, Neele JM, van Achterberg TA, et al. Human activin-A is expressed in the atherosclerotic lesion and promotes the contractile phenotype of smooth muscle cells. Circ Res. 1999 Nov 12;85(10):931-9.

Engelse MA, Lardenoye JH, Neele JM, Grimbergen JM, De Vries MR, Lamfers ML, Pannekoek H, Quax PH, De Vries CJ. Adenoviral activin a expression prevents intimal hyperplasia in human and murine blood vessels by maintaining the contractile smooth muscle cell phenotype. Circ Res. 2002 May 31;90(10):1128-34.

Enright H., Haake R., Weisdorf D., Ramsay N., McGlave P., Kersey J., Thomas W., MvKenzie D., Miller W. Cytomegalovirus pneumonia after bone marrow transplantation. Risk factors and response to therapy. Transplantation 1993 jun;55(6):1339-46.

Erntell M, Ljunggren K, Gadd T, Persson K. Erythema nodosum--a manifestation of Chlamydia pneumoniae (strain TWAR) infection. Scand J Infect Dis. 1989;21(6):693-6.

Esposito S, Bosis S, Begliatti E, Droghetti R, Tremolati E, Tagliabue C, Bellasio M, Blasi F, Princip $\mathrm{N}$. Acute tonsillopharyngitis associated with atypical bacterial infection in children: natural history and impact of macrolide therapy. Clin Infect Dis. 2006 Jul 15;43(2):206-9.

Everett KD, Bush RM, Anderssen AA Emended description of the order Chlamydiales, proposal of ParaChlamydiacae fam.nov., each containing one monotypic genus, revised taxonomy of the family Chlamydiaceae, including a new genus and five new species, and standards for the identification of the organisms. Int. J. Syst. Bacteriol. 1999 49: 415-440.

Evers DL, Wang X, Huong SM, et al. Inhibition of human cytomegalovirus signaling and replication by the immunosuppressant FK778. Antiviral Res. 2005; 65: 1-12.

Ezzahiri, R., Nelissen-Vrancken, H.J., Kurvers, H.A., et al., Chlamydophila pneumoniae (Chlamydia pneumoniae) accelerates the formation of complex atherosclerotic lesions in Apo E3-Leiden mice. cardiovasc Res, 2002. 56(2): p. 269-76.

Falagas ME, Snydman DR, Griffith J, Ruthazer R, Werner BG. Effect of cytomegalovirus infection status on first-year mortality rates among orthotopic liver transplant recipients. The Boston Center for Liver Transplantation CMVIG Study Group. Ann Intern Med 1997; 126: 275-279.

Fang JC, Kinlay S, Kundsin R, Ganz P. Chlamydia pneumoniae infection is frequent but not associated with coronary arteriosclerosis in cardiac transplant recipients. Am J Cardiol. 1998 Dec 15;82(12): 1479-83.
Fateh-Moghadam S, Bocksch W, Wessely R, Jager G, Hetzer R, Gawaz M. Cytomegalovirus infection status predicts progression of heart-transplant vasculopathy. Transplantation. 2003 Nov 27;76(10):1470-4

Fitzgibbon GM, Kafka HP, Leach AJ, Keon WJ, Hooper GD, Burton JR. Coronary bypass graft fate and patient outcome: angiographic follow-up of 5,065 grafts related to survival and reoperation in 1,388 patients during 25 years. J Am Coll Cardiol. 1996 Sep;28(3):616-26.

Fong IW, Chiu B, Viira E, Jang D, Mahony JB. De Novo induction of atherosclerosis by Chlamydia pneumoniae in a rabbit model. Infect Immun. 1999 Nov;67(11):6048-55.

Fujinami RS, Nelson JA, Walker L, Oldstone MB. Sequene homology and immunologic-crossreactivity of human cytomegalovirus with HLA-DR beta chain: a means for graft rejection and immunosuppression. J Virol 1988; 62: 100-105.

Gaede KI, Wilke G, Brade L, Brade H, Schlaak M, Muller-Quernheim J. Anti-Chlamydophila mmunoglobulin prevalence in sarcoidosis and usual interstitial pneumoniae. Eur Respir J. 2002 Feb;19(2):267-74.

Gaydos CA, Summersgill JT, Sahney NN, Ramirez JA, Quinn TC. Replication of Chlamydia pneumoniae in vitro in human macrophages, endothelial cells, and aortic artery smooth muscle cells. Infect Immun. 1996 May;64(5):1614-20

George SJ, Baker AH, Angelini GD, Newby AC. Gene transfer of tissue inhibitor of metalloproteinase-2 inhibits metalloproteinase activity and neointima formation in human saphenous veins. Gene Ther. 1998 Nov;5(11):1552-60

George SJ, Johnson JL, Angelini GD, Newby AC, Baker AH. Adenovirus-mediated gene transfer of the human TIMP-1 gene inhibits smooth muscle cell migration and neointimal formation in human saphenous vein. Hum Gene Ther. 1998 Apr 10;9(6):867-77.

George SJ, Lloyd CT, Angelini GD, Newby AC, Baker AH. Inhibition of late vein graft neointima formation in human and porcine models by adenovirus-mediated overexpression of tissue inhibitor of metalloproteinase-3. Circulation. 2000 Jan 25;101(3):296-304.

George SJ, Angelini GD, Capogrossi MC, Baker AH. Wild-type p53 gene transfer inhibits neointima formation in human saphenous vein by modulation of smooth muscle cell migration and induction of apoptosis. Gene Ther. 2001 May;8(9):668-76.

Gencay M, Rudiger JJ, Tamm M, Soler M, Perruchoud AP, Roth M. Increased frequency of Chlamydia pneumoniae antibodies in patients with asthma. Am J Respir Crit Care Med. 2001 Apr;163(5):1097 100.

Gewurz BE, Wang EW, Tortorella D, Schust DJ, Ploegh HL. Human cytomegalovirus US2 endoplasmic reticulum-lumenal domain dictates association with major histocompatibility complex class I in a locus-specific manner. J. Virol. 2001;75:5197-5204.

Gieffers J, Füllgraf H, Jahn J, Klinger M, Dalhoff K, Katus HA, Solbach W, Maass M. Chlamydia pneumoniae infection in circulating human monocytes is refractory to antibiotic treatment. Circulation. 2001 Jan 23;103(3):351-6.

Glagov, S., Intimal hyperplasia, vascular modeling, and the restenosis problem. Circulation, 1994. 89(6): p. 2888-91

Glanville AR, Gencay M, Tamm M, Chhajed P, Plit M, Hopkins P, Aboyoun C, Roth M, Malouf M. Chlamydia pneumoniae infection after lung transplantation. J Heart Lung Transplant. 2005 Feb;24(2):131-6

Gonczol E, Plotkin S. Development of a cytomegalovirus vaccine: lessons from recent clinical trials. Expert Opin Biol Ther. 2001 May;1(3):401-12.

de Graaf R, F.R.M. Stassen, G. Kloppenburg, C.A. Bruggeman, P.J.H.M. Kitslaar, A. Tintu, PhD, E. Rouwet. $\mathrm{N}$-acetylcysteine attenuates hyperoxia induced venous smooth muscle cell proliferation and neointima formation in a rat venous graft model (manuscript in preparation). 
de Graan-Hentzen YC, Gratama JW, Mudde GC, Verdonck LF, Houbiers JG, Brand A, Sebens FW, van Loon AM, The TH, Willemze R Prevention of primary cytomegalovirus infection in patients with hematologic malignancies by intensive white cell depletion of blood products. Transfusion. 1989 NovDec;29(9):757-60

Grattan MT, Moreno-Cabral CE, Starnes VA, Oyer PE, Stinson EB, Shumway NE. Cytomegalovirus infection is associated with cardiac allograft rejection and atherosclerosis. JAMA. 1989 Jun 23-30;261(24):3561-6.

Grayston JT, Kuo CC, Wang SP, Altman J. A new Chlamydia psittaci strain, TWAR, isolated in acute respiratory tract infections. N Engl J Med. 1986 Jul 17;315(3):161-8.

Grayston JT. Infections caused by Chlamydia pneumoniae strain TWAR. Clin Infect Dis. 1992 Nov; 15(5):757-61.

Grayston JT, Aldous MB, Easton A, Wang SP, Kuo CC, Campbell LA, Altman J. Evidence that Chlamydia pneumoniae causes pneumonia and bronchitis. J Infect Dis. 1993 Nov;168(5):1231-5.

Griffiths PD, Emery VC. Cytomegalovirus. In: Richman DD, Whitley RJ, Hayden FG. Clinical Virology. 1997 Churchill Livingstone, New York.

Gross JG, Bozette SA, Mathews WC, Spector SA, Abamson IS, McCuthchan JA, et al. Longitudinal study of cytomegalovirus retinitis in acquired immune deficiency syndrome. Opthalmology 1990;97:681-6. Grundy JE, McKeating, Griffiths PD. Cytomegalovirus strain AD 169 binds beta 2 microglobulin in vitro after release from cells. J. Gen. Virol. 1987;68:777.

Guetta E, Guetta V, Shibutani T, Epstein SE. Monocytes harboring cytomegalovirus: interactions with endothelial cells, smooth muscle cells, and oxidized low-density lipoprotein. Possible mechanisms for activating virus delivered by monocytes to sites of vascular injury. Circ Res. 1997 Jul;81(1):8-16.

Gulizia JM, Kandolf R, Kendall TJ, Thieszen SL, Wilson JE, Radio SJ, Costanzo MR, Winters GL, Miller LL, MCManus BM. Infrequency of cytomegalovirus genome in coronary arteriopathy of human heart allografts. Am J Pathol. 1995 Aug; 147(2):461-75.

Gupta S, Leatham EW, Carrington D, Mendall MA, Kaski JC, Camm AJ. Elevated Chlamydia pneumoniae antibodies, cardiovascular events, and azithromycin in male survivors of myocardial infarction. Circulation. 1997 Jul 15;96(2):404-7.

Hammerschlag MR, Qumei KK, Roblin PM. In vitro activities of azithromycin, clarithromycin, L-ofloxacin, and other antibiotics against Chlamydia pneumoniae. Antimicrob Agents Chemother. 1992 Jul; 36(7):1573-4

Hammerschlag MR Chlamydia pneumoniae and the lung. Eur. Respir. J. 2002 ;51001-1007.

Hannu T, Puolakkainen M, Leirisalo-Repo M. Chlamydia pneumoniae as a triggering infection in reactive arthritis. Rheumatology (Oxford). 1999 May;38(5):411-4.

Haubitz M, Votsch K, Woywodt A, Nashan B, Groh A, Haller H, Brunkhorst R. Serologic evidence of Chlamydia pneumoniae infection as a long-term predictor of cardiovascular death in renal transplant recipients. Transplantation. 2004 May 27;77(10):1517-21.

Hayashida K, Tanaka M, Morita H, Hayashi F, Inada T, Suzuki H, Sakamoto T, Katsuragawa M, Hibino Kambara H. Chlamydia pneumoniae seropositivity predicts the risk of restenosis after percutaneous transluminal coronary angioplasty. Heart Vessels 2002 May; 16(4):137-45.

Hedman A, Larsson PT, Alam M, Wallen NH, Nordlander R, Samad BA. CRP, IL-6 and endothelin-1 levels in patients undergoing coronary artery bypass grafting. Do preoperative inflammatory parameters predict early graft occlusion and late cardiovascular events? Int J Cardiol. 2007 Aug 9;120(1):108-14

Hendrix MG, Salimans MM, van Boven CP, Bruggeman CA. High prevalence of latently present cytomegalovirus in arterial walls of patients suffering from grade III atherosclerosis. Am J Pathol. 1990 Jan;136(1):23-8.
Homman-Loudiyi MK, Hultenby W, Britt and Soderberg-Naucler C. Envelopment of human cytomegalovirus occurs by budding into Golgi-derived vacuole compartments positive for GB, Rab 3 , transgolgi network 46, and mannosidase II. J Virol 2003;77:3191

Horne, B.D., et al., Greater pathogen burden but not elevated C-reactive protein increases the risk of clinical restenosis after percutaneous coronary intervention. Am Heart J, 2002. 144(3): p. 491 500.

IwataA, SaiS, NittaYet al. Liposome-mediated gene transfection of endothelial nitric oxide synthase reduces endothelial activation and leukocyte infiltration in transplanted hearts. Circulatio 2001; 103: 2753.

Jarvis MA, Nelson JA. Human cytomegalovirus persistence and latency in endothelial cells and macrophages. Curr Opin Microbiol. 2002 Aug;5(4):403-7.

Jordan M.C., Rousseau W.T., Stewart J.A., Noble G.R., Chin T.D.I. Spontaneous cytomegalovius mononucleosis. Clinical and laboratory observations in nine cases. Ann Intern Med. 1973;79:153-60.

Kandiel A, Lashner B. Cytomegalovirus colitis complicating inflammatory bowel disease. Am J Gastroenterol. 2006 Dec;101(12):2857-65.

Kangasniemi OP, Biancari F, Luukkonen J, Vuorisalo S, Satta J, Pokela R, Juvonen T. Preoperative $C$-reactive protein is predictive of long-term outcome after coronary artery bypass surgery. Eur $J$ Cardiothorac Surg. 2006 Jun;29(6):983-5.

Kauppinen M, Saikku P: Pneumonia due to Chlamydia pneumoniae: prevalence, clinical features, diagnosis, and treatment. Clin Infect Dis 1995 Dec; 21 Suppl 3: 5244-52.

Kishore J, Ghoshal U, Ghoshal UC, Krishnani N, Kumar S, Singh M, Ayyagari A. Infection with cytomegalovirus in patients with inflammatory bowel disease: prevalence, clinical significance and outcome. J Med Microbiol. 2004 Nov:53(Pt 11):1155-60.

Klemola E, Cytomegalovirus infection in previously healthy adults Ann Intern Med. 1973 ug; 79(2):267-8.

Kloover JS, Soots AP, Krogerus LAet al. Rat cytomegalovirus infection in kidney allograft recipients is associated with increased expression of intracellular adhesion molecule- 1 vascular adhesion molecule-1, and their ligands leukocyte function antigen-1 and very late antigen-4 in the graft. Transplantation 2000; 69:2641.

Kol A, Sperti G, Shani J, Schulhoff N, van de Greef W, Landini MP, La Placa M, Maseri A, Crea F. Cytomegalovirus replication is not a cause of instability in unstable angina. Circulation. 1995 Apr 1;91(7):1910-3

Kol A, Sukhova GK, Lichtman AH, Libby P. Chlamydial heat shock protein 60 localizes in human atheroma and regulates macrophage tumor necrosis factor-alpha and matrix metalloproteinase expression. Circulation. 1998 Jul 28;98(4):300-7.

Konoplev S., Champlin R.E., Giralt S., Ueno N.T., Khouri I., Raad I., Rolston K., Jacobson K., Tarrand J., Luna M., Nguyen Q., Whimbey E. Cytomegalovirus pneumoniae in adult autologus blood and marrow transplant recipients. Bone Marrow transplantation 2001;27:877-881.

Koskinen P, Lemstrom K, Bruggeman C, Lautenschlager I, Hayry P. Acute cytomegalovirus infection induces a subendothelial inflammation (endothelialitis) in the allograft vascular wall. A possible linkage with enhanced allograft arteriosclerosis.Am J Pathol. 1994 Jan;144(1):41-50.

Kotsimbos TC, Snell GI, Levvey B, Spelman DW, Fuller AJ, Wesselingh SL, Williams TJ, Ostergaard L. Chlamydia pneumoniae serology in donors and recipients and the risk of bronchiolitis obliterans syndrome after lung transplantation. Transplantation. $2005 \mathrm{Feb}$ 15;79(3):269-75.

Kuo, C.-C., A. Shor, L. A. Campbell, H. Fukushi, D. L. Patton, and J. T. Grayston. 1993. Demonstration of Chlamydia pneumoniae in atherosclerotic lesions of coronary arteries. J. Infect. Dis. 167:841-849. 
Kuo CC, Chi EY, Grayston JT. Ultrastructural study of entry of Chlamydia strain TWAR into HeLa cells. Infect Immun 1988;56:1668-72.

Kuo C-C, Jackson LA, Campbell LA, Grayston JT. Chlamydia pneumoniae. Clin Microbiol Rev 1995;8:451-61.

Kuo CC and Campell LA Chlamydial infections of the cardiovascular system. Front Bioscie, 2003;8:e36-43.

Kwiatkowski A, Wszola M, Nosek R, Podsiadly E, Meszaros J, Ostrowski K, Lisik W, Michalak G, Chmura A, Kosieradzki M, Danielewicz R, Fesolowicz S, Kasprzyk T, Paczek L, Durlik M, Persson K, Tylewska-Wierzbanowska $S$, Rowinski W. Chlamydia pneumor chronic allograft rejection. Transplant Proc. $2006 \mathrm{Jan}-\mathrm{Feb} ; 38(1): 108-11$.

Lautenschlager I, Soots A, Krogerus L, Kauppinen H, Saarinen O, Bruggeman C, Ahonen J. CMV increases inflammation and accelerates chronic rejection in rat kidney allografts. Transplant Proc. 1997 Feb-Mar;29(1-2):802-3.

Lautenschlager I, Hockerstedt K, Jalanko H, Loginov R, Salmela K, Taskinen E, Ahonen J. Persistent cytomegalovirus in liver allografts with chronic rejection. Hepatology 1997; 25: 190-194.

LeePC, WangZL, QianSet al. Endothelial nitric oxide synthase protects aortic allografts from the development of transplant arteriosclerosis. Transplantation 2000; 69: 1186.

Lemström KB, Bruning JH, Bruggeman CA, Lautenschlager IT, Häyry PJ. Cytomegalovirus infection enhances smooth muscle cell proliferation and intimal thickening of rat aortic allografts. J Clin Invest. 1993 Aug;92(2):549-58.

Lemstrom K, Kallio E, Krebs R, Bruggeman C, Hayry P, Koskinen P. Cytomegalovirus infection accelerates obliterative bronchiolitis of rat tracheal allografts. Transpl Int. 1996;9 Suppl 1:S221-2.

Lemström K, Koskinen P, Krogerus L, Daemen M, Bruggeman C, Häyry P. Cytomegalovirus antigen expression, endothelial cell proliferation, and intimal thickening in rat cardiac allografts after cytomegalovirus infection. Circulation. 1995 Nov 1;92(9):2594-604.

Lemström K, Sihvola R, Bruggeman C, Häyry P, Koskinen P. Cytomegalovirus infection-enhanced cardiac allograft vasculopathy is abolished by DHPG prophylaxis in the rat. Circulation. 1997 Jun $17 ; 95(12): 2614-6$.

Lemström KB, Bruning JH, Bruggeman CA, Lautenschlager IT, Häyry PJ. Triple drug mmunosuppression significantly reduces immune activation and allograft arteriosclerosis in cytomegalovirus-infected rat aortic allografts and induces early latency of viral infection. Am J Pathol. 1994 Jun;144(6):1334-47

Lemstrom K, Bruning J, Koskinen P, Bruggeman C, Lautenschlager I, Hayry P. Triple-drug mmunosuppression significantly reduces chronic rejection in noninfected and RCMV-infected rats. Transplant Proc. 1994 Jun;26(3):1727-8.

Li FL, Grauls G, Yin M, Bruggeman CA. Correlation between the intensity of cytomegalovirus infection and the amount of perivasculitis in aortic allografts. Transpl Int. 1996;9 Suppl 1:S340-4.

Liuba P, Karnani P, Pesonen E, Paakkari I, Forslid A, Johansson L, Persson K, Wadström T, Laurini R. Endothelial dysfunction after repeated Chlamydia pneumoniae infection in apolipoprotein E-knockout mice. Circulation. 2000 Aug 29;102(9):1039-44

Ljungstrom L, Franzen C, Schlaug M, Elowson S, Viidas U. Reinfection with Chlamydia pneumoniae may induce isolated and systemic vasculitis in small and large vessels. Scand J Infect Dis Suppl. 1997; 104:37-40.

LoGerfo FW, Quist WC, Cantelmo NL, Haudenschild CC. Integrity of vein grafts as a function of initial intimal and medial preservation. Circulation. 1983 Sep;68(3 Pt 2):II117-24.

Lopez, C., Simmons, R.L., Mauer, S.M., Najarian, J.S., Good, R.A. and Gentry, S., Association of renal allograft rejection with virus infections. Am J Med, 1974. 56(3): p. 280-9.
Lotz G, Simon S, Patonai A, Sotonyi P, Nemes B, Sergi C, Glasz T, Fule T, Nashan B, Schaff Z. Detection of Chlamydia pneumoniae in liver transplant patients with chronic allograft rejection Transplantation. 2004 May 27;77(10):1522-8.

Macejak DG, Lin H, Webb S, Chase J, Jensen K, Jarvis TC, Leiden JM, Couture L. Adenovirusneointima formation in vivo. JVirol. 1999 Sep;73(9):7745-

Mann MJ, Whittemore AD, Donaldson MC, Belkin M, Conte MS, Polak JF, Orav EJ, Ehsan A, Dell'Acqua G, Dzau VJ. Ex-vivo gene therapy of human vascular bypass grafts with E2F decoy: the PREVENT single-centre, randomised, controlled trial. Lancet. 1999 Oct 30;354(9189):1493-8.

MarteliusT, SalmiM, WuHet al. Induction of vascular adhesion protein-1 during liver allograf rejection and concomitant cytomegalovirus infection in rats. Am J Pathol 2000; 157: 1229.

Matthews T, Boehme R. Antiviral activity and mechanism of action of ganciclovir. Rev. Infect. Dis. 1988:10(suppl. 3):S490-S494

Mettenleiter TC. Herpesvirus assembly and egress. J. Virol. 2002;76:1537.

Miller W., Flynn P., McCullough J., Balfour H.H., Goldman A., Haake R., McGlave P., Ramsay N., Kersey J. Cytomegalovirus infection after bone marrow transplantation: an association with acute graft versus host disease. Blood 1986;67:1162-7.

Miyashita N, Fukano $\mathrm{H}$, Niki $\mathrm{Y}$, Matsushima T. In vitro activity of telithromycin, a new ketolide, gainst Chlamydia pneumoniae. J Antimicrob Chemother. 2001 Sep;48(3):403-5.

Mocarski ES, Courcell Tan C. Cytomegalovirus and their replication. In Fields Virology 2001; vol2. Knipe DM and Howley PM eds. Lippincott Williams \& Wilkins, Philadelphia, p. 2629.

Morishita R, Gibbons GH, Horiuchi M, Ellison KE, Nakama M, Zhang L, Kaneda Y, Ogihara T, Dzau VJ. A gene therapy strategy using a transcription factor decoy of the E2F binding site inhibits smooth muscle proliferation in vivo. Proc Natl Acad Sci U S A. 1995 Jun 20;92(13):5855-9.

Mueller C, Hodgson JM, Bestehorn HP, Brutsche M, Perruchoud AP, Marsch S, Roskamm H, Buettne HJ. Previous cytomegalovirus infection and restenosis after aggressive angioplasty with provisional stenting. J Interv Cardiol. 2003 Aug: 16(4):307-13.

O'Connor CM, Dunne MW, Pfeffer MA, Muhlestein JB, Yao L, Gupta S, Benner RJ, Fishe MR, Cook TD; Investigators in the WIZARD Study. Azithromycin for the secondary prevention of coronary heart disease events: the WIZARD study: a randomized controlled trial. JAMA. 2003 Sep 17;290(11):1459-66

[No authors listed] Intravenous versus oral ganciclovir: European/Australian comparative study of efficacy and safety in the prevention of cytomegalovirus retinitis recurrence in patients with AIDS. The Oral Ganciclovir European and Australian Cooperative Study Group. AIDS. 1995 May;9(5):471-7.

Neumann F, Kastrati A, Miethke T, Pogatsa-Murray G, Mehilli J, Valina C, Jogethaei N, da Costa CP, Wagner $\mathrm{H}$, Schömig A. Treatment of Chlamydia pneumoniae infection with roxithromycin and effect on neointima proliferation after coronary stent placement (ISAR-3): a randomised, double-blind, placebo-controlled trial. Lancet. 2001 Jun 30;357(9274):2085-9.

Neumann FJ, Kastrati A, Miethke T, Mehilli J, Pogatsa-Murray G, Koch W, Seyfarth M, Schömig A. Previous cytomegalovirus infection and restenosis after coronary stent placement. Circulation. 200 Sep 4;104(10):1135-9.

Nieto FJ, Adam E, Sorlie P, Farzadegan H, Melnick JL, Comstock GW, Szklo M. Cohort study of cytomegalovirus infection as a risk factor for carotid intimal-medial thickening, a measure of subclinical atherosclerosis. Circulation. 1996 Sep 1;94(5):922-7.

Normann E, Gnarpe J, Gnarpe H, Wettergren B. Chlamydia pneumoniae in children with acute respiratory tract infections. Acta Paediatr. $1998 \mathrm{Jan} ; 87(1): 23-7$. 
Pass RF, Dulieg A, Boppana S, Selulovich R, Percell S, Britt W, Burke RL. A subunit cytomegalovirus vaccinebased on recombinant envelope glycoprotein B end a new adjuvant. J. Infect. Dis. $1999 ; 180$ ;970-975

Patel, P., et al., Association of Helicobacter pylori and Chlamydia pneumoniae infections with coronary heart disease and cardiovascular risk factors. Bmj, 1995. 311(7007): p. 711-4

Patnode, D., S.-P. Wang, and J. T. Grayston. 1990. Persistence of Chlamydia pneumoniae, strain TWAR, microimmunofluorescent antibody, p. 406-409. In W. R. Bowie, H. D. Caldwell, R. P. Jones, P.-A. Mårdh, G. L. Ridgway, J. Schachter, W. E. Stamm, and M. E. Ward (ed.), Chlamydial infections. Proceedings of the Seventh International Symposium on Human Chlamydial Infections. Cambridge University Press, Cambridge, United Kingdom.

Paya CV, Marin E, Keating M, Dickson R, Porayko M, Wiesner R. Solid organ transplantation: results and implications of acyclovir use in liver transplants. J Med Virol 1993; 1(Suppl): 123-127.

Paya C, Humar A, Dominguez E, Washburn K, Blumberg E, Alexander B, Freeman R, Heaton N, Pescovitz MD; Valganciclovir Solid Organ Transplant Study Group. Efficacy and safety of valganciclovir vs. oral ganciclovir for prevention of cytomegalovirus disease in solid organ transplant recipients. Am J Transplant. 2004 Apr; 4(4):611-20.

Paz MA, Lupon J, Bosch X, Pomar JL, Sanz G. Predictors of early saphenous vein aortocoronary bypass graft occlusion. The GESIC Study Group. Ann Thorac Surg. 1993 Nov;56(5):1101-6.

Pethig, K., Heublein, B., Wahlers, T. and Haverich, A., Mechanism of luminal narrowing in cardiac allograft vasculopathy: inadequate vascular remodeling rather than intimal hyperplasia is the majo predictor of coronary artery stenosis. Working Group on Cardiac Allograft Vasculopathy. Am Heart J, 1998. 135(4):p. 628-33.

Pieniazek, P., Stepien, E., Sadowski, J., Impact of Chlamydia pneumoniae infection on survival rate after heart transplantation. Med Sci Monit, 2003. 9(2): p. CR67-72.

Plotkin SA, Higgins R, Kurtz JB, Morris PJ, Campbell DA Jr, Shope TC, Spector SA, Dankner WM. Multicenter trial of Towne strain attenuated virus vaccine in seronegative renal transplant recipients. Transplantation. 1994 Dec 15;58(11):1176-8.

Plotkin SA. Cytomegalovirus and Herpes Simplex Vaccines. In vaccines 2004. Plotkin SA and Orenstein WA eds. (Philadelphia: Saunders), 1199-1207.

Porter KE, Thompson MM, Loftus IM, MCDermott E, Jones L, Crowther M, Bell PR, London NJ. Production and inhibition of the gelatinolytic matrix metalloproteinases in a human model of vein graft stenosis. Eur J Vasc Endovasc Surg. 1999 May;17(5):404-12.

Potena L, Holweg CT, Chin C, Luikart H, Weisshaar D, Narasimhan B, Fearon WF, Lewis DB, Cooke JP, Mocarski ES, Valantine HA. Acute rejection and cardiac allograft vascular disease is reduced by suppression of subclinical cytomegalovirus infection. Transplantation. 2006 Aug 15;82(3):398-405.

Prosch S., Docke W.D., Reinke P., Volk H.D., Kruger D.H. Human cytomegalovirus reactivation in bone-marrow derived granulocyte/monocyte progenitor cells and mature monocytes. Intervirology. 1999;42(5-6):308-13.

PryzdialEL, WrightJF. Prothrombinase assembly on an enveloped virus: evidence that the cytomegalovirus surface contains procoagulant phospholipid. Blood 1994; 84: 3749.

Quinn TC, Gaydos CA. In vitro infection and pathogenesis of Chlamydia pneumoniae in endovascular cells. Am Heart J. 1999 Nov; 138(5 Pt 2):S507-11.

Rahel BM, Visseren FL, Suttorp MJ, Plokker TH, Kelder JC, de Jongh BM, Diepersloot RJ, Verkooyen RP, Bouter KP. Cytomegalovirus and Chlamydia pneumoniae as predictors for adverse events and angina pectoris after percutaneous coronary intervention. Am Heart J. 2004 Oct;148(4):670-5.

Ramirez JA. Isolation of Chlamydia pneumoniae from the coronary artery of a patient with coronary atherosclerosis. The Chlamydia pneumoniae/Atherosclerosis Study Group. Ann Intern Med.

1996 Dec ;125(12):979-82.
Reinhardt B, Mertens T, Mayr-Beyrle U, Frank $\mathrm{H}$, Lüske A, Schierling K, Waltenberger J. HCMV infection of human vascular smooth muscle cells leads to enhanced expression of functionally intact PDGF beta-receptor. Cardiovasc Res. 2005 Jul 1;67(1):151-60

Reinhardt B, Winkler M, Schaarschmidt P, Pretsch R, Zhou S, Vaida B, Schmid-Kotsas A, Michel D, Walther $P$, Bachem M, Mertens T. Human cytomegalovirus-induced reduction of extracellular matrix proteins in vascular smooth muscle cell cultures: a pathomechanism in vasculopathies? J Gen Virol. 2006 Oct; 87 (Pt 10):2849-58.

Reischig T, Jindra P, Svecova M, Kormunda S, Opatrny K Jr, Treska V.The impact of cytomegalovirus disease and asymptomatic infection on acute renal allograft rejection. J Clin Virol. 2006 Jun;36(2):146-51.

Reusser P, Atenhofer R, Hebart H, Helg C, Chapuis B, Einsele H. Cytomegalovirus specific T-cell immunity in recipients of autologous peripheral blood stem cell or bone marrow transplants. Blood. 1997;89;3873-3879

Revello M.G., Gerna G. Pathogenesis and prenatal diagnosis of human cytomegalovirus infection J Clin Virol. 2004 Feb;29(2):71-83.

Ringdén, O., B. Lönnqvist, T. Paulin, J. AhImen, G. Klintman, B. Wahren, and J.-O. Lernestedt. 1986. Pharmacokinetics, safety and preliminary clinical experiences using foscarnet in the treatment of cytomegalovirus infections in bone marrow and renal transplant recipients. J. Antimicrob. Chemother. 17:373-387.

Roig J, Casal J, Gispert P, Gea E. 13--Antibiotic therapy of community-acquired pneumonia (CAP) caused by atypical agents. Med Mal Infect. 2006 Nov-Dec;36(11-12):680-9.

Roizmann B, Desrosiers RC, Fleckenstein B, Lopez C, Minson AC, Studdert MJ. The family Herpesviridae: an update. The Herpesvirus Study Group of the International Committee on Taxonomy of Viruses. Arch Virol. 1992;123(3-4):425-49

Rödel J, Woytas M, Groh A, Schmidt KH, Hartmann M, Lehmann M, Straube E. Production of basic fibroblast growth factor and interleukin 6 by human smooth muscle cells following infection with Chlamydia pneumoniae. Infect Immun. 2000 Jun;68(6):3635-41.

Rubin RH. Impact of cytomegalovirus infection on organ transplant recipients. Rev Infect Dis. 1990 Sep-Oct;12 Suppl 7:S754-66.

Saikku, P., M. Leinonen, K. Mattila, M.-R. Ekman, M. S. Nieminen, P. H. Mäkelä, J. K. Huttunen and V. Valtonen. 1988. Serological evidence of an association of a novel chlamydia, TWAR, with chronic coronary heart disease and acute myocardial infarction. Lancet ii:983-986.

Sander D, Winbeck K, Klingelhöfer J, Etgen T, Conrad B. Reduced progression of early carotid therosclerosis after antibiotic treatment and Chlamydia pneumoniae seropositivity. Circulation. 2002 Nov 5;106(19):2428-33.

Sata M, Perlman H, Muruve DA, Silver M, Ikebe M, Libermann TA, Oettgen P, Walsh K.

Fas ligand gene transfer to the vessel wall inhibits neointima formation and overrides the adenovirus-mediated T cell response. Proc Natl Acad Sci U S A. 1998 Feb 3;95(3):1213-7

Schiele F, Batur MK, Seronde MF, Meneveau N, Sewoke P, Bassignot A, Couetdic G, Caulfield F Bassand JP. Cytomegalovirus, Chlamydia pneumoniae, and Helicobacter pylori IgG antibodies and restenosis after stent implantation: an angiographic and intravascular ultrasound study. Heart. 2001 Mar;85(3):304-11

Schmidt R, Redecke V, Breitfeld $Y$, Wantia N, Miethke T, Massberg S, Fischel S, Neumann FJ, Schömig A, May AE. EMMPRIN (CD 147) is a central activator of extracellular matrix degradation by Chlamydia pneumoniae-infected monocytes. Implications for plaque rupture. Thromb Haemost. 2006 Jan;95(1):151-8 
Schooley RT. Cytomegalovirus in the setting of infection with human immunodeficiency virus. Rev Infect Dis. 1990 Sep-Oct; 12 Suppl 7:S811-9.

Schwartz RS, Henry TD. Pathophysiology of coronary artery restenosis. Rev Cardiovasc Med. 2002;3 Suppl 5:S4-9.

Shah PJ, Gordon I, Fuller J, Seevanayagam S, Rosalion A, Tatoulis J, Raman JS, Buxton BF. Factors affecting saphenous vein graft patency: clinical and angiographic study in 1402 symptomatic patients operated on between 1977 and 1999. J Thorac Cardiovasc Surg. 2003 Dec;126(6):1972-7.

Sinisalo J, Mattila K, Valtonen V, Anttonen O, Juvonen J, Melin J, Vuorinen-Markkola H, Nieminen MS; Clarithromycin in Acute Coronary Syndrome Patients in Finland (CLARIFY) Study Group. Effect of 3 months of antimicrobial treatment with clarithromycin in acute non-q-wave coronary syndrome. Circulation. 2002 Apr 2;105(13):1555-60.

Söderberg C, Larsson S, Bergstedt-Lindqvist S, Möller E. Identification of blood mononuclear cells permissive of cytomegalovirus infection in vitro. Transplant Proc. 1993 Feb;25:1416-8.

Span AH, Mullers W, Miltenburg AM, Bruggeman CA. Cytomegalovirus induced PMN adherence in relation to an ELAM-1 antigen present on infected endothelial cell monolayers. Immunology. 1991 Mar;72(3):355-60.

Speir E, Modali R, Huang ES, Leon MB, Shawl F, Finkel T, Epstein SE. Potential role of human cytomegalovirus and $\mathrm{p} 53$ interaction in coronary restenosis. Science. $1994 \mathrm{Jul}$ 15;265(5170):391-4.

SpeirE, YuZX, FerransVJ, HuangES, EpsteinSE. Aspirin attenuates cytomegalovirus infectivity and gene expression mediated by cyclooxygenase-2 in coronary artery smooth muscle cells. Circ Res 1998 83:210.

Stagno S., Pass R.F., Dworsky M.E., Alford C.A. Maternal cytomegalovirus infection and perinatal 63. In: KnoX GE, editor. Clinicla obstetrics and gyneacology. J.B. Lippincott, Philadelphía 1982: 563-76.

Stagno S., Pass R.F., Dworsky M.E., Alford C.A. Congenital and perinatal cyomegalovirus infections. Semin. Perinatol. 1983;7:31-42.

Staras SA, Dollard SC, Radford KW, Flanders WD, Pass RF, Cannon MJ. Seroprevalence of cytomegalovirus infection in the United States, 1988-1994. Clin Infect Dis. 2006 Nov 1;43(9):1143-51.

Stassen FR, Vega-Córdova X, Vliegen I, Bruggeman CA. Immune activation following cytomegalovirus infection: more important than direct viral effects in cardiovascular disease? J Clin Virol. 2006 Mar;35(3):349-53.

Stassen FR, Vainas T, Bruggeman CA. Infection and atherosclerosis. An alternative view on an outdated hypothesis. Pharmacol Rep. 2008 Jan-Feb;60(1):85-92

Stratton CW, Wheldon DB. Multiple sclerosis: an infectious syndrome involving Chlamydophila pneumoniae. Trends Microbiol. 2006 Nov; 14(11):474-9.

Streblow DN, Soderberg-Naucler C, Vieira J, Smith P, Wakabayashi E, Ruchti F, Mattison K, Altschuler $Y$, Nelson JA. The human cytomegalovirus chemokine receptor US28 mediates vascular smooth muscle cell migration. Cell. 1999 Nov 24;99(5):511-20.

Subramanian AK, Quinn TC, Kickler TS, Kasper EK, Tucker PC. Correlation of chlamydia pneumoniae infection and severity of accelerated graft arteriosclerosis after cardiac transplantation. Transplantation. 2002 Mar 15;73(5):761-4.

Summersgill JT, Molestina RE, Miller RD, Ramirez JA. Interactions of Chlamydia pneumoniae with human endothelial cells. J Infect Dis. 2000 Jun;181 Suppl 3:S479-82

Tanaka, H., et al., Activation of smooth muscle and endothelial cells following balloon injury. Ann N Y Acad Sci, 1995. 748: p. 526-9.

Tanaka, K., et al., Effects of human cytomegalovirus immediate-early proteins on p53-mediated apoptosis in coronary artery smooth muscle cells. Circulation, 1999. 99(13): p. 1656-9.
Tanaka T, Matsushita M, Oka Y, Sada T, Kira Y, Effect of Chlamydia pneumoniae infection on coronary flow reserve and intimal hyperplasia after stent implantation in patients with angina pectoris. J Cardiol. 2001 Dec;38(6):311-7.

Taylor-Wiedeman J, Sissons JG, Borysiewicz LK, Sinclair JH. Monocytes are a major site of ersistence of human cytomegalovirus in peripheral blood mononuclear cells. J Gen Virol. 199 Sep;72 ( Pt 9):2059-64.

Tenney, D. J., G. Yamanaka, S. M. Voss, C. W. Cianci, A. V. Tuomari, A. K. Sheaffer, M. Alam, and R. J. Colonno. 1997. Lobucavir is phosphorylated in human cytomegalovirus-infected and -uninfected cells and inhibits the viral DNA polymerase. Antimicrob. Agents Chemother. 41:2680-2685.

Tesi, R.J., Elkhammas, E.A., Henry, M.L., Davies, E.A., Salazar, A. and Ferguson, R.M., Acute rejection episodes: best predictor of long-term primary cadaveric renal transplant survival. Transplant Proc, 1993. 25(1 Pt 2): p. 901-2

Thorpe C, Edwards L, Snelgrove R, Finco O, Rae A, Grandi G, Guilio R, Hussell T. Discovery of vaccine antigen that protects mice from Chlamydia pneumoniae infection. Vaccine. $2007 \mathrm{Mar}$ 8;25(12):2252-60.

Tikkanen JM, Kallio EA, Bruggeman CA, Koskinen PK, Lemstrom KB. Prevention of cytomegalovirus infection-enhanced experimental obliterative bronchiolitis by antiviral prophylaxis or immunosuppression in rat tracheal allografts. Am J Respir Crit Care Med. 2001 Aug 15;164(4):672-9.

Tong CY, Potter F, Worthington E, Mullins P. Chlamydia pneumoniae myocarditis.

Lancet. 1995 Sep 9;346(8976):710-1.

Tu W, Potena L, Stepick-Biek P, Liu L, Dionis KY, Luikart H, Fearon WF, Holmes TH, Chin C, Cooke JP, Valantine HA, Mocarski ES, Lewis DB. T-cell immunity to subclinical cytomegalovirus infection reduces cardiac allograft disease. Circulation. 2006 Oct 10;114(15):1608-15.

Varagunam M, Finney H, Trevitt R, Sharples E, McCloskey DJ, Sinnott PJ, Raftery MJ, Yaqoob MM. Pretransplantation levels of C-reactive protein predict all-cause and cardiovascular mortality, but no graft outcome, in kidney transplant recipients. Am J Kidney Dis. 2004 Mar;43(3):502-7.

Volanen I, Vainionpää R, Ilonen J, Markula P, Kallio K, Kaitosaari T, Helenius H, Simell O. A prospective study of Chlamydia pneumoniae antibodies in children between 7 months and 8 years of age. Scand J Infect Dis. 2003;35(8):471-7.

Walter EA, Greenberg PD, Gilbert MJ, Finch RJ, Watanabe KS, Thomas ED, Riddell SR. Reconstruction of cellular immunity against cytomegalovirus in recipients of allogeneic bone marrow by transfer of T-cell clones from the donor. N. Engl. J. Med. 1995;333:1038-1044.

Wan S, George SJ, Nicklin SA, Yim AP, Baker AH. Overexpression of p53 increases lumen size and blocks neointima formation in porcine interposition vein grafts. Mol Ther. 2004 May;9(5):689-98

Ward M.E. The chlamydial developmental cycle. In: Baron A.L., ed. Microbiology of Chlamydiae. Boca Raton, Fla: CRC Press INC,; 1988.

Weis M, Kledal TN, Lin KY, Panchal SN, Gao SZ, Valantine HA, Mocarski ES, Cooke JP. Cytomegalovirus infection impairs the nitric oxide synthase pathway: role of asymmetric dimethylarginine in transplant arteriosclerosis.Circulation. 2004 Feb 3; 109(4):500-5.

West NE, Qian H, Guzik TJ, Black E, Cai S, George SE, Channon KM. Nitric oxide synthase (nNOS) gene transfer modifies venous bypass graft remodeling: effects on vascular smooth muscle cell differentiation and superoxide production. Circulation. 2001 Sep 25;104(13):1526-32

Winters, G.L., Kendall, T.J., Radio, S.J., et al., Posttransplant obesity and hyperlipidemia: major predictors of severity of coronary arteriopathy in failed human heart allografts. J Heart Transplant, 1990. 9(4): p. 364-71.

Wittwer T, Pethig K, Heublein B, Teebken OE, Harringer W, Haverich A, Wahlers T. Impact of chronic infection with chlamydia pneumoniae on incidence of cardiac allograft vasculopathy. Transplantation. 2000 May 15;69(9):1962-4. 
Chapter 1

Wolff RA, Ryomoto M, Stark VE, Malinowski R, Tomas JJ, Stinauer MA, Hullett DA, Hoch JR. Antisense to transforming growth factor-beta1 messenger RNA reduces vein graft intimal hyperplasia and monocyte chemotactic protein 1. J Vasc Surg. 2005 Mar;41(3):498-508.

Wright JF, Kurosky A, Pryzdial EL, Wasi S. Host cellular annexin II is associated with cytomegalovirus particles isolated from cultured human fibroblasts. J. Virol 1995; 69:4784.

Xiong, X., C. Flores, M. D. Fuller, D. B. Mendel, A. S. Mulato, K. Moon, M. S. Chen, and J. M. Cherrington. 1997. In vitro characterization of the anti-human cytomegalovirus activity of PMEA (Adefovir). Antiviral Res. 36:131-137.

Yeung AC, Davis SF, Hauptman PJ, et al. Incidence and progression of transplant coronary artery disease over 1 year: results of a multicenter trial with use of intravascular ultrasound. Multicenter Intravascular Ultrasound Transplant Study Group. J Heart Lung Transplant 1995; 14(6 Pt 2):S215-S220.

Yokouchi K, Numaguchi Y, Kubota R, Ishii M, Imai H, Murakami R, Ogawa Y, Kondo T, Okumura $K$, Ingber DE, Murohara T. I-Caldesmon regulates proliferation and migration of vascular smooth muscle cells and inhibits neointimal formation after angioplasty. Arterioscler Thromb Vasc Biol. 2006 Oct;26(10):2231-7.

Yucescan $C$ and Sriram Chlamydia pneumoniae infection of the central nervous system. Curr. Opin. Neurol 2001;14 (3):355-9.

Zamorano J, García-Tejada J, Suárez A, Culebras E, Castañón J, Moreno R, Reguillo F, Gil M, Picazo J, Sánchez-Harguindey L. Chlamydia pneumoniae in the atherosclerotic plaques of patients with unstable angina undergoing coronary artery bypass grafting: does it have prognostic implications? Int unstable angina undergoing coronary

Zhou YF, Leon MB, Waclawiw MA, Popma JJ, Yu ZX, Finkel T, Epstein SE. Association between prior cytomegalovirus infection and the risk of restenosis after coronary atherectomy. N Engl J Med. 1996 Aug 29;335(9):624-30.

Zhou YF, Shou M, Guetta E, Guzman R, Unger EF, Yu ZX, Zhang J, Finkel T, Epstein SE. Cytomegalovirus infection of rats increases the neointimal response to vascular injury without consistent evidence of direct infection of the vascular wall. Circulation. 1999 Oct 5;100(14):1569-75.

ZhouYF, YuZX, WanishsawadC, ShouM, EpsteinSE. The immediate early gene products of human cytomegalovirus increase vascular smooth muscle cell migration, proliferation, and expression of PDGF beta-receptor. Biochem Biophys Res Commun 1999; 256: 608.

Zhou YF, Shou M, Harrell RF, Yu ZX, Unger EF, Epstein SE. Chronic non-vascular cytomegalovirus infection: effects on the neointimal response to experimental vascular injury. Cardiovasc Res. 2000 Mar;45(4):1019-25.

Zou, R., J. C. Drach, and L. B. Townsend. 1997. Design, synthesis, and antiviral evaluation of 2-chloro-5,6-dihalo-1-beta-D-ribofuranosylbenzimidazoles as potential agents for human cytomegalovirus infections. J. Med. Chem. 40:811-818.

Zorc M, Vraspir-Porenta O, Kese D, Petrovic D, Legan M. Detection of Chlamydia pneumoniae DNA in the coronary arteries and bypass in three patients with diffuse coronary artery disease. Cardiology. 2005;103(3):121-2. 


\section{Chapter 2}

Cytomegalovirus aggravates intimal hyperplasia in rats by stimulating smooth muscle cell proliferation 


\section{Abstract}

Epidemiological and animal studies suggest a role for cytomegalovirus (CMV) in restenosis. Previously we demonstrated that proliferating smooth muscle cells in the injury arterial wall are particularly susceptible for CMV induced effects. Therefore, we hypothesized that, depending on the time point of infection after vascular injury, CMV infection may affect cell proliferation either in the media or in the neointima thereby aggravating the process of restenosis. In the present study we focused on the individual layers of the arterial wall by evaluating, besides neointima to media ratio, the medial and neointimal area and cellularity in the rat femoral artery.

Vascular injury was photochemically induced in rat femoral arteries. Immediately or 14 days thereafter rats were infected with rat CMV (RCMV) or mock. The presence of RCMV in the vascular wall was determined at 3, 5, 14 and 35 days after infection by quantitative real time PCR.

When rats were infected immediately after injury a significant increase was only seen in the medial but not in the neointimal cross sectional area. On the other hand, when rats were infected 14 days after the initial injury, a significant increase was only seen in the neointimal area, thereby confirming our hypothesis that RCMV infection primary affect proliferating SMC's. As the mean number of smooth muscles cells per $\mu \mathrm{m} 2$ in both cell layers was unchanged despite an increase in cross sectional area, this implies that RCMV stimulated smooth muscle cell proliferation. Furthermore, these vascular effects were observed without the virus being abundantly present in the vascular wall suggesting that inflammatory and immune mediated responses to RCMV infection are more important in aggravating the response to vascular injury than the virus itself.

\section{Introduction}

Arterial stenosis, resulting from advanced atherosclerosis, is commonly treated with angioplasty (PTCA). Nevertheless, since the introduction of PTCA more than 20 years ago, the problem of renewed narrowing of the initially successful dilated lesion has plagued this procedure in $30-50 \%$ of all cases (Glagov 1994). Despite intensive investigation, the exact underlying mechanism still has to be elucidated and pharmacological therapy hasn't been found yet to completely prevent restenosis. A hyperplastic smooth muscle cell (SMC) response is considered to be the main cause for limiting the long-term success of the angioplastic procedures (Tanaka 1995). Recent epidemiological studies indicated that infectious agents may increase the risk of restenosis after PTCA, although reported results have not always been consistent (Horne 2002, Anderson 1998, Patel 1995). These infectious agents, and cytomegalovirus (CMV) in particular, have been suggested to promote SMC proliferation by blocking the anti-proliferative effect of the tumour suppressor gene p53 and by doing so increase the risk for restenosis (Castillo 2000, Epstein 1996, Rodriguez-Campos 2001, Tanaka 1999, Zhou 1999a). Besides SMC proliferation, CMVinduced immune activation may also contribute to the process of restenosis (Zhou 1999b).

To date, several experimental approaches have been used to induce intimal hyperplasia and thickening. Most of these techniques are based on endothelial denudation by a flexible wire (Lindner 1993), a balloon catheter (Clowes 1986), air-drying (Fishman 1975) or laser (Hanke 1991). Although all of these procedures are intended to induce intimal damage, which then results in neointima formation, they are relatively inaccurate regarding the extent of intimal damage and are mostly difficult to perform (Indolfi 1995). In regard of this imperfection, we used a simple and reproducible thrombosis model to induce intimal thickening in the rat femoral artery as described previously (Kikuchi 1996). This method is based on a photochemical reaction between green light and intravenously administered rose bengal (Saniabadi 1995, Paczkowski 1985). The model represents a non-invasive and non-mechanical approach to induce endothelial damage and neointima formation.

The aim of the current study was to elucidate in more detail the role of CMV in the process of restenosis, induced by the 'rose bengal model'. Previous studies already delineated the stimulating effect of CMV on the hyperplastic response following balloon denudation (Zhou 1999b, 2000). Nonetheless, in these studies the main focus was on the neointima/media ratio and no attention has been paid to individual layers 
of the vascular wall (i.e. media and neointima). Previously, we demonstrated that proliferating smooth muscle cells are particularly susceptible for CMV induced effects (Persoons 1997). Therefore, we hypothesized that, depending on the time point of infection, CMV may affect cell proliferation either in the media or in the neointima. For that reason, we evaluated, besides neointima to media ratio, the medial and neointimal area and cellularity in the rat femoral artery when rats were infected either immediately or 2 weeks after injury.

Although CMV may stimulate the hyperplastic response following endothelial injury, it still remains a matter of debate whether this results from a direct effect of CMV in the vascular wall or from an indirect effect resulting from an increased influx of inflammatory cells in the vascular wall of infected animals. Although CMV has been demonstrated in the vascular wall by sensitive PCR methods, we used the quantitative real time PCR technique to determine the exact number of CMV DNA copies in the vascular wall at various time points post infection.

\section{Methods}

\section{Animals}

Specific pathogen-free (SPF), inbred male Lewis rats were obtained from the Department of Experimental Animal Service of the University of Maastricht, the Netherlands. Experiments were carried out on animals aged 12 weeks, weighing 300 to 400 gram. Housing and care of the animals, and all the procedures used in these studies were approved by the Ethical Committee for the Use of Experimental Animals of the institution, and conform with the Guide for the Care and the Use of Laboratory Animals, published by the US National Institute of Health (NIH Publication No. 85-23, revised 1985). Rats were fed standard rat chow and tap water at libitum. All surgical procedures were performed under general anaesthesia and using sterile technique.

\section{Experimental design}

Vascular injury was photochemically induced in the rat femoral artery (Kikuchi 1996, Saniabadi 1985). The rats were anaesthetised with sodium pentobarbital $(60 \mathrm{mg} /$ kg body weight, intraperitoneally (i.p.)), and the right femoral artery was carefully exposed. The exposed segment was proximally and distally covered with gauze soaked with physiological salt solution (PBS) to prevent the surrounding tissue from desiccation, leaving only 5-10 mm of the arterial segment uncovered. Thereafter, bengal rose ( $50 \mathrm{mg} / \mathrm{kg}$, Sigma Chemical Co U.S.A.) was administered intravenously via the penile vein. Transillumination of the exposed segment during 13 minutes was done with a cold light source (KL 2500 LCD, SCHOTT) equipped with a halogen reflector lamp (Osram, type HLX 64653) and a green filter (540 nm). Transillumination time was chosen based on a pilot study, which indicated that 13 minutes was the most suitable exposure time for providing endothelial damage resulting in neointima formation without causing an occlusive thrombus. After exposure, the wound was closed and the animal was returned to its cage to recover from anaesthesia. Animals were kept warm by a heat-lamp during the time of surgery and during the recovery phase. Infection was established by inoculating rats i.p. with $1.25^{*} 10^{6}$ plaque forming units (PFU) of homogenised salivary gland derived RCMV (Maastricht strain) (Bruggeman 1982) immediately after surgery or 14 days after closure of the wound. Controls were injected i.p. with $1 \mathrm{ml}$ mock solution (salivary gland homogenate). Animals ( $\mathrm{n}=16$ per group) were sacrificed 35 days post surgery.

\section{Histological and morphometrical procedures}

Five weeks after surgery, rats were anaesthetised, the chest and abdominal cavities were opened and a catheter was inserted into the apex of the heart. Vessels were initially flushed with physiological salt solution and then perfusion fixed with $3.7 \%$ formaldehyde in phosphate buffered saline, $\mathrm{pH} 7.4$, at physiological pressure $(100 \mathrm{~mm} \mathrm{Hg})$. Femoral arteries were removed and fixed overnight in the same fixative. Furthermore, tissue biopsies of liver, spleen, lung and salivary gland were collected. The fixed femoral artery was cut in three or four segments, routinely processed and paraffin embedded. Cross-sections $(4 \mu \mathrm{m})$ were taken for morphometrical analysis at $200 \mu \mathrm{m}$ intervals and mounted on glass slides for haematoxylin-eosin and Lawson staining. Medial, neointimal and luminal areas were determined in those crosssections of the femoral artery where a neointima was seen (average of 10 crosssections per artery) by using a computer-assisted morphometry system (analysIS ${ }^{\circledR}$, Soft Imaging System, $\mathrm{GmbH}$ ). The cross-sectional area of the media was defined as the area surrounded by the external and internal elastic lamina. The neointimal cross-sectional area was defined by the area surrounded by the internal elastic lamina and the arterial lumen. Final scores were given as percentage of the mock-injected group. 


\section{Quantification of number of cells in the intima and media}

The number of cells in the intima and media was quantified by counting the total number of nuclei using a microscope. All nuclei were counted in those haematoxylineosin stained cross-sections in which a neointima was observed. Final scores were expressed as number of cells per area and values are given as median.

\section{Detection of RCMV DNA after endothelial injury by real time PCR}

Lewis rats ( $\mathrm{n}=3$ per time point) were used for the detection of RCMV. Surgical procedures were performed as described above. Rats were inoculated i.p. with $1.25^{*} 10^{6}$ plaque forming units RCMV (Maastricht strain, derived from homogenised salivary glands) immediately after surgery (group A) or 14 days (group B) after closure of the wound. Animals were sacrificed at various time points post infection $(3,5$, 14 and 35 days p.i.). This implicates that in group A animals were sacrificed 3, 5, 14 and 35 days after surgery and in group B 17, 19, 28 and 35 days after surgery. Right (injured) and left (control) femoral arteries and tissue biopsies from the lung, spleen and salivary glands were collected and stored in liquid nitrogen. For the detection of viral DNA within the tissues, total genomic DNA was extracted from tissue using the WIZARD ${ }^{\circledR}$ method (Promega Corporation, Madison, WI). To determine the number of RCMV DNA copies in all tissues quantitative real time PCR was used as recently described (Kaptein 2003)

\section{Statistical Analysis}

Morphological data were expressed as percentage of the data obtained in the mockinjected group. Cell count numbers are expressed as mean \pm SEM. Values were compared using the Mann Whitney $U$ test and $p<0.05$ was considered as statistically significant.

\section{Results}

\section{Animal conditions}

No apparent clinical signs of illness were observed in any of the animals during the 5 - week follow-up period. Starting body weights ranged from $300 \mathrm{~g}$ to $400 \mathrm{~g}$ while at the end of the experiments animal weights ranged from $350 \mathrm{~g}$ to $445 \mathrm{~g}$. There were no significant differences between the experimental groups.

\section{Vascular remodelling}

RCMV administration in the rats immediately after endothelial damage had no significant effect on the cross-sectional area of the neointima or the neointima to media ratio (figure $1 \mathrm{~A}$ and $\mathrm{C}$ ) at 35 days after surgery. However, at this time point a significant increase in the medial cross-sectional area was observed when rats were infected immediately after surgery (figure 1B).

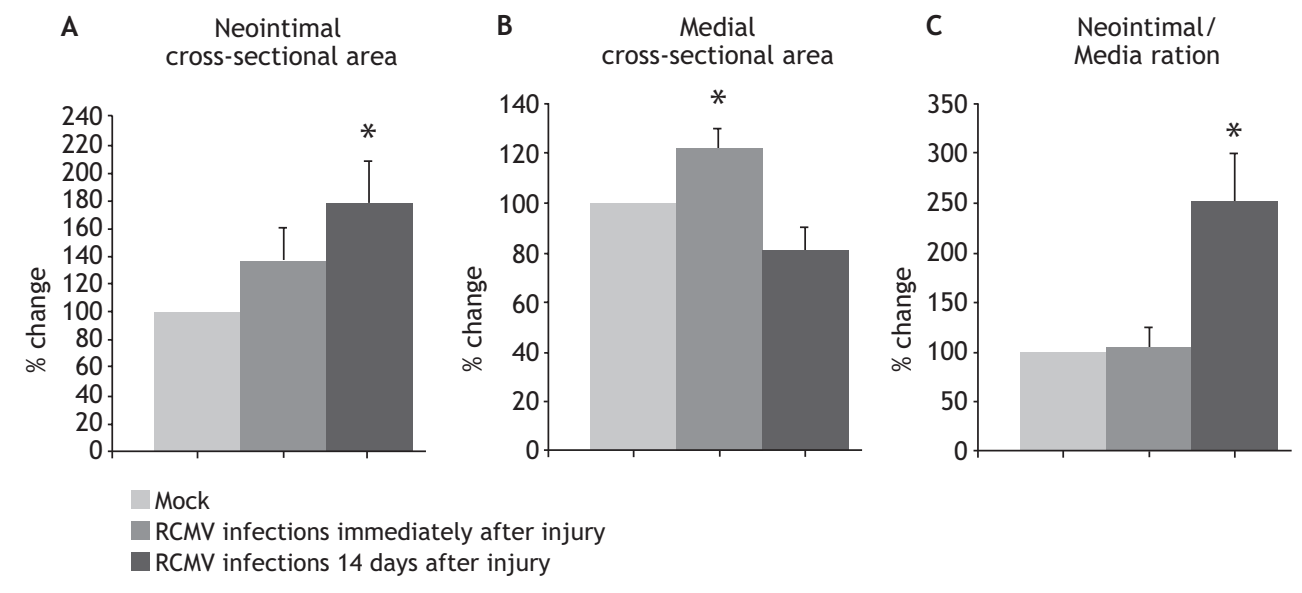

Figure 1 | Effect of RCMV infection on neointimal and medial cross-sectional area.

Rats were infected with RCMV or mock immediately or 14 days after injury and vascular remodelling was determined 35 days after the initial injury. Data are expressed as percentage of mock. ${ }^{*} P<0.05$
(RCMV compared to mock)

In contrast, a significant increase in neointimal cross-sectional area was observed in injured arteries from rats infected with RCMV 14 days after the initial injury while no significant effect was observed on the medial cross-sectional area (figure $1 \mathrm{~A}$ and B). Consequently, administration of RCMV 14 days after injury did also result in a significant increase in neointimal/medial ratio (figure 1C). No differences were seen in luminal stenosis or luminal cross-sectional area (data not shown).

\section{Cell numbers in the neointima and media}

Although the medial cross-sectional area was significantly increased at 35 days when rats were infected immediately after surgery, average number of cells $/ \mu \mathrm{m}^{2}$ was not different in the media (table 1). This implies that the total number of cells in the media is increased and suggests that cell proliferation in the media has been 
stimulated by RCMV. Nevertheless, at the time of sacrifice this stimulating effect could not be detected anymore as the percentage of PCNA positive cells had returned to levels comparable to mock (Intima: $7.3 \pm 0.03 \%$ (RCMV) vs. $12.0 \pm 3.5 \%$ (mock), n.s. Media: $11.0 \pm 4.5 \%$ (RCMV) vs. $12.0 \pm 4.6 \%$ (mock), n.s.). In contrast, the mean number of cells $/ \mu \mathrm{m}^{2}$ was significantly decreased in the neointima despite an unchanged crosssectional area.

Table 1 | Effect of RCMV infection on number of cells in intima and media.

\begin{tabular}{ccccc}
\hline $\begin{array}{c}\text { Cells } \\
\left(\times 10^{-3}\right) / \mu m^{2}\end{array}$ & $\begin{array}{c}\text { RCMV } \\
\mathrm{t}=0\end{array}$ & $\begin{array}{c}\text { MOCK } \\
\mathrm{t}=0\end{array}$ & $\begin{array}{c}\text { RCMV } \\
\mathrm{t}=14\end{array}$ & $\begin{array}{c}\text { MOCK } \\
\mathrm{t}=14\end{array}$ \\
\hline intima & $11.1 \pm 1.0^{*}$ & $19.6 \pm 4.9$ & $14.2 \pm 4.0$ & $20.2 \pm 6.1$ \\
media & $4.5 \pm 1.0$ & $4.7 \pm 0.5$ & $4.1 \pm 0.7^{*}$ & $2.8 \pm 0.1$ \\
\hline
\end{tabular}

${ }^{a}$ Cell count numbers in sections with neointima in rat femoral arteries 35 days after injury.

b Rats injected with RCMV or mock immediately $(\mathrm{t}=0)$ or at 14 days $(\mathrm{t}=14)$ after injury. Data are expressed as mean \pm SEM * $P<0.05$ (RCMV compared with mock at same time point).

When rats were infected 14 days after the initial injury, the mean cell number $/ \mu \mathrm{m}^{2}$ in the neointima was not significantly altered at 35 days post surgery notwithstanding the significant increase in neointimal cross-sectional area (table 1). This resembles the results seen in the media when rats were infected immediately after surgery and strengthens the idea that RCMV infection stimulates the proliferative response in SMC's following arterial injury. On the other hand, however, the mean number of cells $/ \mu \mathrm{m}^{2}$ in the media was significantly increased following RCMV infection without any increase in medial cross-sectional area. But, as in the early infection group, at the stage no difference in PCNA positive cells could be detected anymore in either the media or the intima (Intima: $7.7 \pm 0.03 \%$ (RCMV) vs. $18.3 \pm 5.8 \%$ (mock), n.s. Media: $10.8 \pm 4.1 \%(\mathrm{RCMV})$ vs. $22.0 \pm 5.0 \%$ (mock), n.s.)

\section{Detection of RCMV DNA by real time PCR}

The number of RCMV DNA copies was determined in various organs (liver, lung, spleen) at different time points p.i. As expected, in group A (infection immediately after surgery) RCMV DNA could be detected in all organs at day 3, 5 and $14 \mathrm{pi}$, indicating that the RCMV infection was successful. The highest amount of RCMV DNA copies was found in the spleen at 5 days p.i. $\left(6,9 * 10^{3}\right.$ copies of RCMV DNA per $1 \mu$ g total DNA). organs, indicating that the virus was cleared from these tissues. However, at this time point the highest amount of RCMV DNA was found in the salivary gland $\left(7,6 * 10^{5}\right.$ copies of RCMV DNA per $1 \mu$ g total DNA). In group B (infection 14 days post surgery), similar results were obtained with highest copy numbers in the spleen at 5 days p.i. $\left(4,8 * 10^{3}\right.$ copies of RCMV DNA per $1 \mu \mathrm{g}$ total DNA) and in the salivary gland at 21 days p.i $\left(\sim 35\right.$ days after surgery, $3,9 * 10^{4}$ copies of RCMV DNA per $1 \mu \mathrm{g}$ total DNA)

In the femoral arteries only limited number of RCMV DNA copies could be detected (table 2). Although RCMV DNA could be detected for a longer period of time in the arteries when rats were infected immediately after injury compared to infection 14 days after injury, no significant differences in RCMV DNA copy numbers were observed either between injured or uninjured arteries or when rats were infected immediately or 14 days after injury.

\section{Cell numbers in the neointima and media}

Although the medial cross-sectional area was significantly increased at 35 days when rats were infected immediately after surgery, average number of cells $/ \mu \mathrm{m}^{2}$ was not different in the media (table 1). This implies that the total number of cells in the media is increased and suggests that cell proliferation in the media has been stimulated by RCMV. Nevertheless, at the time of sacrifice this stimulating effect could not be detected anymore as the percentage of PCNA positive cells had returned to levels comparable to mock (Intima: $7.3 \pm 0.03 \%$ (RCMV) vs. $12.0 \pm 3.5 \%$ (mock), n.s. Media: $11.0 \pm 4.5 \%$ (RCMV) vs. $12.0 \pm 4.6 \%$ (mock), n.s.). In contrast, the mean number of cells $/ \mu \mathrm{m}^{2}$ was significantly decreased in the neointima despite an unchanged crosssectional area.

When rats were infected 14 days after the initial injury, the mean cell number $/ \mu \mathrm{m}^{2}$ in the neointima was not significantly altered at 35 days post surgery notwithstanding the significant increase in neointimal cross-sectional area (table 1). This resembles the results seen in the media when rats were infected immediately after surgery and strengthens the idea that RCMV infection stimulates the proliferative response in SMC's following arterial injury. On the other hand, however, the mean number of cells $/ \mu \mathrm{m}^{2}$ in the media was significantly increased following RCMV infection without any increase in medial cross-sectional area. But, as in the early infection group, at the stage no difference in PCNA positive cells could be detected anymore in either the media or the intima (Intima: $7.7 \pm 0.03 \%$ (RCMV) vs $18.3 \pm 5.8 \%$ (mock), n.s. Media: $10.8 \pm 4.1 \%$ (RCMV) vs. $22.0 \pm 5.0 \%$ (mock), n.s.) 


\section{Detection of RCMV DNA by real time PCR}

The number of RCMV DNA copies was determined in various organs (liver, lung, spleen) at different time points p.i. As expected, in group A (infection immediately after surgery) RCMV DNA could be detected in all organs at day 3, 5 and $14 \mathrm{pi}$, indicating that the RCMV infection was successful. The highest amount of RCMV DNA copies was found in the spleen at 5 days p.i. $\left(6,9 * 10^{3}\right.$ copies of RCMV DNA per $1 \mu$ g total DNA). After 35 days no RCMV DNA could be detected anymore in these initially positive organs, indicating that the virus was cleared from these tissues. However, at this time point the highest amount of RCMV DNA was found in the salivary gland $\left(7,6 * 10^{5}\right.$ copies of RCMV DNA per $1 \mu$ g total DNA). In group B (infection 14 days post surgery), similar results were obtained with highest copy numbers in the spleen at 5 days p.i. $\left(4,8 * 10^{3}\right.$ copies of RCMV DNA per $1 \mu \mathrm{g}$ total DNA) and in the salivary gland at 21 days p.i ( $\sim 35$ days after surgery, $3,9 * 10^{4}$ copies of RCMV DNA per $1 \mu \mathrm{g}$ total DNA)

In the femoral arteries only limited number of RCMV DNA copies could be detected (table 2). Although RCMV DNA could be detected for a longer period of time in the arteries when rats were infected immediately after injury compared to infection 14 days after injury, no significant differences in RCMV DNA copy numbers were observed either between injured or uninjured arteries or when rats were infected immediately or 14 days after injury.

Table 2 | Presence of RCMV in rat femoral arteries.

Group A: Infection immediately after injury

\begin{tabular}{ccc}
\hline days post infection & left femoral artery a & right femoral artery \\
\hline 3 & $28,1 \pm 22,3$ & $10,3 \pm 10,3$ \\
5 & $62,8 \pm 36,3$ & $5,5 \pm 5,5$ \\
14 & $21,8 \pm 15,8$ & $68,9 \pm 50,0$ \\
35 & $1,7 \pm 1,7$ & $0,0 \pm 0,0$ \\
\hline Group B: Infection 14 days after injury & \\
\hline days post infection & left femoral artery a & right femoral artery \\
\hline 3 & $170,1 \pm 98,8$ & $14,1 \pm 8,7$ \\
5 & $0,0 \pm 0,0$ & $0,0 \pm 0,0$ \\
14 & $0,0 \pm 0,0$ & $0,0 \pm 0,0$ \\
21 & $0,0 \pm 0,0$ & $0,0 \pm 0,0$ \\
\hline
\end{tabular}

a RCMV DNA is expressed as the number of copies per $1 \mu \mathrm{g}$ total DNA.

Data are expressed as mean \pm SEM.

\section{Discussion}

Restenosis is a common problem occurring in $30-50 \%$ of all cases after an initially successful PTCA. And although subject for research for several decades, the exact underlying mechanism for restenosis has not been elucidated yet. Here, we investigated the role of RCMV on the process of restenosis, thereby focusing on the effect of infection on the different layers of the vessel wall. Furthermore, as it is still a matter of debate whether the effect of RCMV is attributable to a direct effect of the virus on components of the vascular wall we decided to determine the number of RCMV DNA copies in the (injured) vascular wall at various time points post infection.

In the current study, we used a different model for endothelial denudation than the classical balloon injury model. The present model is based on a photochemical reaction between green light and rose bengal, which causes endothelial injury followed by ICAM, VCAM, E/P-selectin expression and monocyte recruitment, as well as platelet adhesion, aggravation, and formation of a platelet- and fibrin-rich thrombus at the site of the reaction (Saniabadi 1995). This photochemical model is a simple, noninvasive and non-mechanical animal model to study the neointimal formation after vascular injury as compared to flexible wire and balloon catheter injury. However, the morphological and proliferative changes observed after endothelial injury in this model, with respect to thrombus formation and SMC's proliferation, still mimics the phenomenon seen after balloon angioplasty and flexible wire injury (Kikuchi 1998). In conformity with previous studies this model proved to be a reproducible, simple and practical approach to study SMC replication, migration and neointimal formation and to study possible risk factors on the process of restenosis.

After endothelial injury, platelets adhere to the denuded surface thereby releasing their granules, which contain vasoactive, thrombotic factors as well as several growth factors. Subsequently, the following cellular events can be described by three partially overlapping phases; (1) proliferation of SMC's in the media; (2) migration of SMC's from the media to luminal surface and (3) proliferation of SMC's in the neointima (Schwartz 1995). We focused on the two proliferative phases since stimulatory effects of CMV infection on the proliferation and accumulation of SMC's have been described in detail previously (Yonemitsu 1997, Castillo 2000, Tanaka 1999).

Previously, we demonstrated that the smooth muscle phenotype determines the susceptibility for RCMV infection. When arterial SMC's exhibit a contractile phenotype they seem rather resistant against RCMV infection as illustrated by the 
absence of RMCV antigens in the normal media following RCMV infection (Persoons 1994). However, it has been demonstrated that the arterial SMC phenotype changes from contractile to synthetic/proliferative shortly after injury of the vascular wall thereby rendering them more susceptible for infection. This is supported by the observation that RCMV antigens and DNA could be demonstrated in the neointima but not in the media when rats were infected 14 days post angioplasty when intimal but not medial SMC display the proliferative phenotype (Persoons 1997). Thus, we infected rats immediately after injury, when dedifferentiation of the medial smooth muscle layer is initiated. This resulted in a noticeable effect on medial cross sectional area, which was significantly enlarged compared to the medial area in mock-injected rats. Since the mean number of cells per $\mu \mathrm{m}^{2}$ did not alter, this implicates an increase in the total number of cells underlying the increase in medial cross-sectional area. However, no difference in the number of PCNA positive cells was observed anymore suggesting that the stimulating effect of RCMV on SMC proliferation had taken place in the early phase after infection. On the other hand, no effect was seen on the neointimal cross-sectional area. This suggests that RCMV is able to infect the vascular wall when dedifferentiated SMC's are present and exert a transient effect, which is only reflected by the increase in the medial cross-sectional area. This concept is supported by the data obtained when rat were infected with RCMV 14 days after the initial injury. Previous data demonstrated that at this stage medial SMC proliferation has returned to control values but intimal SMC proliferation is still submaximal. Under these conditions, a significant increase in neointimal cross-sectional area was observed with no effect on the media. Consequently, the neointima-to-media ratio was significantly augmented. Furthermore, the absence of significant differences in the number of PCNA positive cells again suggest that the RCMV effect on SMC proliferation takes place at an early stage after infection.

The absence of an increase in neointima-to-media ratio, when rats were infected immediately after injury, is in contrast with earlier studies. Zhou and colleagues previously reported an increase in the neointima-to media ratio in a similar experiment (Zhou 1999b). Nevertheless, for various reasons, their results may differ from the ones in the present study. First of all, we used a different model as compared to Zhou et al. Since the degree of neointima formation is linearly correlated with the amount of damage to the vascular wall (Indolfi 1995) and as the model we used may result in less damage to the medial layer than a balloon catheter this may partially explain the observed differences. In particular when the stimulating effect of RCMV is mainly restricted to dedifferentiated SMC's as suggested in the present study. Furthermore,
Zhou et al. used a different RCMV stain as in the present study (Priscott vs. Maastricht strain). Studies in the mouse already pointed out that the cardiovascular effects of different CMV strains may differ (Fairweather 1998) thereby offering an alternative explanation, e.g. that vascular effects of RCMV are also strain-specific.

Interestingly, a significant increase in the neointima-to-media ratio was observed when rats were infected 14 days after the initial injury. These results are in conflict with data previously published by our group. When we infected rats at a similar time point after balloon injury no significant effects on this ratio were observed (Persoons 1994). Nonetheless, the present study differs at several important aspects from the previous one. In these earlier experiments immuno-compromised rats were used to give the virus the chance to proliferate and initiate an infection (Stals 1990). Indeed, a large number of cells in the neointima of the common carotid arteries was positive for RCMV antigens and genome, as shown with immunohistochemical and in situ hybridisation techniques. This is in contrast with the present study where no RCMV antigens could be detected in the vascular wall (data not shown) and only a limited number of RCMV DNA copies per $\mu \mathrm{g}$ total DNA was found with the far more sensitive real time PCR technique. Nonetheless, in the earlier study no effect on SMC proliferation was found while in the present study the neointimal area as well as the neointima-to-media ratio was significantly increased following RCMV infection. These data suggest that the abundant presence of the virus in the vascular wall is not mandatory to exert an effect on SMC proliferation and indicates that indirect effects of RCMV infection may be of more importance.

Indirect effects may result from the systemic production of various proinflammatory cytokines such as IL-2, IL-4 or IFN- $\gamma$. Indeed, elevated serum levels of these cytokines have been described following RCMV infection (Zhou 2000). Also, the transient presence of RCMV in the vascular wall may result in an increased influx of immune cells such as macrophages and T-cells. These cells then may responsible for an increased local production of pro-inflammatory cytokines and growth factors thereby stimulating SMC proliferation and growth. Interestingly, we recently demonstrated an increased influx of T-cells in atherosclerotic plaques of apoE-/- mice following MCMV infection despite the absence of MCMV DNA in the vascular wall (Vliegen 2002). The importance of a functional immune system in the hyperplastic response was also emphasized by Lemström and colleagues, who demonstrated that RCMV infection increased SMC proliferation and neointimal thickness of aortic allografts, even though there was no evidence of active viral infection in the graft tissue (Lemström 1993). When systemic and/or local immune responses are indeed more important 
for stimulation of SMC proliferation than the actual presence of the virus, this may explain our previous results showing a lack of effect of RCMV infection on neointima formation in immuno-compromised rats.

In de novo atherosclerosis as well as in restenosis two factors are related to the severity of luminal stenosis: plaque mass or intimal hyperplasia and arterial remodelling. Nevertheless, we did not observe an increase in the neointima/lumen ratio in rats, which were infected 14 days after initial surgery despite a significant increase in the neointimal area. This suggests that the observed increase in intimal area is followed by compensatory outward remodelling. Such compensatory enlargement, in particular of coronary arteries partly occluded by atherosclerotic plaques, has previously been described (Glagov 1987, Hernmiller 1986, Isner 1986). Furthermore, a positive correlation has been observed between vessel enlargement and intimal area so that the lumen cross-sectional area tends to be maintained at a near normal level for extended periods of time (Masawa 1994). This compensatory enlargement ensures that adequate amounts of nutrients and oxygen can still be transported to tissues, which are supplied by post stenotic arteries and may result from an increase in shear stress sensed by the regenerating endothelium on the intimal smooth muscle cell layer. Such augmentation in shear stress has been demonstrated to be a powerful stimulus for outward remodelling (Pouradeaud 1997).

We also found a decrease in the number of cells per $\mu \mathrm{m}^{2}$ in the intima at 35 days after injury when rats were RCMV infected immediately after endothelial injury. This observation suggests that either the cells in the intima in the infected group became hypertrophic or that extracellular matrix proteins take a larger proportion of the neointimal area. Unfortunately, due to technical imperfections we were unable to quantify the amount of extracellular matrix by using a Sirius red staining. Nevertheless, RCMV is not present in the arterial wall at this time point and the link between prior infection and cellular hypertrophy or extracellular matrix production in the intima 35 days after infection remains subject for further study.

In summary, we demonstrated that RCMV infection stimulates arterial SMC proliferation when vascular injury is induced by a photochemical reaction resulting in endothelial damage and neointima formation. Furthermore, we showed that the increase in the medial or intimal cross-sectional area was dependent on the time point of infection. Importantly, this RCMV induced effect occurs even when there are only low amounts of virus present in the arterial wall, suggesting that inflammatory and immune responses to RCMV infection are more important in exaggerating the response to vascular injury than the virus itself.

\section{References}

Anderson, J.L., et al., Evaluation of C-reactive protein, an inflammatory marker, and infectious serology as risk factors for coronary artery disease and myocardial infarction. J Am Coll Cardiol, 1998. 32(1): p. 35-41.

Bruggeman, C.A., et al., Isolation of a cytomegalovirus-like agent from wild rats. Arch Virol, 1982. 73(3-4): p. 231-41

Castillo, J.P., A.D. Yurochko, and T.F. Kowalik, Role of human cytomegalovirus immediate-early proteins in cell growth control. J Virol, 2000. 74(17): p. 8028-37.

Clowes, A.W. and M.M. Clowes, Kinetics of cellular proliferation after arterial injury. IV. Heparin inhibits rat smooth muscle mitogenesis and migration. Circ Res, 1986. 58(6): p. 839-45.

Epstein, S.E., et al., The role of infection in restenosis and atherosclerosis: focus on cytomegalovirus. Lancet, 1996. 348(Suppl 1): p. s13-7.

Fairweather, D., et al., Wild isolates of murine cytomegalovirus induce myocarditis and antibodies that cross-react with virus and cardiac myosin. Immunology, 1998. 94(2): p. 263-70.

Fishman, J.A., G.B. Ryan, and M.J. Karnovsky, Endothelial regeneration in the rat carotid artery and the significance of endothelial denudation in the pathogenesis of myointimal thickening. Lab Invest, 1975. 32(3): p. 339-51.

Glagov, S., et al., Compensatory enlargement of human atherosclerotic coronary arteries. N Engl Med, 1987. 316(22): p. 1371-5.

Glagov, S., Intimal hyperplasia, vascular modeling, and the restenosis problem. Circulation, 1994 89(6): p. 2888-91.

Hanke, H., et al., Morphological changes and smooth muscle cell proliferation after experimental excimer laser treatment. Circulation, 1991. 83(4): p. 1380-9.

Hermiller, J.B., et al., In vivo validation of compensatory enlargement of atherosclerotic coronary arteries. Am J Cardiol, 1993. 71(8): p. 665-8.

Horne, B.D., et al., Greater pathogen burden but not elevated C-reactive protein increases the isk of clinical restenosis after percutaneous coronary intervention. Am Heart J, 2002. 144(3): p. 491 500.

Indolfi, C., et al., Smooth muscle cell proliferation is proportional to the degree of balloon injury in a rat model of angioplasty. Circulation, 1995. 92(5): p. 1230-5.

Isner, J.M., et al., Attenuation of the media of coronary arteries in advanced atherosclerosis. Am J Cardiol, 1986. 58(10): p. 937-9.

Kaptein, S.J., et al., The rat cytomegalovirus R78 G protein-coupled receptor gene is required for production of infectious virus in the spleen. J Gen Virol, 2003. 84(Pt 9): p. 2517-30.

Kikuchi, S., et al., Tranilast suppresses intimal hyperplasia after photochemically induced endothelial injury in the rat. Eur J Pharmacol, 1996. 295(2-3): p. 221-7.

Kikuchi, S., et al., Photochemically induced endothelial injury in the mouse as a screening model for inhibitors of vascular intimal thickening. Arterioscler Thromb Vasc Biol, 1998. 18(7): p. 1069-78.

Lemstrom, K.B., et al., Cytomegalovirus infection enhances smooth muscle cell proliferation and intimal thickening of rat aortic allografts. J Clin Invest, 1993. 92(2): p. 549-58.

Lindner, V., J. Fingerle, and M.A. Reidy, Mouse model of arterial injury. Circ Res, 1993. 73(5): p. $792-6$. 
Chapter 2

Masawa, N., S. Glagov, and C.K. Zarins, Quantitative morphologic study of intimal thickening at the human carotid bifurcation: II. The compensatory enlargement response and the role of the intima in tensile support. Atherosclerosis, 1994. 107(2): p. 147-55

Paczkowski, J., et al., Photophysical properties of rose bengal and its derivatives (XII). J Free Radic Biol Med, 1985. 1(5-6): p. 341-51.

Patel, P., et al., Association of Helicobacter pylori and Chlamydia pneumoniae infections with coronary heart disease and cardiovascular risk factors. Bmj, 1995. 311(7007): p. 711-4.

Persoons, M.C., et al., Active cytomegalovirus infection of arterial smooth muscle cells in immunocompromised rats. A clue to herpesvirus-associated atherogenesis? Circ Res, 1994. 75(2): p. 214-20.

Persoons, M.C., et al., Neointimal smooth muscle cell phenotype is important in its susceptibility to cytomegalovirus (CMV) infection: a study in rat. Cardiovasc Res, 1997. 36(2): p. 282-8.

Pourageaud, F. and J.G. De Mey, Structural properties of rat mesenteric small arteries after 4-wk exposure to elevated or reduced blood flow. Am J Physiol, 1997. 273(4 Pt 2): p. H1699-706.

Rodriguez-Campos, A., et al., Mitogen-induced p53 downregulation precedes vascular smooth muscle cell migration from healthy tunica media and proliferation. Arterioscler Thromb Vasc Biol, 2001. 21(2): p. 214-9.

Saniabadi, A.R., et al., Vessel wall injury and arterial thrombosis induced by a photochemical reaction. Thromb Haemost, 1995. 73(5): p. 868-72.

Schwartz, S.M., M.W. Majesky, and C.E. Murry, The intima: development and monoclonal responses to injury. Atherosclerosis, 1995. 118(Suppl): p. S125-40.

Stals, F.S., et al., An animal model for therapeutic intervention studies of $\mathrm{CMV}$ infection in the immunocompromised host. Arch Virol, 1990. 114(1-2): p. 91-107.

Tanaka, H., et al., Activation of smooth muscle and endothelial cells following balloon injury. Ann NY Acad Sci, 1995. 748: p. 526-9.

Tanaka, K., et al., Effects of human cytomegalovirus immediate-early proteins on p53-mediated apoptosis in coronary artery smooth muscle cells. Circulation, 1999. 99(13): p. 1656-9.

Vliegen, I., et al., MCMV infection increases early T-lymphocyte influx in atherosclerotic lesions in apoE knockout mice. J Clin Virol, 2002. 25 Suppl 2: p. S159-71.

Yonemitsu, Y., et al., The immediate early gene of human cytomegalovirus stimulates vascular smooth muscle cell proliferation in vitro and in vivo. Biochem Biophys Res Commun, 1997. 231(2): p. 447-51.

Zhou, Y.F., et al., The immediate early gene products of human cytomegalovirus increase vascular smooth muscle cell migration, proliferation, and expression of PDGF beta-receptor. Biochem Biophys Res Commun, 1999a. 256(3): p. 608-13.

Zhou, Y.F., et al., Cytomegalovirus infection of rats increases the neointimal response to vascular injury without consistent evidence of direct infection of the vascular wall. Circulation, 1999b. 100(14): p. 1569-75.

Zhou, Y.F., et al., Chronic non-vascular cytomegalovirus infection: effects on the neointimal response to experimental vascular injury. Cardiovasc Res, 2000. 45(4): p. 1019-25. 


\section{Chapter 3}

FK778 attenuates

cytomegalovirus-enhanced vein graft intimal hyperplasia in a rat model 


\section{Abstract}

Venous grafts are commonly used to treat drug resistant coronary artery disease although long term functionality is limited because of proliferation and migration of smooth muscle cells (SMC). As proliferating SMC are particularly susceptible for the stimulating effects of cytomegalovirus (CMV), we hypothesized that CMV infection may enhance cell proliferation and graft failure. Furthermore, we evaluated the potential of FK778 to prevent intimal hyperplasia. Apart from its antiviral properties, FK778 is a new immunosuppressive agent which may also affect SMC proliferation making it an interesting drug to prevent (CMV-enhanced) venous graft intimal hyperplasia.

In 4 groups ( $\mathrm{n}=10$ rats/group), epigastric vein-to-common femoral artery interposition grafts were placed. Rats received either FK778 (oral treatment, 15mg/ $\mathrm{kg})$, were infected with CMV $\left(1,25 \times 10^{6} \mathrm{PFU}\right)$ or were both treated and infected.

CMV infection resulted in a significant increase in intimal and medial cross sectional area and medial wall thickness of the vein grafts. This effect was diminished by administration of FK778. Moreover, FK778 treatment alone resulted in a significant decrease in neointimal area and percentage of stenosis vs. the control group.

These data suggest a role of $C M V$ in venous graft failure. Also, our results suggest a prospective role for the new immunosuppressive drug FK778 in the prevention of (CMV-mediated) vein graft initimal hyperplasia.

\section{Introduction}

Autologus vein grafts are commonly used for coronary artery bypass grafting, along with angioplasty, for the treatment of advanced arterial stenosis and drugresistent angina pectoris. Although the initial results of venous grafts are successful, the symptoms tend to recur due to degeneration and occlusion of the graft. Early thrombosis and neointimal hyperplasia are thought to be the primary causes of graft failure. Intimal hyperplasia $(\mathrm{IH})$, defined as the accumulation of smooth muscle cells (SMC) and extracellular matrix in the intimal component of the vein, is the major disease process in the venous graft within the first year. It has been strongly suggested that $\mathrm{IH}$ is associated with extensive endothelial denudation and destruction of venous grafts, resembling a response to injury as seen after PTCA often leading to restenosis of the denuded artery (LoGerfo 1983). Previous studies indicated that infectious agents, and in particular cytomegalovirus (CMV), increase the risk of restenosis after PTCA (Horne 2002, Mueller 2003) and coronary atherectomy (Zhou 1996). In addition, we recently showed that $C M V$ aggravates intimal hyperplasia in rats by stimulating SMC proliferation in an arterial injury model (Kloppenburg 2005).

Although multiple studies demonstrated a role for $\mathrm{CMV}$ in $\mathrm{IH}$, a possible contribution of CMV in venous bypass failure received only limited attention so far and results have been inconclusive hitherto (Bartels 1999, 2000, Ibrahim 2005, Limnell 2004). Therefore, we decided to elucidate the role of $C M V$ on vein graft $I H$ in an experimental animal model. Moreover, we evaluated whether treatment with FK778 i) could restrain vein graft stenosis, ii) reduced the aggravating effects of CMV on $\mathrm{IH}$ due to its antiviral properties. The synthetic malononitrilamide FK778 (MNA 715 ) is one of the most interesting new immunosuppressive/anti-proliferative drugs (Vincenti 2002). It is a derivative of A77 1726, the active metabolite of leflunomide, which already has been shown to be effective in reducing rat aortic SMC proliferation (Czech 1999). FK778 binds specifically to the enzyme dihydro-orotate dehydrogenase thereby inhibiting the de novo pyrimidine biosynthesis (Silva 1997) and consequently cell proliferation. Besides its effect on pyrimidine synthesis FK778 may also affect other processes potentially involved in IH. E.g., FK778 has been shown to reduce endothelial adhesion molecule up-regulation and to attenuate lymphocyteendothelium interaction (Deuse 2004). In addition FK778 effectively attenuated vascular response to injury by diminishing neointima formation through the inhibition of receptor tyrosine kinase activity in vascular SMC or their progenitors (Savikko 2003). Furthermore, despite different modes of action, antiviral properties have 
been attributed to both FK778 and A77 1726 (Evers 2005, Waldman 1999a, 1999b). These vasculoprotective and antiviral properties of FK778 make it a potentially interesting drug to prevent not only venous graft intimal hyperplasia, but also inhibit the aggravating effects of $\mathrm{CMV}$ infections on this process. In the present study both issues were addressed.

\section{Materials and Methods}

\section{Animal Conditions and Vein Grafting Procedure}

Male inbred specific pathogen free (SPF) Lewis (LEW) rats were obtained from the Department of Experimental Animal service of the University of Maastricht, the Netherlands. Experiments were carried out on animals aged 12 weeks weighing 250-350 gram. Housing and care of the animals, and all the procedures used in this study were approved by the Ethical Committee for the Use of Experimental Animals of the institution, and conform the Guide for the Care and the Use of Laboratory Animals, published by the US National Institute of Health (NIH Publication No. 85-23, revised 1985). Rats were fed standard rat chow and tap water at libitum. All surgical procedures were performed under general anesthesia and using sterile technique. Epigastric vein-to-common femoral artery interposition grafts were placed in rats by the use of a method similar to that described earlier by Hoch et al. (Hoch 1994). In brief, each animal was anesthetized with an intraperitoneal (i.p.) injection of pentobarbital sodium $(60 \mathrm{mg} / \mathrm{kg})$. An $8 \mathrm{~mm}$ segment of the ipsilateral epigastric vein was carefully harvested, gently irrigated with heparinized saline solution $(100 \mathrm{U} / \mathrm{ml})$, and placed as reverse interposition graft into a segmental $3 \mathrm{~mm}$ defect of the common femoral artery with 8 to 10 interrupted sutures of 11-0 nylon (Ethicon). The entire procedure was carried out with standard microsurgical techniques. The total ischemic time was kept to less than $30 \mathrm{~min}$. Graft patency, defined as a condition of flow through the graft, was verified by visual inspection.

\section{Experimental Design}

The whole experiment consisted of a total of four experimental groups ( $\mathrm{n}=10$ animals/ group) which all underwent surgery. Furthermore, rats were either infected with CMV, treated with FK778 or both. A control group only received the FK778 solvent ( $1 \mathrm{ml}$ of a $1 \%$ carboxymethyl cellulose solution in water). Infection was established by inoculating rats i.p. with $1,25 \times 10^{6}$ plaque forming units (PFU) of homogenized salivary gland-derived rat CMV (RCMV, Maastricht strain) (Bruggeman 1982) immediately after surgery.

FK778 was supplied by Fujisawa Healthcare Inc. (Osaka, Japan). For oral administration, FK778 powder was suspended in 1\% carboxymethyl cellulose solution in water, until a final concentration of $5 \mathrm{mg} / \mathrm{ml}$ was reached. Animals received an oral dose of $15 \mathrm{mg} / \mathrm{kg}$ body weight per day from one day prior to the operation till the day of tissue harvest.

\section{Histological and Morphometrical Procedures}

Three weeks after surgery, rats were anaesthetized and graft patency was verified by visual inspection. Then, the chest and abdominal cavities were opened and a catheter was inserted into the apex of the heart. Vasculature was initially flushed with physiological salt solution and then perfusion fixed with $3.7 \%$ formaldehyde in phosphate-buffered saline, $\mathrm{pH} 7.4$, at physiological pressure $(100 \mathrm{mmHg})$. Vein grafts were removed and fixed overnight in the same fixative and routinely processed for paraffin embedding. Cross-sections $(4 \mu \mathrm{m})$ were taken for morphometrical analysis and haematoxylin-eosin or Lawson stained (average of three cross-sections per graft). Intimal and medial areas were quantified using a computer assisted morphometry system (analySIS $®$, Soft Imaging System, GmbH). The cross-sectional area of the media was defined as the area surrounded by the external and internal elastic lamina. The neointimal cross-sectional area was defined by the area surrounded by the internal elastic lamina and the arterial lumen. Next, the percentage of stenosis was calculated which is defined as the percentage of cross-sectional area of the former lumen occluded by the neointima. Final scores were given as percentage of the control group.

\section{Quantification of number of cells in the intima and media}

The number of cells in the intima and media was quantified by counting the total number of nuclei using a microscope. All nuclei were counted in haematoxylin-eosin stained cross-sections taken from patent grafts in which a neointima was observed. Final scores were expressed as number of cells per $\mu \mathrm{m}^{2}$ and values are given as mean.

\section{Immunohistochemistry}

Paraffin sections $(4 \mu \mathrm{m})$, taken from vein grafts three weeks after surgery, were routinely processed and stained with the two-layer indirect immunoperoxidase 
technique using monoclonal antibodies (mAb). The following mAbs were used in this study: anti-rat CD3 (Sera-lab, Crawley Down, UK); anti-a smooth muscle actin (Sigma, Missouri, USA); ED-1, a mouse mAb to monocytes/macrophages was kindly supplied by Dr. A.M. Duijvestijn (Dept. of Immunology, University Maastricht, the Netherlands).

Sections were incubated with 2\% BSA in phosphate-buffered saline (PBS) (ED-1 and a-actin) for $15 \mathrm{~min}$ at room temperature and treated with antigen retrieval buffer (CD3) for 25min at $95^{\circ} \mathrm{C}$ (McKechnie 1997). Monoclonal antibodies were diluted (ED-1 1/20, a-actin 1/1500 and CD3 1/400) in PBS and applied to the slides for 60 min at $37^{\circ} \mathrm{C}$. After three washes with PBS for $5 \mathrm{~min}$, a biotinylated goat anti-mouse secondary antibody (1/1200, DAKO Glostrup Denmark) was applied for 30 min at room temperature. Finally, sections were incubated with alkaline phosphatase-coupled streptavidin ( $A B C$ reagent, Vector Laboratories), followed by immunodetection using fast red as a substrate. Then, the presence of positive cells was analyzed by microscopy and scored semi-quantitatively $(0=$ no staining, $1=$ positive staining and $2=$ extensive positive staining) by an observer blinded to the specimen group.

\section{Statistical analysis}

All data were expressed as mean \pm S.E.M. To analyze differences for statistical significance, a Mann-Whitney $U$ test was performed using SPSS 11.0 for Windows (SPSS, Chicago IL, USA). Differences were considered to be statistical significant when $P$ values were less than 0.05

\section{Results}

\section{Animal condition and grafts}

No apparent clinical signs of illness were observed in any of the animals during the follow-up period. Starting body weight ranged from $250 \mathrm{~g}$ to $350 \mathrm{~g}$; at the end of the experiments animal weight ranged from $325 \mathrm{~g}$ to $405 \mathrm{~g}$. The overall graft patency was $90 \%$. There were no significant differences in body weights or graft patency between the experimental groups (data not shown). There were no structural abnormalities at the anastomotic regions of the grafts. The gross appearance of the veins and adjoining arteries was normal.
Table 1 | Summary of morphological alterations found in CMV-infected rats.

\begin{tabular}{|c|c|c|c|c|}
\hline & Intimal area & Medial area & Stenosis \% & \multirow[t]{2}{*}{ Wall } \\
\hline & \multicolumn{3}{|c|}{ thickness } & \\
\hline CMV & $\boldsymbol{4}$ & 4 & $=$ & 4 \\
\hline CMV + FK778 & $=$ & 4 & $\downarrow$ & 4 \\
\hline FK778 & $\downarrow$ & $=$ & $\downarrow$ & $=$ \\
\hline
\end{tabular}

FK778-treated rats or CM-infected/FK778 -treated animals three weeks after vein grafting. All data were compared to data obtained in control rats. 4 : significant increase, $\downarrow$ : significant decrease, $=$ : no significant change.

FK778 attenuates CMV aggravated intimal hyperplasia

Three weeks after bypass grafting, medial cross-sectional area was increased and a pronounced neointimal thickening was observed in all grafted veins (figure 1 and $2 \mathrm{~A}$ ). CMV infection immediately after vein grafting resulted in a significant increase in intimal cross-sectional area, medial cross-sectional area and medial wall thickness at three weeks after surgery as compared to the control group (figure 1 and 2B). This effect was partially reversed by FK778 treatment, resulting in a significant decrease of the CMV aggravated neointimal cross-sectional area as well as percentage of stenosis but not medial cross-sectional area or medial thickness. Furthermore, FK778 treatment alone resulted in a significant decrease in neointimal area and percentage of stenosis as compared to the control group although no effects were seen on medial cross-sectional area or medial thickness (figure 1, table 1).

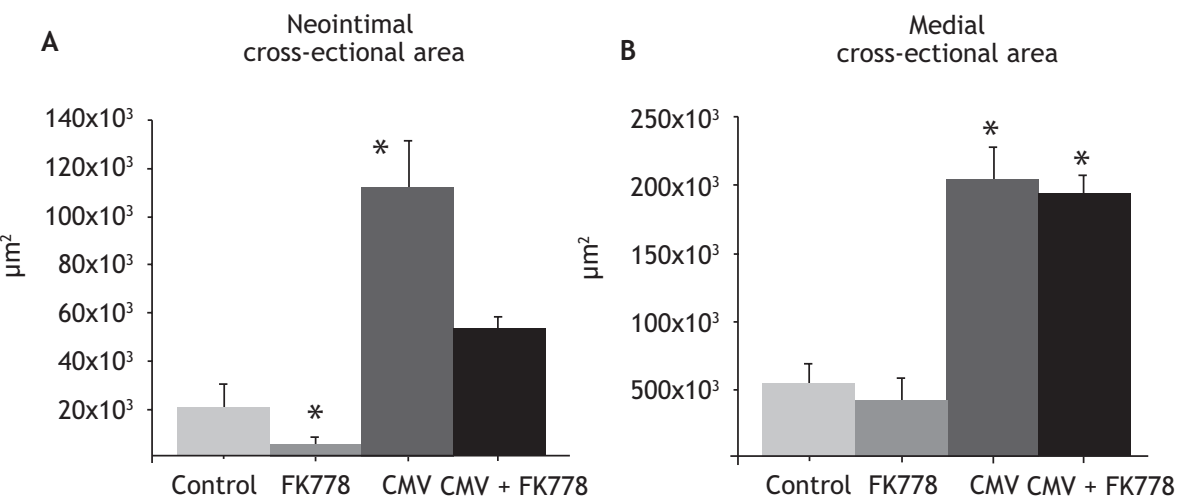

Figure 1 | Effect of FK778, CMV or co administration of CMV and FK778 on neointimal (A) and medial (B) cross sectional areas three weeks after vein grafting. *: $P<0.05$ vs. controls. 


\section{Quantification of number of cells in the intima and media}

Although the medial and intimal cross-sectional area was significantly increased at 3 weeks when rats were infected immediately after surgery, the average number of cells $/ \mu \mathrm{m}^{2}$ was not different as compared to the control group (table 2). This implies that the total number of cells in the intima and media is increased and suggests that CMV predominantly stimulated cell proliferation. FK778 treatment resulted in a decrease of intimal cross-sectional area but again average number of cells $/ \mu \mathrm{m}^{2}$ was not different as compared to the control group (table 2). This implies that the total number of cells in the intima is decreased and suggests that cell proliferation has been attenuated by FK778.

Table 2 | Cellular density in both media and neointima of all groups.

\begin{tabular}{lcccc}
\hline & Control & CMV & FK778 & CMV+FK778 \\
\hline media & $4,4 \pm 0,7$ & $4,9 \pm 0,6$ & $4,3 \pm 0,6$ & $4,7 \pm 0,3$ \\
neointima & $16,4 \pm 3,5$ & $15,4 \pm 3,6$ & $18,1 \pm 2,1$ & $16,5 \pm 3,1$ \\
\hline
\end{tabular}

Data are expressed as $\times 10^{-3}$ cells $/ \mu m^{2}$. No significant differences were observed between groups

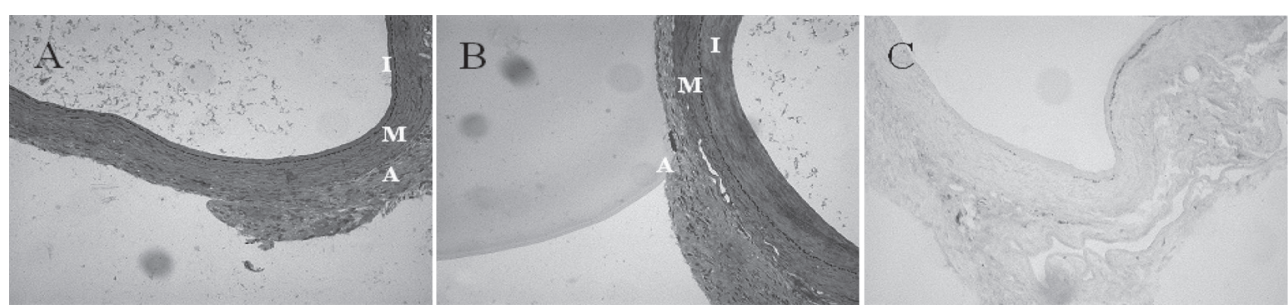

Figure 2 | Showing typical examples of venous grafts cross-sections 21 days after grafting. A) Lawson staining venous graft control group, B) Lawson staining venous graft CMV infected group, C) ED-1 monocyte macrophage staining. I = Intima, $M=$ Media, A = Adventitia. (see page 166 for color picture)

\section{Immunohistochemistry}

The number of T-cells in the venous graft three weeks after surgery was minimal with an average of one to three T-cells per cross-section. No difference in T cell number/ section was observed between groups. Presence of macro- phages was abun-dant and cells were most frequently detected in the subendothelial space as well as in the intima (figure $2 \mathrm{C}$ ). However, when stainings were analyzed in a semi-quantitative way, no significant differences were noted between groups (data not shown). Alphaactin staining showed SMC to be the main content of the intima and media with little extra-cellular matrix accumulation in all groups.

\section{Discussion}

Venous graft failure is a common problem, occurring in 10-15\% of grafts during the first year increasing up to $40 \%$ within 10 years (Fitzgibbon 1996). Early thrombosis and neointimal hyperplasia are considered to be the primary causes of graft failure. Nonetheless, although a research subject for several decades, the exact underlying mechanism of venous graft failure has not been elucidated yet. As CMV infections have been shown to accelerate arterial restenosis, we hypothesized that the virus may also contribute to venous graft failure. This was addressed in the present study in which we investigated whether CMV contributes to venous graft failure in a rat epigastric vein-to-common femoral artery graft model. In addition, we studied the therapeutic potential of the immunosuppressive/anti-proliferate drug FK778 in preventing intimal hyperplasia $(\mathrm{IH})$ with or without a concomitant CMV infection. Here we present for the first time evidence that CMV contributes to the process of venous graft failure. Furthermore, we demonstrate that FK778 is able to partially prevent $\mathrm{IH}$ in a venous bypass graft in non-infected animals, while the drug was also able to reverse the additional effect of a concomitant CMV infection on IH (table 2).

Neointimal hyperplasia, defined as the accumulation of SMC and extracellular matrix in the intimal compartment of blood vessels, is the major disease process in venous grafts within the first year. Nearly all veins implanted into an arterial circulation develop intimal wall thickening thereby reducing the lumen size. This is confirmed by our results in the rat venous graft model. In the epigastric vein-tocommon femoral artery interposition grafts a significant enlargement of the vascular wall was observed at 3 weeks post transplantation, which is in agreement with earlier data presented by others (Hoch 1994).

This intimal wall thickening predominantly results from excessive SMC proliferation in response to injury. Under normal conditions SMC in the media of blood vessels proliferate at very low rates, but can switch very rapidly from quiescence to a proliferative state in response to appropriate stimuli like bypass grafting or angioplasty (Majesky 1987). Previously it has been shown that CMV accelerates cellular proliferation (Speir 1994). This suggestion is supported by the present 
data. Although the total intimal area was significantly increased following CMV infection, the average number of cells per $\mu \mathrm{m}^{2}$ was unchanged, indicating that CMV stimulates SMC proliferation but not cellular hypertrophy or extensive accumulation of extracellular matrix ultimately resulting in an enlarged medial and intimal area. The latter was confirmed by a-actin immunostaining showing that the majority of the intima and media consisted of SMC. These results are in accordance with earlier data from our group, in which we demonstrated that CMV stimulates SMC proliferation in the thrombosis-induced intimal thickening in the rat femoral artery (Kloppenburs 2005). Although the exact mechanism is unclear until now, it has previously been suggested that inhibition of the p53 suppressor effects are the predominant cause of CMV-induced stimulation of SMC proliferation (Speir 1994). Nevertheless, additional research is required to further clarify the effect of $C M V$ on cellular proliferation.

The new malononitrilamide FK778 is currently being evaluated as an immunosuppressant for organ transplantations as it effectively inhibits T-cell proliferation and alloantibody synthesis by B cells (Kurrle 1996). Furthermore, besides being immunosuppressive, vasculoprotective properties have also been attributed to FK778. More precisely, it has been shown that FK778 may inhibit SMC proliferation. In various experimental models it has been demonstrated that FK778 effectively attenuates vascular responses to injury by diminishing neointima formation and fibrointimal hyperplasia, perhaps through inhibition of the receptor tyrosine kinase activity in vascular SMC or their progenitors (Savikko 2003, Hoch 1994, Janhke 2005). Also in our rat model of epigastric vein-to-common femoral artery interposition grafts a daily regimen of $15 \mathrm{mg} / \mathrm{kg}$ FK778 significantly reduced intimal hyperplasia resulting in a lower percentage stenosis as compared to the control group. Quantification of the number of cells per $\mu \mathrm{m}^{2}$ revealed no significant differences between groups, indicating that the reduction in cross-sectional intimal area caused by FK778 is due to a decrease in SMC proliferation.

Along with its antiproliferative activity, antiviral properties against cytomegalovirus have been assigned to FK778 (Waldman 1997, 1999). FK778 is a potent and effective inhibitor of CMV and its mode of antiviral action appears to mirror the biochemical mechanism described to be responsible for its immunosuppressive properties: inhibition of protein tyrosine phosphorylation and inhibition of cellular de novo pyrimidine biosynthesis (Evers 2005). Here we demonstrate that FK778 is able to partially prevent the CMV-mediated enhancement of $\mathrm{IH}$ in the venous graft. Treatment with FK778 significantly reduced the effect of CMV on intimal area as well as on the percentage stenosis. In contrast, no effects of FK778 treatment were observed on the medial cross-sectional area.
It remains to be established whether the antiviral or the anti-proliferative properties of FK778 are predominantly responsible for its inhibitory effect on the CMV-mediated enhancement of intima formation in infected animals. Previously, we demonstrated that CMV aggravates intimal hyperplasia in a thrombosis-induced intimal thickening model mainly by stimulating SMC proliferation (Zhou 1996). As hardly any virus could be detected in the vascular wall at various stages of the hyperplastic process, it was suggested that inflammatory and immune responses are more important in the CMV-mediated augmentation of the hyperplasic response than the virus itself. Based on these findings we assume that the effects of FK778 in our venous graft model should not be ascribed to its antiviral characteristics.

Although inhibition of the cellular and humoral immune response is of great importance in preventing acute rejection and also chronic allograft dysfunction in transplantation, it is questionable whether it plays a significant role in venous graft failure. Hoch et al. showed the relative absence of $\mathrm{CD} 4^{+}$and $\mathrm{CD} 8^{+}$cells in the epigastric vein-to-common femoral artery interposition grafts in the rat model (Hoch 1994). Likewise, we also found only a limited number of $\mathrm{CD}^{+}$cells in the grafts at three weeks after surgery with no clear difference between the infected, treated and the control group. This also suggests that it is unlikely that the effect of FK778 on intima hyperplasia is due to its immunosuppressive activity. Alternatively, it has recently been shown that FK778 directly reduces ICAM-1 and VCAM-1 up regulation and attenuates lymphocyte-endothelium interaction (Deuse 2004). We therefore speculated that administration of FK778 might result in a decreased influx of macrophages in our venous grafts. However, immunological staining showed no clear differences in the influx of macrophages in the grafts at three weeks after surgery. In conclusion, the majority of our data suggest that the effect of FK778 on intima hyperplasia has mainly to be attributed to its effect on SMC proliferation.

In conclusion, in a well defined animal model, we present for the first time evidence for a possible role of $C M V$ in the process of venous graft failure, which could partially be inhibited by the new immunosuppressive agent FK778. These data suggest that FK778 might be a potential candidate to prevent intimal hyperplasia following venous bypass surgery. 


\section{References}

Bartels C, Maass M, Bein G, et al. Detection of Chlamydia pneumoniae but not cytomegalovirus in occluded saphenous vein coronary artery bypass grafts. Circulation. 1999; 99: 879-82.

Bartels C, Maass M, Bein G, et al. Association of serology with the endovascular presence of Chlamydia pneumoniae and cytomegalovirus in coronary artery and vein graft disease. Circulation. 2000; 101: 137-41.

Bruggeman CA, Meijer H, Dormans PH, et al. Isolation of a cytomegalovirus-like agent from wild rats. Arch Virol. 1982; 73: 231-41.

Czech J, Kurrle R, Schorlemmer HU. The antiproliferative effect of malononitrilamides (MNAs) on vascular smooth muscle cells is antagonized by exogenous uridine. Inflamm Res. 1999; 48 Supp 2:S128-9.

Deuse T, Schrepfer S, Schafer H, et al. FK778 attenuates lymphocyte-endothelium interaction after cardiac transplantation: in vivo and in vitro studies. Transplantation. 2004; 78: 71-7.

Evers DL, Wang X, Huong SM, et al. Inhibition of human cytomegalovirus signaling and replication by the immunosuppressant FK778. Antiviral Res. 2005; 65: 1-12.

Fitzgibbon GM, Kafka HP, Leach AJ, et al. Coronary bypass graft fate and patient outcome: angiographic follow-up of 5,065 grafts related to survival and reoperation in 1,388 patients during 25 years. J Am Coll Cardiol. 1996; 28: 616-26.

Hoch, J.R., Stark, V.K., Hullett, D.A. et al. Vein graft intimal hyperplasia: leukocytes and cytokine gene expression. Surgery. 1994; 116: 463-70.

Horne BD, Muhlestein JB, Strobel GG, et al. Intermountain Heart Collaborative (IHC) Study Group. Greater pathogen burden but not elevated $\mathrm{C}$-reactive protein increases the risk of clinical restenosis after percutaneous coronary intervention. Am Heart J. 2002; 144: 491-500.

Ibrahim Al, Obeid MT, Jouma MJ, et al. Detection of herpes simplex virus, cytomegalovirus and Epstein-Barr virus DNA in atherosclerotic plaques and in unaffected bypass grafts. J Clin Virol. 2005; 32: 29-32.

Jahnke T, Schafer FK, Bolte H, et al. 2005 Dr. Gary J. Becker Young Investigator Award: periprocedural oral administration of the leflunomide analogue FK778 inhibits neointima formation in a double-injury rat model of restenosis. J Vasc Interv Radiol. 2005; 16: 903-10.

Kloppenburg G, de Graaf R, Herngreen S, et al. Cytomegalovirus aggravates intimal hyperplasia in rats by stimulating smooth muscle cell proliferation. Microbes Infect. 2005; 7: 164-70.

Kurrle R, Bartlett R, Ruuth $E$, et al. Malononitrilamides inhibit $T$ - and B-cell responsiveness. Transplant Proc. 1996; 28: 3053-6.

Limnell V, Pasternack R, Karjalainen J, et al. Seropositivity for Helicobacter pylori antibodies is associated with lower occurrence of venous bypass graft occlusion. Scand J Infect Dis. 2004; 36 : $601-3$.

LoGerfo FW, Quist WC, Cantelmo NL, et al. Integrity of vein grafts as a function of initial intimal and medial preservation. Circulation 1983; 68: II117-24.

Majesky MW, Schwartz SM, Clowes MM, et al. Heparin regulates smooth muscle S phase entry in the injured rat carotid artery. Circ Res. 1987; 61: 296-300.

McKechnie NM, Gurr W, Braun G. Immunization with the cross-reactive antigens Ov39 from Onchocerca volvulus and hr44 from human retinal tissue induces ocular pathology and activates retinal microglia. J Infect Dis. 1997; 176:1334-43.
Mueller $C$, Hodgson JM, Bestehorn HP, et al. Cytomegalovirus infection and restenosis after aggressive angioplasty with provisional stenting. J Interv Cardiol. 2003; 16: 307-13.

Pan F, Ebbs A, Wynn C et al. FK778, a powerful new immunosuppressant, effectively reduces functional and histological changes of chronic rejection in rat renal allografts. Transplantation. 2003; 75:1110-4.

Persoons MC, Daemen MJ, Bruning JH, et al. Active cytomegalovirus infection of arterial smooth muscle cells in immunocompromised rats. A clue to herpesvirus-associated atherogenesis? Circ Res. 1994; 75: 214-20.

Savikko J, Von Willebrand E, Hayry P. Leflunomide analogue FK778 is vasculoprotective independent of its immunosuppressive effect: potential applications for restenosis and chronic rejection. Transplantation. 2003; 76: 455-8.

Silva HT Jr, Cao W, Shorthouse RA, et al. In vitro and in vivo effects of leflunomide, brequinar, and cyclosporine on pyrimidine biosynthesis. Transplant Proc. 1997; 29: 1292-3.

Speir E, Modali R, Huang ES, et al. Potential role of human cytomegalovirus and p53 interaction in coronary restenosis. Science. 1994; 265: 391-4.

Vincenti $F$. What's in the pipeline? New immunosuppressive drugs in transplantation. Am J Transplant. 2002; 2: 898-903.

Waldman WJ, Knight DA, Lurain NS, et al. Novel mechanism of inhibition of cytomegalovirus by the experimental immunosuppressive agent leflunomide. Transplantation. 1999; 68: 814-25.

Waldman WJ, Knight DA, Blinder L, et al. Inhibition of cytomegalovirus in vitro and in vivo by the experimental immunosuppressive agent leflunomide. Intervirology. 1999; 42: 412-8.

Zhou YF, Leon MB, Waclawiw MA, et al. Association between prior cytomegalovirus infection and the risk of restenosis after coronary atherectomy. N Engl J Med. 1996; 29; 335: 624-30. 


\section{Chapter 4}

Chlamydia pneumoniae aggravates vein graft intimal hyperplasia in a rat model 


\section{Abstract}

Along with angioplasty, autologus vein grafts are commonly used for artery bypass grafting in patients with advanced arterial stenosis and drug-resistant angina pectoris. Although initially a successful procedure, long-term functionality is limited due to proliferation and migration of smooth muscle cells. Like in atherosclerosis, common chronic infections caused by viruses and bacteria may contribute to this process of vein graft failure. Here we investigated the possible role of Chlamydia pneumoniae (C. pneumoniae) in the pathogenesis of venous graft failure in an experimental animal model.

In 2 groups ( $\mathrm{n}=10 \mathrm{rats} / \mathrm{group}$ ), an epigastric vein-to-common femoral artery interposition graft was placed. Immediately thereafter, rats were infected with C. pneumoniae $\left(5^{*} 10^{8} \mathrm{IFU}\right)$ or injected with control solutions. Rats were sacrificed three weeks after surgery and the grafts were harvested for morphometrical and immunohistochemical analysis.

C. pneumoniae administration immediately after vein grafting resulted in a significant increase in medial cross-sectional area, wall thickness and total wall area. There were no significant differences in T-cell or macrophage influx. Likewise, although positive immunostaining for both HSP60 and CRP could be detected, no differences were found between groups. Based on the observation that the number of cells $/ \mu \mathrm{m}^{2}$ was also not altered, we conclude that $C$. pneumoniae infection stimulates smooth muscle cell proliferation by hereunto unknown molecular mechanisms, resulting in a significant increase in intimal hyperplasia.

In conclusion, in a well defined animal model we present here for the first time evidence for a role of Chlamydia pneumoniae in the process of venous graft failure.

\section{Introduction}

Besides internal mammary arteries, autologus saphenous vein grafts are commonly used for coronary artery bypass grafting (CABG) in angina pectoris patients, resistant to aggressive medical therapy or patients with advanced coronary artery stenosis not suitable for percutaneous transluminal coronary angioplasty (PTCA). Although the initial results of venous grafts are excellent, the symptoms tend to recur due to vein graft degeneration and stenosis greatly limiting the long term success of bypass surgery. Early failure occurs within the first 1 to 2 months probably from primary thrombosis often due to technical failure or poor runoff in severely stenotic distal coronary arteries (Cox 1991). Late failure occurs from several months to years after bypass surgery and is caused by neointimal hyperplasia $(\mathrm{NIH})$ with subsequent atherosclerosis in the saphenous vein graft (Nwasokwa 1995). NIH, defined as the accumulation of phenotypically altered medial smooth muscle cells (SMC) and extracellular matrix in the intimal component of the vein, is most prominent in the venous graft within the first year. Several factors interact to influence the development of NIH mostly initiated by ischemia of the venous wall, mechanical trauma and hemodynamic stress. Moreover, convincing evidence suggested that $\mathrm{NIH}$ is associated with extensive endothelial denudation and destruction of venous grafts (Logerfo 1983), resembling a response to injury as seen after angioplasty often leading to restenosis of the denuded artery.

Today it is generally accepted that atherosclerosis is an inflammatory diseases and that atherogenesis as well as disease progression result from inflammation and immune responses towards various stimuli. Common chronic infections caused by viruses and bacteria have been suggested to contribute to this inflammatory process. Most compelling evidence comes from data concerning the intracellular pathogen Chlamydia pneumonia (C. pneumoniae). Although this bacterium was initially identified as a causative factor in (a-)symptomatic inflammation of the airways, clinical studies demonstrated that patients with high titers of antibody against $C$. pneumoniae have an increased risk for cardiovascular complications (Wimmer 1996, Saikku 1988). This is supported by studies revealing significant accelerations of lesion development in animals and a large variety of pro-atherogenic effects in vitro (Ezzahiri 2002, Mahony 2001, Campbell 2004). In addition, recent studies have shown that $C$. pneumoniae infection promotes a proliferative phenotype in the vasculature, which makes $C$. pneumoniae also a likely risk factor for vein graft failure (Rupp 2005, Hirono 2003). This is supported by the work of Bartels et al., who observed a 
strong correlation between elevated $C$. pneumoniae IgG titers and the detection of C. pneumoniae in occluded vein grafts (Bartels 2000). Similar data were shown by Zorc et al., implicating a possible relationship between $C$. pneumoniae presence and occluded arterial bypass grafts (Zorc 2005). These studies suggest that $C$. pneumoniae is present in occluded grafts, however, experimental evidence for this is currently lacking. In the present paper we addressed this by examining the contribution of $C$. pneumoniae to neointimal hyperplasia in a well defined animal model for autologous vein grafting. To our knowledge this is the first paper which addresses the possible contribution of $C$. pneumoniae infection to the pathogenesis of venous graft failure in an experimental model.

\section{Methods}

\section{Animals and vein grafting procedure}

Male inbred specific pathogen free (SPF) male Lewis (LEW) rats were obtained form the Department of Experimental Animal service of the University of Maastricht, the Netherlands. Experiments were carried out on animals aged 12 weeks weighing 250-350 gram. Housing and care of the animals, and all the procedures used in this study were approved by the Ethical Committee for the Use of Experimental Animals of the institution, and conform the Guide for the Care and the Use of Laboratory Animals, published by the US National Institute of Health (NIH Publication No. 85-23, revised 1985). Rats were fed standard rat chow and tap water at libitum. All surgical procedures were performed under general anesthesia and using sterile techniques. Epigastric vein-to-common femoral artery interposition grafts were placed in rats in a similar way as previously described by Hoch et al. (Hoch 1994). In brief, each animal was anaesthetized with an intraperitoneal (i.p.) injection of pentobarbital sodium $(60 \mathrm{mg} / \mathrm{kg})$. An $8 \mathrm{~mm}$ segment of ipsilateral epigastric vein was carefully harvested, gently irrigated with heparinized saline solution $(100 \mathrm{U} / \mathrm{ml})$, and placed as reverse interposition graft into a segmental $3 \mathrm{~mm}$ defect of the common femoral artery with 8 to 10 interrupted sutures of 11-0 nylon (Ethicon). The entire procedure was carried out with standard microsurgical techniques. The total ischemic time was kept to less than $30 \mathrm{~min}$. Graft patency, defined as a condition of flow through the graft, was verified by visual inspection at the end of the surgical procedure.

\section{Experimental design}

Two experimental groups were used. Directly after the grafting procedure, rats ( $\mathrm{n}=10$ animals/group) were either $C$. pneumoniae-infected by i.p. injection $(1 \mathrm{ml}$ of $5 \times 108$ inclusion forming units (IFU) dissolved in a sucrose-phosphate-glucose solution) or received a $1 \mathrm{ml}$ i.p. injection of a sucrose-phosphate-glucose solution. The i.p. inoculation route instead of the intranasal route was used because of the high infectious dosage required in rat experiments. Previous experiments done in our laboratory have demonstrated no significant differences in systemic dissemination of C. pneumoniae between intranasal and i.p. injection (Ezzahiri, personal communication).

\section{Histological and morphometrical procedures}

Three weeks after surgery, rats were anaesthetized, the chest and abdominal cavities were opened and a catheter was inserted into the apex of the heart. Vessels were initially flushed with physiological salt solution and then perfusion fixed with 3,7\% formaldehyde in phosphate-buffered saline (PBS, pH 7.4) at physiological pressure $(100 \mathrm{mmHg})$. Vein grafts were removed and fixed overnight in the same fixative and routinely processed for paraffin embedding. Cross-sections $(4 \mu \mathrm{m})$ were haematoxylin-eosin or Lawson stained for morphometrical analysis (average of three cross-sections per graft). Intimal and medial areas were quantified using a computerassisted morphometry system (analySIS ${ }^{\circledR}$, Soft Imaging System, GmbH). The crosssectional area of the media was defined as the area surrounded by the external and internal elastic lamina. The neointimal cross-sectional area was defined by the area surrounded by the internal elastic lamina and the arterial lumen. Final scores were given as means $\pm \mathrm{SEM}$.

\section{Quantification of cell number in the intima and media}

The number of cells in the intima and media was quantified by counting the total number of nuclei using a microscope. All nuclei were counted in haematoxylin-eosin stained cross-sections. Final scores were expressed as number of cells per area and values are given as means \pm S.E.M.

\section{Immunohistochemistry}

Paraffin sections $(4 \mu \mathrm{m})$, taken from vein grafts three weeks after surgery, were routinely processed and stained with the two-layer indirect immunoperoxidase technique using monoclonal antibodies (mAb). 
The following mAbs were used in this study: Anti-rat CD3 (Sera-lab, Crawley Down, UK), a mouse mAb against T-cells; anti-a smooth muscle actin (ASMA, Sigma, Missouri, USA), ED-1, a mouse mAb to monocytes/macrophages (kindly supplied by Dr. A.M. Duijvestijn Dept. of Immunology, University Maastricht, the Netherlands), a rabbit anti-HSP60 (CST, Danvers, USA) and anti-CRP (R\&D systems, Minneapolis, USA) a mouse $\mathrm{mAb}$ against $\mathrm{C}$-reactive protein.

Sections were incubated with $2 \%$ BSA/PBS (ED-1, CRP and ASMA) for $15 \mathrm{~min}$ at room temperature and treated with antigen retrieval buffer (CD3) for 25 min at $95^{\circ} \mathrm{C}$ [13]. Sections for HSP60 staining were incubated with $10 \mathrm{mM}$ sodium citrate buffer $\mathrm{pH} 6.0$ and microwave boiled for $10 \mathrm{~min}$ at $95-99^{\circ} \mathrm{C}$. Monoclonals were diluted (ED-1 $1 / 20$, ASMA 1/1500, CD3 1/400, CRP 1/100) in PBS and applied to the slides for $60 \mathrm{~min}$ at $37^{\circ} \mathrm{C}$. HSP60 monoclonals were diluted $1 / 100$ in PBS and applied to the slides overnight at $4^{\circ} \mathrm{C}$. After three wash steps with PBS for $5 \mathrm{~min}$, a biotinylated goat anti-mouse secondary antibody (1/1200, DAKO Glostrup Denmark) was applied for $30 \mathrm{~min}$ at room temperature. Finally, sections were incubated with alkaline phosphatase-coupled streptavidin ( $A B C$ reagent, Vector Laboratories), followed by immunodetection using fast red as a substrate. To visualize nuclei, sections were counterstained with haematoxylin. Then, the presence of positive cells was analyzed by microscopy and scored semi-quantitatively, using a zero to four scale with zero meaning no positive signal and 4 extremely positive, by an observer blinded to the experimental groups. Final values were expressed as mean \pm S.E.M.

\section{Statistical analysis}

Morphometrical data and cell count numbers are expressed as means \pm S.E.M. Values were compared using the Mann Whitney $U$ test and $p<0.05$ was considered as statistically significant.

\section{Results}

\section{Animal condition and grafts}

Starting body weight ranged from $250 \mathrm{~g}$ to $350 \mathrm{~g}$, while at the end of the experimenta period animal weight ranged from $320 \mathrm{~g}$ to $400 \mathrm{~g}$. No differences in body weight were observed between experimental groups. During the experimental phase no apparent clinical signs of illness were observed in any of the animals. The overall graft patency after three weeks was $90 \%$. Early thrombosis seemed the underlying cause of the failed grafts. No structural anomalies at the anastomotic regions of the grafts were observed.

\section{Chlamydia pneumoniae aggravates intimal hyperplasia through} stimulation of SMC proliferation

Three weeks after bypass grafting in all veins a significant increase in medial thickness was observed (medial thickness in normal, non-grafted vein: $10 \pm 2 \mu \mathrm{m}$ vs. $36 \pm 3 \mu \mathrm{m}$ in grafted vein of the control group) and showed neointimal thickening, which is principally absent in non-grafted control veins. C. pneumoniae administration immediately after vein grafting resulted in a significant increase in the medial thickness ( $C$. pneumoniae-group: $50 \pm 3 \mu \mathrm{m}$ vs. control group: $36 \pm 3 \mu \mathrm{m}, \mathrm{p}<0.05$ ), total wall cross-sectional area (C. pneumoniae-group: $184200 \pm 57932 \mu \mathrm{m}^{2}$ vs. control group: $75359 \pm 15473 \mu \mathrm{m}^{2}, \mathrm{p}<0.05$ ) and medial cross-sectional area (C. pneumoniae group: $101731 \pm 22984 \mu \mathrm{m}^{2}$ vs. control group: $\left.54149 \pm 13960 \mu \mathrm{m}^{2}, \mathrm{p}<0.05\right)$ at 3 weeks post surgery (figure 1 ).

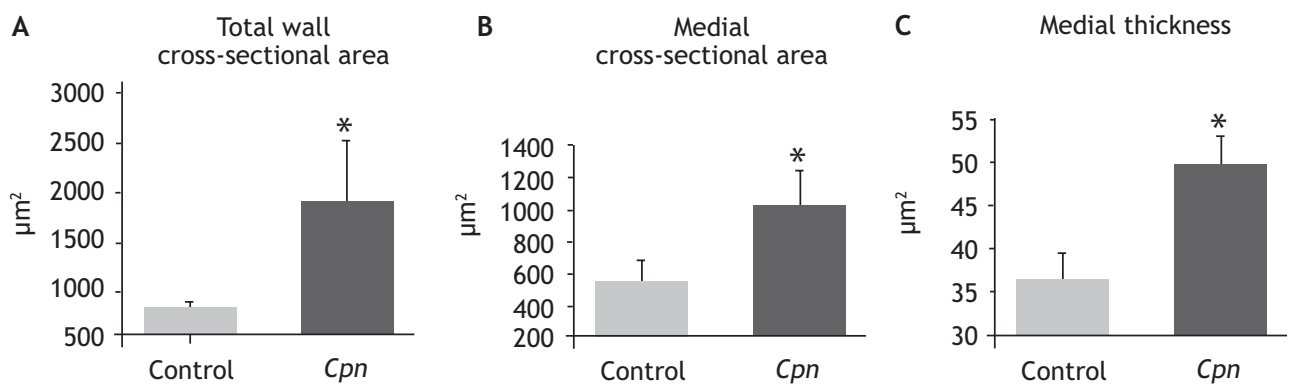

Figure 1 | Effect of Cpn administration on total wall (A) cross-sectional area, medial crosssectional area (B) and wall thickness (C) three weeks after vein grafting. ${ }^{*} \mathrm{P}<0.05$ (values compared with control)

Next, we tried to determine whether the increase in cross-sectional area results from a concomitant increase in cell number or whether the increase is due to cellular hypertrophy, interstitial oedema or an increase in extracellular matrix components. Therefore, we determined cellular density. Our finding that the average number of cells $/ \mu \mathrm{m}^{2}$ was not significantly different between groups (C. pneumoniae-group: $5.0 \pm 0.7 \times 10^{-3}$ cells $/ \mu \mathrm{m}^{2}$ vs. control group: $4.1 \pm 0.5 \times 10-3$ cells $\left./ \mu \mathrm{m}^{2}\right)$, suggests that C. pneumoniae infection stimulates cell proliferation but not cellular hypertrophy 
or interstitial oedema or an increase in extracellular matrix components. After all, the latter are expected to reduce cellular density, a phenomenon which was not observed.

\section{Influx of inflammatory cells}

Staining for inflammatory cells in the venous graft showed a minimal influx of T-cells at three weeks after surgery with an average of one to three T-cells per cross-section. No significant differences between experimental groups were observed. On the other hand, macrophages were notably present in the subendothelial area and in the media, however with a wide variance. Therefore, no significant differences between groups were found. Moreover, alpha-actin staining showed SMC to be the main content of the intima and media with little extra-cellular matrix accumulation in both groups, confirming that the increase in wall mass is predominantly due to smooth muscle cell proliferation.

\section{C-reactive protein}

We also performed an immunostaining to reveal the presence of $\mathrm{C}$-reactive protein (CRP) in the venous graft. Although predominantly produced by the liver, local production of CRP by SMC in response to inflammatory cytokines has also been demonstrated recently (Calabro 2003). Also, evidence suggests that CRP is involved in smooth muscle cell migration and proliferation (Jialal 2004). Truly, positive staining for CRP could be detected mainly in the subendothelial area (typical example shown in figure $2 \mathrm{~A}$ ). Nonetheless, when stainings were quantified in a semi-quantitative manner, no significant differences were observed between groups $(C$. pneumoniae infected: $2.5 \pm 0.8$ vs. control group $2.4 \pm 0.5$, n.s.).

\section{Heat shock protein 60}

Previously we demonstrated the noticeable presence of heat shock protein 60 (HSP60) in occluded veins (de Graaf 2006). Furthermore, we were able to demonstrate that HSP60 is able to stimulate SMC proliferation in a TLR2/4 dependent way (de Graaf 2006). To determine whether HSP60 also plays a role in graft failure in the present model and whether $C$. pneumoniae affects the presence of HSP60 in the grafts, we stained HSP60 in grafts from both the control group and the $C$. pneumoniae-infected group. Indeed, HSP60 positive staining could be revealed in both groups (typical example shown in figure $2 \mathrm{C}$ ). Also, semi-quantitative analysis showed a trend towards group: $3.3 \pm 0.5$ vs. control group: $2.8 \pm 0.7$, n.s.), although the difference was not statistically significant.
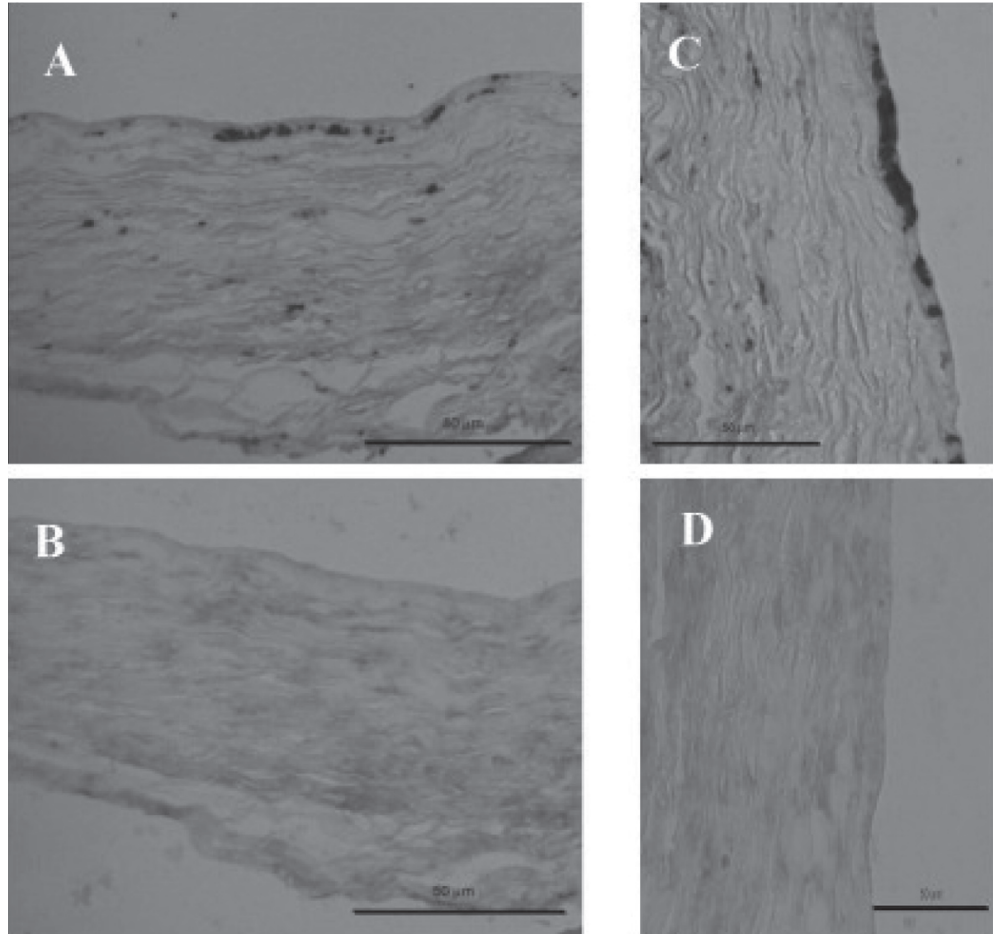

D

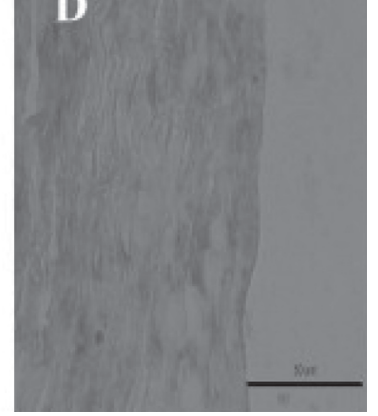

Figure 2| Photomicrographs showing subsequent immunolabeling of a venous bypass graft 3 weeks after surgery (A: CRP, C:HSP60) as well as their representative negative controls (B,D). (see page 167 for color figure)

\section{Discussion}

Saphenous vein graft failure is a common problem after CABG. Approximately $15 \%$ to $30 \%$ of vein grafts occlude during the first year increasing up to 50\% within 10 years (Fitzgibbon 1996). Graft failure occurring within one month after surgery is almost always caused by thrombosis. Neointimal hyperplasia as defined as the accumulation of SMC and extracellular matrix in the intimal layer follows a similar pattern in the balloon injured artery or vein graft and is the major disease process in the vein graft resulting in failure during the first year (Motwani 1998). Nearly all veins implanted 
into the arterial circulation develop intimal wall thickening thereby reducing the lumen size. This is confirmed by our results in the rat venous graft model. At 3 weeks post transplantation, a significant increase in both total and medial cross-sectional area as well as media thickness was observed in the epigastric vein grafts, which is in agreement with earlier data from Hoch and colleagues (Hoch 1999).

To unravel the underlying molecular mechanisms contributing to the pathology of vein graft failure a large variety of studies have been carried out of the past decades in order to find an effective intervention. However, until now these mechanisms haven't been completely elucidated yet. Recently, sero-epidemiologic studies have suggested a role for $C$. pneumoniae the development of vascular disease. $C$. pneumoniae is an obligatory intracellular Gram-negative bacterium that was first isolated as a respiratory pathogen. This micro-organism has also been isolated from coronary arteries of patients with acute coronary syndrome (Zorc 2005), as well as from carotid arteries (Johnston 2005), the aorta and peripheral arteries (Gutierrez 2001). These observations in combination with multiple in vitro findings (Mahony 2001) demonstrating a stimulating effect of $C$. pneumoniae on SMC proliferation, supported a role for $C$. pneumoniae in obstructive vascular disease. Nonetheless, in contrast to atherosclerosis, a possible role of $C$. pneumoniae in venous bypass failure has been less subject of study. Bartels et al. (Bartels 1999) studied the prevalence of C. pneumoniae in occluded vein grafts and native saphenous veins and showed that C. pneumoniae was frequently present in occluded CABG but not in normal veins. C. pneumoniae DNA could be detected by PCR in $25 \%$ of the cases, while viable $C$. pneumoniae was recovered from $16 \%$ of occluded vein grafts. In this study we present for the first time evidence for a role for $C$. pneumoniae in venous graft failure.

When rats were infected with $C$. pneumoniae immediately after surgery, a significant increase in media thickness and total wall cross-sectional area was observed in the epigastric vein-to-common femoral artery graft. To unravel a potential mechanism which might explain the effect of $C$. pneumoniae on intima hyperplasia, we first evaluated the presence of inflammatory cells in the graft. Focal endothelial disruption, occurring during all vein graft harvesting, leads to adherence of platelets and monocytes. Several lines of evidence suggest that $C$. pneumoniae replicate within alveolar cells and can make its way into the wall of the healing graft by using macrophages and monocytes as vectors (Kaukoranta-Tolvanen 1996). Once present in the vascular wall, C. pneumoniae may further enhance the influx of monocytes through the release of monocyte chemoattractant protein 1 by VSMC's. Chronic macrophage infection contributes to local inflammation but it remains unclear whether this aggravates intimal hyperplasia and bypass failure. Hoch et al. demonstrated that depletion of macrophages suppresses intimal hyperplasia indicating the importance of the amount of macrophages present in the graft (Hoch 1999). However immunostaining of the venous graft in our model showed no differences in influx of inflammatory cells between the $C$. pneumoniae infected and the control group, suggesting a different mechanism of action.

C. pneumoniae infection of vascular smooth muscle cells increases interleukin-6 (IL-6) secretion in vitro (Yang 2005). In vivo, IL-6 is a strong inducer of liver C-reactive protein (CRP) production which is able to stimulate endothelial and smooth muscle cell proliferation providing a pathway for $C$. pneumoniae to aggravate vein graft failure (Cirillo 2005). In addition, evidence is accumulating suggesting that SMC are able to produce CRP and stimulate SMC migration and proliferation in an autocrine fashion (Jialal 2004). Indeed, we were able to demonstrate the presence of CRP in particular in the sub-endothelial layer thereby providing further evidence for a role for CRP in intima hyperplasia. Nonetheless, no significant difference between the two groups was observed indicating that $C$. pneumoniae infection does not have an effect on the presence of CRP in the vascular wall at the time point examined. Nevertheless, this does not exclude that $C$. pneumoniae may affect the production of CRP at earlier time points post surgery and contribute as such to the process already at an earlier stage. Further studies are required to unravel this aspect in more detail.

C. pneumoniae is also known to produces large amounts of heat shock protein 60 (HSP 60) during chronic, persistent infections (Costa 2002). C. pneumoniae HSP60, which is well conserved during evolution and shows a high degree of homology with mammalian HSP60, is able to activate vascular endothelium, smooth muscle cells, and macrophages (Kol 1999). HSP60 is also able to stimulate SMC proliferation (de Graaf 2006, Sasu 2001) and may hereby aggravate a hyperplastic response as seen in our model. Therefore, we decided to determine the presence of HSP60 by immunohistochemistry. Actually we were well able to visualize the presence of HSP60 in the grafts of both groups; however, despite the fact that there was a trend towards an increase in the presence of HSP 60 in the venous grafts of the $C$. pneumonia-infected group as compared to the controls, this failed to reach statistical significance.

\section{Conclusion}

Summarizing, we present here for the first time evidence for a possible role of Chlamydia pneumoniae in the process of venous graft failure. In a well defined animal 
model, a significant increase in total and media cross-sectional area as well as media thickness was observed in vein grafts obtained from C. pneumoniae-infected rats, suggesting that $C$. pneumoniae is able to promote the process of intima hyperplasia. Furthermore, cellular density in the vascular wall remained constant indicating that C. pneumoniae stimulates cell proliferation but not hypertrophy nor the formation of institial oedema or the deposition of extracellular matrix components. In addition, we analyzed in more details some of the possible molecular mechanisms which may contribute to the observed $C$. pneumoniae-mediated effects. However, none of the suggested mechanisms (enhanced influx of inflammatory cells, augmented production of CRP or HSP60) seemed primarily responsible for the observed effects and further research is warranted to elucidate in more detail how $C$. pneumoniae affects vein graft failure.

\section{References}

Bartels C, Maas M, Bein G, Malisius R, Brill N, Bechtel JF, Sayk F, Feller AC, Sievers, HH: Detection of Chlamydia pneumoniae but not cytomegalovirus in occluded saphenous vein coronary artery bypass grafts. Circulation. 1999, 99: 879-882

Bartels C, Maas M, Bein G, Brill N, Bechtel JF, Leyh R, Sievers HH: Association of serology with the endovascular presence of Chlamydia pneumoniae and cytomegalovirus in coronary artery and vein graft disease. Circulation. 2000, 101: 137-141.

Calabro P, Willerson JT, Yeh ET: Inflammatory cytokines stimulated C-reactive protein production by human coronary artery smooth muscle cells. Circulation 2003, 108: 1930-1932

Campbell LA, Kuo CC: Chlamydia pneumoniae--an infectious risk factor for atherosclerosis? Nat Rev Microbiol. 2004, 2: 23-32

Cirillo P, Golino P, Calabro P, Cali G, Ragni M, De Rosa S, Cimmino G, Pacileo M, De Palma R, Forte L, Gargiulo A, Corigliano FG, Angri V, Spagnuolo R, Nitsch L, Chiariello M. C-reactive protein induces tissue factor expression and promotes smooth muscle and endothelial cell proliferation. Cardiovasc Res. 2005, 68: 47-55.

Costa CP, Kirschning CJ, Busch D, Durr S, Jennen L, Heinzmann U, Prebeck S, Wagner H, Miethke T. Role of chlamydial heat shock protein 60 in the stimulation of innate immune cells by Chlamydia pneumoniae. Eur J Immunol. 2002, 32: 2460-70.

Cox JL, Chiasson DA, Gotlieb Al. Stranger in a strange land: the pathogenesis of saphenous vein graft stenosis with emphasis on structural and functional differences between veins and arteries. Prog Cardiovasc Dis. 1991, 34: 45-68

Ezzahiri R, Nelissen-Vrancken HJ, Kurvers HA, Stassen FR, Vliegen I, Grauls GE, van Pul MM, Kitslaar PJ, Bruggeman CA: Chlamydophila pneumoniae (Chlamydia pneumoniae) accelerates the formation of complex atherosclerotic lesions in Apo E3-Leiden mice. Cardiovasc Res 2002 56: 269-76.

Fitzgibbon GM, Kafka HP, Leach AJ, Keon WJ, Hooper GD, Burton JR. Coronary bypass graft fate and patient outcome: angiographic follow-up of 5,065 grafts related to survival and reoperation in 1,388 patients during 25 years. J Am Coll Cardiol. 1996, 28: 616-626. de Graaf R, Kloppenburg G, Kitslaar PJ, Bruggeman CA, Stassen F: Human heat shock protein 60 stimulates vascular smooth muscle cell proliferation through Toll-like receptors 2 and 4 . Microbes Infect. 2006, 8:1859-186

Gutierrez J, Linares-Palomino J, Lopez-Espada C, Rodriguez M, Ros E, Piedrola G, del Maroto Infection. 2001, 29: 196-200

Hirono S, Dibrov E, Hurtado C, Kostenuk A, Ducas R, Pierce GN: Chlamydia pneumoniae stimulates proliferation of vascular smooth muscle cells through induction of endogenous heat shock protein 60 . Circ Res. 2003, 93:710-716.

Hoch JR, Stark VK, Hullett DA, Turnipseed, WD: Vein graft intimal hyperplasia: leukocytes and cytokine gene expression. Surgery 1994, 116: 463-470

Hoch, J.R., Stark, V.K., van Rooijen N., Kim J.L., Nutt, M.P., Warner, T.F. Macrophage depletion alters vein graft intimal hyperplasia. Surgery. 1999, 126: 428-37.

Jialal I, Devaraj S, Venugopal SK: C-reactive protein: risk marker or mediator in atherothrombosis? Hypertension 2004, 44; 6-11

Johnston SC, Zhang H, Messina LM, Lawton MT, Dean D. Chlamydia pneumoniae burden in carotid arteries is associated with upregulation of plaque interleukin-6 and elevated C-reactive protein in serum. Arterioscler Thromb Vasc Biol. 2005, 25: 2648-2653.

Kaukoranta-Tolvanen SS, Teppo AM, Laitinen K, Saikku P, Linnavuori K, Leinonen M: Growth of Chlamydia pneumoniae in cultured human peripheral blood mononuclear cells and induction of a cytokine response. Microb Pathog. 1996, 21: 215-221

Kol A, Bourcier T, Lichtman AH, Libby P. Chlamydial and human heat shock protein 60s activate human vascular endothelium, smooth muscle cells, and macrophages. J Clin Invest. 1999, 103: 571-7.

LoGerfo FW, Quist WC, Cantelmo NL, Haudenschild CC: Integrity of vein grafts as a function of initial intimal and medial preservation. Circulation 1983, 68: II117-24.

Mahony JB, Coombes BK: Chlamydia pneumoniae and atherosclerosis: does the evidence support causal or contributory role? FEMS Microbiol Lett 2001,197:1-9

Motwani GJ, Topol EJ. Aortocoronary saphenous vein graft disease: pathogenesis, predisposition, and prevention. Circulation. 1998, 97: 916-931

Nwasokwa ON: Coronary artery bypass graft disease. Ann Intern Med. 1995, 123: 528-45.

Rupp J, Hellwig-Burgel T, Wobbe V, Seitzer U, Brandt E, Maass M: Chlamydia pneumoniae infection promotes a proliferative phenotype in the vasculature through Egr-1 activation in vitro and in vivo. Proc. Natl. Acad. Sci. U.S.A. 2005, 102: 3447-3452.

Saikku P, Mattila K, Nieminen MS, Huttunen JK, Leinonen M, Ekman M-R, Mäkelä PH, Valtonen V: Serological evidence of an association of a novel Chlamydia, TWAR, with chronic coronary heart disease and acute myocardial infarction. Lancet 1988, 332: 983-6.

Sasu S, LaVerda D, Qureshi N, Golenbock DT, Beasley D. Chlamydia pneumoniae and chlamydial heat shock protein 60 stimulate proliferation of human vascular smooth muscle cells via toll-like receptor 4 and p44/p42 mitogen-activated protein kinase activation. Circ Res. 2001, 89: 244-50.

Wimmer ML, Sandmann-Strupp R, Saikku P, Haberl RL: Association of chlamydial infection with cerebrovascular disease. Stroke 1996, 27: 2207-10.

Yang X, Coriolan D, Schultz K, Golenbock DT, Beasley D: Toll-like receptor 2 mediates persistent chemokine release by Chlamydia pneumoniae-infected vascular smooth muscle cells. Arterioscler Thromb Vasc Biol. 2005, 25: 2308-2314.

Zorc M, Vraspir-Porenta O, Kese D, Petrovic D, Legan M: Detection of Chlamydia pneumoniae DNA in the coronary arteries and bypass in three patients with diffuse coronary artery disease. Cardiology 2005, 103: 121-122 


\section{Chapter 5}

Chlamydia pneumoniae infection is not associated with chronic transplant dysfunction in a rat aortic allograft model 


\section{Abstract}

Long-term survival of solid-organ transplants is limited as a result of chronic transplant dysfunction (CTD), which is characterized by occlusion of intragraft vascular tissue due to myointimal hyperplasia. Recent studies showed a role for infections in vascular pathologies. For example, Chlamydia pneumoniae ( $C$. pneumoniae) has been shown to aggravate atherosclerosis and $C$. pneumoniae IgG titers correlate with severity of allograft atherosclerosis after cardiac transplantation. In this study we evaluated the effect of $C$. pneumoniae infection on CTD by using a rat aortic allograft model.

Orthotopic abdominal aorta transplantations ( $\mathrm{Tx}$ ) were performed with $\mathrm{BN}$ rats as donors and Lewis rats as recipients. Rats were sacrificed 1 or 8 weeks after surgery and the graft was processed for DNA isolation and histological examination. Influx of macrophages and T-cells was assessed by immunohistochemistry.

At 1 week after Tx, the perivascular influx of inflammatory cells in the graft was not affected by $C$. pneumoniae infection. Furthermore, only limited numbers of $C$. pneumoniae DNA copies were found in the graft at 1 week after Tx. In addition, $C$. pneumoniae did not alter the severity of myointimal hyperplasia in the rat aortic allograft model at 8 weeks after surgery.

Our data suggest that in the rat aortic allograft model $C$. pneumoniae infection does not influence the influx of inflammatory cells or the severity of CTD.

\section{Introduction}

Organ transplantation has become an increasingly successful medical treatment for patients with end-stage organ failure. However, despite improvements in immunosuppressive drug therapy and treatment of acute rejection, long-term survival of solid-organ transplants is limited as a result of chronic transplant dysfunction (CTD). In the majority of organs, CTD is characterized by a persistent perivascular inflammation which results in a diffuse multifocal myointimal hyperplasia and inadequate vascular remodeling resulting in intimal narrowing of all the vessels in the graft (Pethig 1998). Major risk factors for CTD are humoral and cellular immune responses, hyperlipidemia and viral infections. Regarding the latter, cytomegalovirus (CMV) in particular has been associated with CTD. Multiple experimental as well as clinical data support a detrimental effect of CMV infections on long term graft survival (Lemstrom 1993, 1994, Potena 2003, Arnold 1992, Fitzgerald 2004, FatehMoghadam 2003)

Apart from its effect on CTD, it's becoming increasingly clear that CMV has an effect on other vascular pathologies, like atherosclerosis or restenosis (Vliegen 2002, Bason 2003, Sorlie 2000). Moreover seropositivity for other organisms, like Helicobacter pylori, herpes simplex or hepatitis A virus, has also been shown to be associated with the atherosclerosis (Mayr 2003, Kotronias 2005, Zhu 2000). Most convincing evidence comes from data regarding the intracellular pathogen Chlamydia pneumonia ( $C$. pneumoniae). Although this bacterium was initially identified as a causative factor in (a-) symptomatic inflammation of the airways, numerous clinical studies demonstrated that patients with high titers of antibody against $C$. pneumoniae have an increased risk for cardiovascular complications (Wimmer 1996, Saikku 1988). This is supported by experimental studies which showed an acceleration of lesion development in experimental animals and a large variety of pro-atherogenic effects in vitro (Ezzahiri 2002, Liu 2000, Blessing 2001). Interestingly, recent studies also show a strong correlation between $C$. pneumoniae lgG titer and severity of allograft arteriosclerosis after cardiac transplantation as well as early graft failure (Subramanian 2002, Pieniazek 2003, Wittwer 2000), although results have not been consistent (Fang 1998). Also, an association between the occurrence of $C$. pneumoniae and the presence of foam cell arteriopathy in liver transplant patients with chronic rejection has been suggested (Lotz 2004).

These data suggest that $C$. pneumoniae, apart from its effect on atherosclerosis, may also play a role in CTD. However, until now no studies have been published 
regarding such a role for $C$. pneumoniae in the progression of CTD. For this purpose we used a well established animal model to study the effect of $C$. pneumoniae on transplant related neointima formation which characterizes CTD. The rat aorta transplantation model is easy to perform, has a low post-operative mortality and alterations in the aorta graft are virtually identical with the vascular lesion of chronically rejecting parenchymal organ transplants in human subjects (Mannander 1991, Lemstrom 1993).

\section{Materials and Methods}

\section{Animal conditions}

Male inbred specific pathogen free Lewis (LEW) (Department of Experimental Anima Service of the University of Maastricht, the Netherlands) and BN (Charles river Maastricht, the Netherlands) rats, weighing 200-300 gram, were used as donors and/ or recipients. Housing and care of the animals and all the procedures used in this study were approved by the Ethical Committee for the Use of Experimental Animals of the institution, and conform the Guide for the Care and the Use of Laboratory Animals, published by the US National Institute of Health (NIH Publication No. 85-23, revised 1985). Rats were fed standard rat chow and tap water at libitum. All surgical procedures were performed under general anesthesia and sterile conditions.

\section{Experimental design}

Aortic grafts from BN rats were transplanted to LEW recipients (allogeneic) or to $\mathrm{BN}$ recipients (syngeneic). Aortic allografting was performed as described previously (Mennander 1991). Briefly, the rats were anaesthetized by intraperitoneal injection of pentobarbital $(60 \mathrm{mg} / \mathrm{kg})$. The abdominal aorta from the renal artery to the bifurcation (about $1.8 \mathrm{~cm}$ ) was harvested from Brown Norway (BN) rats after intravenous injection of $50 \mathrm{U}$ of heparin. The aorta grafts were transplanted orthotopically into recipients with the end-to-end anastomosis technique, using non-interrupted 9-0 nylon sutures. Total ischemic time varied from 20 to 25 minutes during which the grafts were kept cold using phosphate buffered saline $\left(4^{\circ} \mathrm{C}\right)$. After transplantation, the animals were randomly divided into several groups (Table 1).

C. pneumoniae infection ( $1 \mathrm{ml}$ of $5 \times 10^{8}$ inclusion forming units (IFU) $/ \mathrm{ml}$ sucrose phosphate-glucose solution) was performed by i.p. injection 24 hours after transplantation. The i.p. inoculation route instead of the intranasal route was use because of the high infectious dosage required in rat experiments.
Table 1 | Summary of experimental groups.

\begin{tabular}{ccccc}
\hline Group & Transplantation & Number of rats & C. pneumoniae infection ${ }^{1}$ & Day of sacrifice \\
\hline 1 & Syngeneic & 5 & - & 7 \\
2 & Syngeneic & 5 & - & 56 \\
3 & Allogeneic & 10 & - & 7 \\
4 & Allogeneic & 10 & + & 7 \\
5 & Allogeneic & 10 & - & 56 \\
6 & Allogeneic & 10 & + & 56 \\
\hline
\end{tabular}

C. pneumoniae infection ( $1 \mathrm{ml}$ of $5 \times 10^{8}$ inclusion forming units)/ml sucrose phosphate-glucose solution) was performed by i.p. injection 24 hours after transplantation.

\section{Histological and morphometrical procedures}

The recipients were sacrificed either at 1 or 8 weeks post-surgery. Vessels were initially flushed with physiological salt solution and then perfusion fixed with $3.7 \%$ formaldehyde in phosphate-buffered saline $(\mathrm{pH} 7.4)$ at physiological pressure $(100 \mathrm{~mm} \mathrm{Hg})$. Aortic grafts were removed and cut in three sections for paraffin embedding, frozen sections and isolation of C. pneumoniae DNA. For histology, a segment of the graft was fixated overnight in $3.7 \%$ formaldehyde in phosphatebuffered saline $(\mathrm{pH} 7.4)$ and embedded in paraffin. Four-micron thick crosssections from the middle part of the graft were stained with haematoxylin-eosin and Lawson. The perimeters of the external elastic lamina, internal elastic lamina and lumen were measured in those cross-sections of the graft, by using a computerassisted morphometry system (analySIS ${ }^{\circledR}$, Soft Imaging System, GmbH). The crosssectional area of the media was defined as the area surrounded by the external and internal elastic lamina. The neointimal cross-sectional area was defined by the area surrounded by the internal elastic lamina and the arterial lumen. Luminal stenosis was defined as percentage of lumen area occluded by neointimal area. Final scores were given as mean $\pm \mathrm{SEM}$.

\section{Immunohistochemistry}

Frozen sections ( $4 \mu \mathrm{m}$ thick), taken from aortic grafts 1 week after Tx, were fixed in acetone $\left(-20^{\circ} \mathrm{C}\right)$ for $15 \mathrm{~min}$ for immunohistochemistry and stained with the twolayer indirect immunoperoxidase technique using monoclonal antibodies (mAb). After fixation, the sections were air-dried for $30 \mathrm{~min}$. 
The following mAbs used in this study were purchased from Sera-lab (Crawley Down, UK): W3/13, a mouse IgG1 mAb to $\mathrm{CD}^{+}$cells, W3/25, a mouse IgG1 mAb to rat $C D 4^{+}$cells and $0 x-8$, a mouse IgG1 mAb to rat $C D 8^{+}$cells. ED-1, a mouse mAb to monocytes/macrophages was kindly supplied by Dr. A.M. Duijvestijn (department of Immunology, Universiteit Maastricht, the Netherlands). Monoclonals were diluted in TBS and applied to the slides for $60 \mathrm{~min}$ at room temperature. After three washes with TBS for $5 \mathrm{~min}$, a biotinylated horse anti-mouse secondary antibody (1:400 dilution Dako) was applied for $30 \mathrm{~min}$ at room temperature. Finally, sections were incubated with alkaline phosphatase-coupled streptavidin (ABC reagent, Vector Laboratories), followed by immunodetection using fast red as a substrate and finally counterstained with haematoxylin. Then, the presence of positive cells was analyzed by microscopy and scored semi-quantitatively by an observer blinded to the specimen group.

\section{Detection of $C$. pneumoniae DNA by real-time PCR}

At 1 week post-surgery, a small part of the aorta grafts was processed for DNA isolation and detection of $C$. pneumoniae DNA in the tissues by real time PCR. In addition, a part of the recipient's spleen was processed to confirm dissemination of C. pneumoniae throughout the animal. Total genomic DNA was extracted from tissue using the WIZARD ${ }^{\circledR}$ method (Promega Corporation, Madison, WI). DNA content of each sample was measured using the The NanoDrop ${ }^{\circledR}$ ND-1000, a full-spectrum $(220-750 \mathrm{~nm})$ spectrophotometer. Next, real-time PCR (ABI Prism 7000, Applied Biosystems, Foster City, USA) was applied to detect and quantify C. pneumoniae DNA copy numbers. The sequences of the primers and probes were based on a variable domain of the ompA gene, VD4, as described before (Tondella 2002). PCR was performed with a total volume of $25 \mu \mathrm{l}$; consisting of $12.5 \mu \mathrm{l}$ TaqMan Universal Master Mix (Applied Biosystems, 2x concentrated), 300 nM forward primer (5'TCCGCATTGCTCAGCC3'), $900 \mathrm{nM}$ reverse primer (5'AAACAATTTGCATGAAGTCTGAGAA3'), 200 mM probe (5'-FAMTAAACTTAACTGCATGGAACCCTTCTTTACTAGG3'-TAMRA), $3.5 \mu$ l NASBA water and $1 \mu \mathrm{g}$ DNA ( $5 \mu \mathrm{l}$ of the sample). Serial dilutions of the plasmid, containing the VD4 part of the $C$. pneumoniae ompA gene (GenBank, accession number AY426607) and a negative control, containing reagents only were applied to create the standard curve. The concentrations of the plasmid dilutions were: $10^{6}, 10^{5}, 10^{4}, 10^{3}, 10^{2}, 10^{1}$ copies of ompA plasmid. For the quantification of $C$. pneumoniae DNA in the samples, $A B I$ Prism 7000 SDS software was applied. Thermal cycling started with UNG activation for 2 min at $50^{\circ} \mathrm{C}$, followed by HotStarTaq activation during $10 \mathrm{~min}$ at $95^{\circ} \mathrm{C}$. Afterwards 42 cycles of amplification were run consisting of 15 seconds at $95^{\circ} \mathrm{C}$ and $1 \mathrm{~min}$ at $60^{\circ} \mathrm{C}$.

\section{Statistical analysis}

Morphometrical data were expressed as mean \pm S.E.M. Values were compared using the Mann-Whitney $U$-test and $p<0.05$ was considered to be statistically significant.

\section{Results}

\section{Animal conditions}

No apparent clinical signs of illness were observed in any of the animals during the follow-up period. Starting body weight ranged from $200 \mathrm{~g}$ to $300 \mathrm{~g}$; at the end of the experiments animal weight ranged from $325 \mathrm{~g}$ to $405 \mathrm{~g}$. There were no significant differences between the experimental groups.

\section{Detection of $C$. pneumoniae DNA by real-time PCR}

The number of $C$. pneumoniae DNA copies was determined in aorta graft and recipient's spleen at 1 week post-surgery. Although substantial levels of $C$. pneumoniae DNA were found in the recipient's spleen (464 \pm 163 copies of Cpn DNA per $\mu \mathrm{g}$ total DNA) only a limited amount of $C$. pneumoniae DNA was detected in 4 out of 10 samples taken from the transplanted aorta $(3 \pm 1$ copies of $C$. pneumoniae DNA per $\mu$ g total DNA).

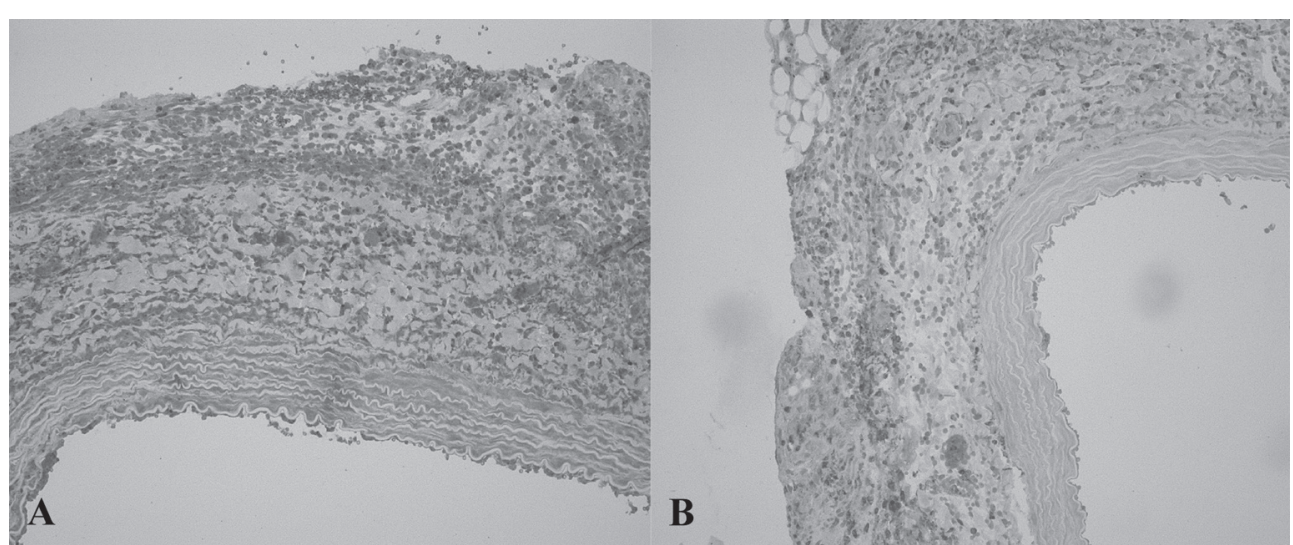

Figure 1 Photomicrographs of rat aortic allograft 1 week after transplantation. ED-1 immunoperoxidase staining against monocytes/macrophages. A) Allogeneic group with C. pneumoniae infection 24 hours after transplantation. B) Allogeneic control group. No statistical significant differences were observed. (see page 166 for color picture) 


\section{Inflammatory infiltrate in the graft}

At 1 week post Tx an abundant influx of monocyte/macrophages and T-cells was observed in the perivascular area in contrast to only limited amounts (less than 5 per section) of inflammatory cells seen in the intima and media of the vessel wall (figure 1). Nevertheless, no differences were observed between the C. pneumoniaeinfected and control allogeneic group, either for the amount of influx of monocyte/ macrphages or the amount of T-cells in the perivascular area, media or intima. In contrast, significantly less perivascular inflammation was seen in the syngeneic group.

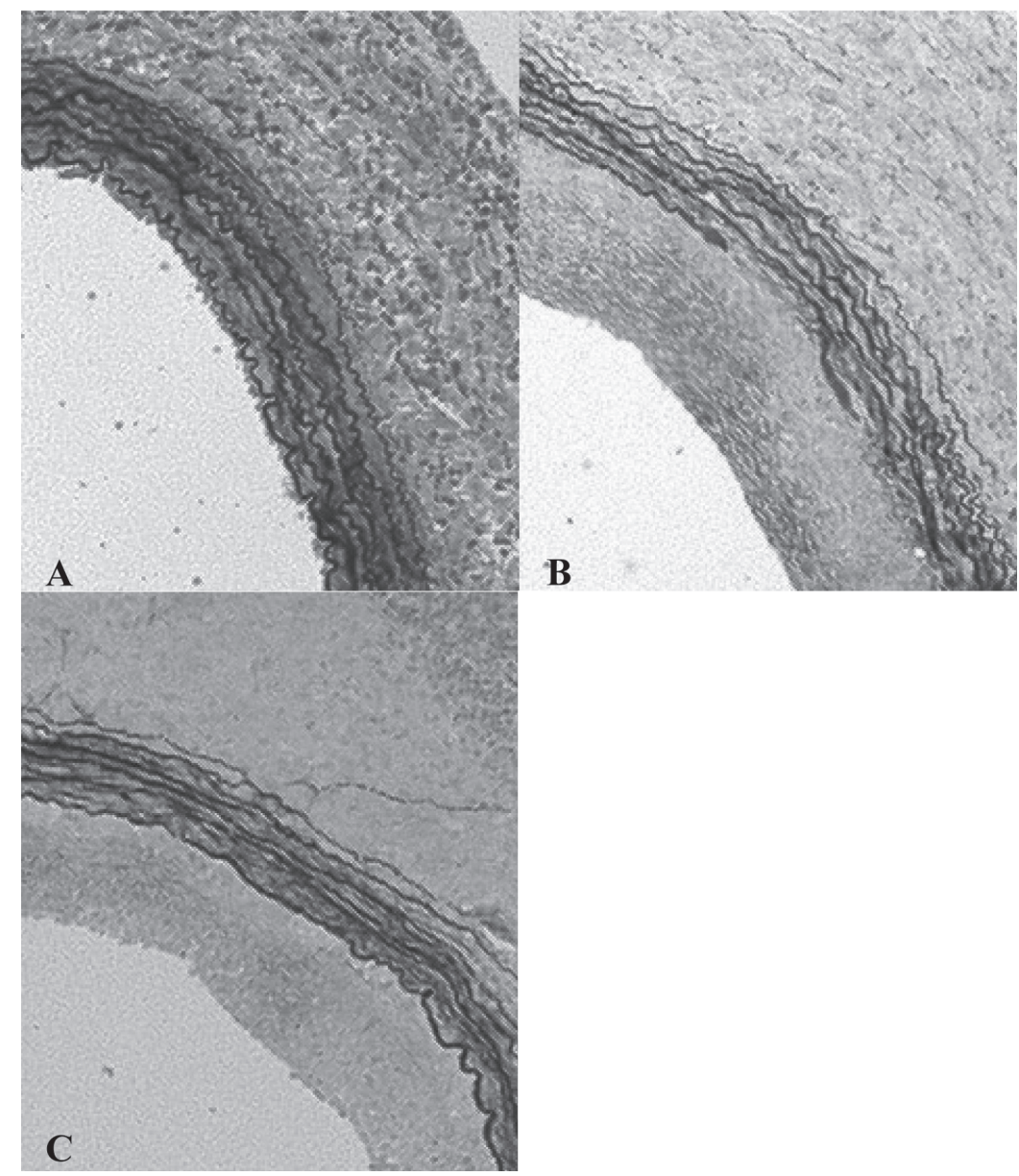

Figure 2 | Representative photomicrographs of rat aortic grafts weeks after transplantation. Lawson staining. A) syngeneic group B) allogeneic control group C) allogeneic group with C. pneumoniae infection 24 hours after transplantation. (see page 170 for color picture)

\section{Vascular remodeling}

C. pneumoniae administration in the rats 24 hours after aortic Tx had no significant effect on the mean neointimal cross-sectional area or the percentage of luminal stenosis at 8 weeks post surgery as compared to the control group (figure 2). In addition, no differences in medial cross-sectional area, luminal cross-sectional area, neointimal/medial ratio or neointimal/lumen ratio were seen (data not shown). As expected, no neointima formation was seen in the syngeneic group at 8 weeks after Tx (figure 3). No neointima was observed in the rats sacrificed 1 week after Tx in either of the groups.

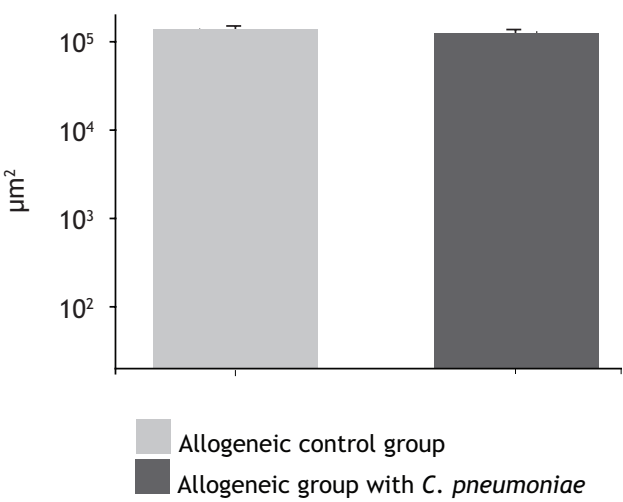

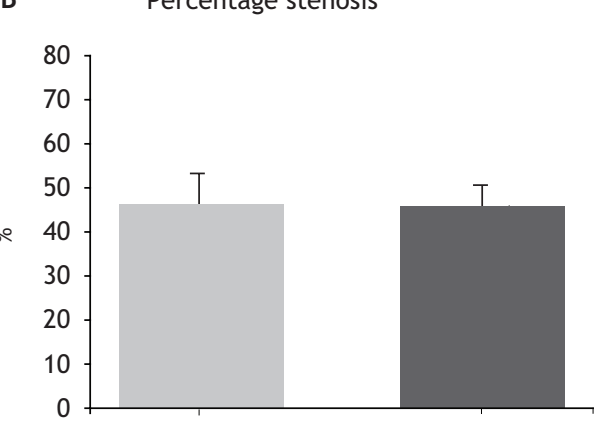

Figure 3 | Effect of C. pneumoniae infection on neointimal cross-sectional area and percentage stenosis. Rats were infected with C. pneumoniae 24 hours after aortic transplantation and vascular remodeling was determined 56 days after surgery. A) neointimal cross-sectional area B) percentage stenosis. No significant differences between allogeneic groups.

\section{Discussion}

Previous data compellingly demonstrated that cytomegalovirus affects cardiovascular disorders such as atherosclerosis, restenosis and transplant arteriosclerosis. Likewise, C. pneumoniae has been suggested to aggravate atherosclerosis by similar mechanisms. Nonetheless, to our knowledge it has not yet been determined whether C. pneumoniae also affects CTD. Here, we demonstrate that $C$. pneumoniae has no 
effect on neointima formation following allogeneic aorta transplantation in a well established rat model.

Transplantation associated arteriosclerosis is the most important cause of graft failure after the first post-transplant year (Paul 1993). Although the exact pathogenesis of CTD remains to be established, several risk factors, like humoral and cellular immune responses, hyperlipidema and frequency and intensity of acute rejection episodes have been described to contribute to the development of CTD (Cramer 1989, Tesi 1993, Winters 1990). Evidence linking infections and acute or chronic solid organ transplant rejection was first presented in the early 1970s and primarily refer to the role of herpes viruses (Lopez 1974). Also, based on seroepidemiologic surveys, an acute rejection-causing effect of the influenza B virus and the adenoviruses has been suggested (Gabriel 1976). Nevertheless, cytomegalovirus shows the strongest epidemiological connection with CTD. Several clinical studies demonstrated a role for cytomegalovirus infection in chronic hepatic allograft dysfunction (Arnold 1992, O'Grady 1988). In addition, clinically relevant CMV infection has been shown to negatively influence the coronary remodeling modalities during the first follow up year after heart transplantation (Potena 2003). Also, pre-transplant CMV seropositivity is associated with decreased patient and allograft survival after kidney transplantation (Fitzgerald 2004). Furthermore, the association between CMV and CTD is supported by various experimental studies. For example, Lemström et al. demonstrated the stimulating effect of cytomegalovirus infection on CTD in the rat aortic allograft model (Lemstrom 1993, 1994). Likewise, Lautenschlager et al. showed that CMV prolonged and increased the graft inflammation and accelerated chronic rejection of rat renal allografts under triple-drug treatment (Lautenschlager 1997).

As CMV also affects other cardiovascular diseases and atherosclerosis in particular, it may be hypothesized that other micro-organisms, similarly affecting atherosclerosis, may also have an impact on CTD. In this respect, $C$. pneumoniae might be the most promising candidate. The pathogenic role of $C$. pneumonia in cardiovascular pathologies is widely supported. Since the original observation by Saikku and colleagues, demonstrating an increased incidence of myocardial infarction among $C$. pneumoniae positive coronary heart disease patients (Saikku 1992), the role of $C$. pneumoniae in atherosclerosis has been confirmed by many others (Jaremo 2004, Mitusch 2005). Most of the suggested mechanisms by which C. pneumoniae may affect atherosclerosis highly resemble those by which $C M V$ has been suggested to affect the disease. Therefore, it is plausible that C. pneumoniae, similar to CMV, is also involved in other cardiovascular pathologies like CTD. This is supported by the observation that $C$. pneumoniae is a potential risk factor for cardiac allograft vasculopathy (Wittwer 2000) and that C. pneumoniae IgG titers correlate with severity of allograft atherosclerosis after cardiac transplantation as well as early graft failure (Subramanian 2002)

Nevertheless, a direct cause-effect relationship between C. pneumoniae and CTD has not yet been demonstrated. Thus, we studied the effect of $C$. pneumoniae infection on CTD by using a rat aortic allograft model. However, when we evaluated various morphological parameters at 8 weeks post-transplantation no effect of $C$. pneumoniae could be observed. While no intima hyperplasia could be observed following syngeneic transplantation, a significant neointima could be observed in the allogeneic group. However, neither the amount of neointima nor the percentage of stenosis was significantly affected by concomitant $C$. pneumoniae infection.

Despite the fact that significant amounts of $C$. pneumoniae could be detected in the spleen of infected rats, indicating that the bacteria was disseminated throughout the body, only a few $C$. pneumoniae DNA copies could be detected in some graft early after infection. This may partially explain the lack of effect of the infection on intimal thickening. On the other hand, CMV, which also can be hardly detected in the graft, has been shown to exert a prominent effect on intimal thickening despite the relative absence of the virus in the vascular wall. Similarly, we recently demonstrated a marked effect of CMV infection on intima hyperplasia following arterial injury even in the absence of large amounts of virus in the vascular wall (Kloppenburg 2005). Therefore, to affect the remodeling process the presence of the microbes in the graft may not be a pre-requisite.

Thus, alternative routes have been suggested for the CMV-enhanced graft arteriosclerosis. Interestingly, CMV infection enhances the early, prominent inflammatory episode in the allograft adventitia with a pronounced influx of macrophages and T-cells. This enhanced inflammatory response is accompanied by a significant up-regulation of PDGF and TGF-B mRNA expression in the graft following CMV infection. However, following $C$. pneumoniae infection no clear difference in perivascular inflammation could be observed between infected and control rats, thereby providing an additional reason for the lack of effect of $C$. pneumoniae on intimal thickening. Nevertheless, $C$. pneumoniae is able to promote a proliferative phenotype as the post-infectious mRNA expression of Egr-1, an angiogenic transcription factor, was significantly up-regulated both in vitro (coronary artery smooth muscle cells) and ex vivo in a rat aortic ring model of focal vascular chlamydial infection (Mitusch 2005). Therefore, it remains to be established why $C$. pneumoniae has no effect on intimal thickening in vivo. 
Although ample literature is available concerning C. pneumoniae infection, dissemination and subsequent immune responses in mice, less is known about $C$. pneumoniae infections in rats. Although a few papers demonstrated that rats can be infected with C. pneumoniae (Damy 2003) and that C. pneumoniae infection may result in vascular alterations (Chrapusta 2002, Herrera 2003) the exact course of infection as well as the immunological response of rats towards $C$. pneumoniae is, at least to our knowledge, unknown. Although we demonstrated the systemic dissemination of $C$. pneumoniae early after infection, we were unable to detect IgG antibodies directed against $C$. pneumoniae in the majority of the infected rats at 8 weeks post infection (data not shown). This suggests that the early immune response is able to eliminate the microbe rapidly. Interestingly, pronounced vascular effects of C. pneumoniae are seen in mice, which mount a strong IgG antibody response against C. pneumoniae. Yet, further research is required to elucidate the exact role of the different parts of the immune system in $C$. pneumoniae-mediated vascular effects.

In summary, we demonstrated that $C$. pneumoniae is able to disseminate in rats following i.p. infection. However, hardly any C. pneumoniae DNA was found in the transplanted graft and no enhancement of the perivascular inflammation was observed. To some extent, this may explain the lack of effect of $C$. pneumoniae infection on the intimal thickening in the allogeneic aortic graft model. In conclusion, our data suggest that $C$. pneumoniae infection may be of minor importance for the severity of CTD as seen in the rat aortic allograft model.

\section{References}

Arnold, J.C., Portmann, B.C., O'Grady, J.G., Naoumov, N.V., Alexander, G.J. and Williams, R. Cytomegalovirus infection persists in the liver graft in the vanishing bile duct syndrome. Hepatology, 1992. 16(2): p. 285-92.

Bason, C., Corrocher, R., Lunardi, C., et al., Interaction of antibodies against cytomegalovirus with heat-shock protein 60 in pathogenesis of atherosclerosis. Lancet, 2003. 362(9400): p. 1971-7.

Blessing, E., Campbell, L.A., Rosenfeld, M.E., Chough, N. and Kuo, C.C., Chlamydia pneumoniae infection accelerates hyperlipidemia induced atherosclerotic lesion development in C57BL/6J mice. Atherosclerosis, 2001. 158(1): p. 13-7.

Cramer, D.V., Qian, S.Q., Harnaha, J., et al., Cardiac transplantation in the rat. I. The effect of histocompatibility differences on graft arteriosclerosis. Transplantation, 1989. 47(3): p. 414-9.

Chrapusta, S.J. and M. Walski, latrogenic Chlamydia infection-associated damage in the basilar arterial wall of the rat. Folia Histochem Cytobiol, 2002. 40(4): p. 385-7.

Damy, S.B., de Lourdes Higuchi, M., Timenetsky, J., Sambiase, N.V., Reis, M.M. and Ortiz, S.C., Coinfection of laboratory rats with Mycoplasma pulmonis and Chlamydia pneumoniae. Contemp Top Lab Anim Sci, 2003. 42(1): p. 52-6.

Ezzahiri, R., Nelissen-Vrancken, H.J., Kurvers, H.A., et al., Chlamydophila pneumoniae (Chlamydia pneumoniae) accelerates the formation of complex atherosclerotic lesions in Apo E3-Leiden mice. Cardiovasc Res, 2002. 56(2): p. 269-76.

Fang, J.C., Kinlay, S., Kundsin, R. and Ganz, P., Chlamydia pneumoniae infection is frequent but not associated with coronary arteriosclerosis in cardiac transplant recipients. Am J Cardiol, 1998. 82(12): p. 1479-83.

Fateh-Moghadam, S., Bocksch, W., Wessely, R., Jager, G., Hetzer, R. and Gawaz, M., Cytomegalovirus infection status predicts progression of heart-transplant vasculopathy. Transplantation, 2003. 76(10): p. 1470-4.

Fitzgerald, J.T., Gallay, B., Taranto, S.E., et al., Pretransplant recipient cytomegalovirus seropositivity and hemodialysis are associated with decreased renal allograft and patient survival. Transplantation, 2004. 77(9): p. 1405-11.

Gabriel, R., Selwyn, S., Brown, D., et al., Virus infections and acute renal transplant rejection. Nephron, 1976. 16(4): p. 282-6.

Hayry, P., Mennander, A., Tissala, S., Halttunen, J., Yilmaz, S. and Paavonen, T., Rat aortic allografts: an experimental model for chronic transplant arteriosclerosis. Transplant Proc, 1991. 23(1 Pt 1): p. 611-2.

Herrera, V.L., Shen, L., Lopez, L.V., Didishvili, T., Zhang, Y.X. and Ruiz-Opazo, N., Chlamydia pneumoniae accelerates coronary artery disease progression in transgenic hyperlipidemia-genetic hypertension rat model. Mol Med, 2003. 9(5-8): p. 135-42.

Jaremo, P. and A. Richter, Chlamydia pneumoniae lgG and the severity of coronary atherosclerosis. Eur J Intern Med, 2004. 15(8): p. 508-510.

Kloppenburg, G., de Graaf, R., Herngreen, S., Grauls, G., Bruggeman, C. and Stassen, .., Cytomegalovirus aggravates intimal hyperplasia in rats by stimulating smooth muscle cell proliferation. Microbes Infect, 2005. 7(2): p. 164-70.

Kotronias, D. and N. Kapranos, Herpes simplex virus as a determinant risk factor for coronary artery atherosclerosis and myocardial infarction. In Vivo, 2005. 19(2): p. 351-7.

Lautenschlager, I., Soots, A., Krogerus, L., et al., CMV increases inflammation and accelerates chronic rejection in rat kidney allografts. Transplant Proc, 1997. 29(1-2): p. 802-3. 
Lemstrom, K.B., Bruning, J.H., Bruggeman, C.A., Lautenschlager, I.T. and Hayry, P.J., Cytomegalovirus infection enhances smooth muscle cell proliferation and intimal thickening of rat aortic allografts. J Clin Invest, 1993. 92(2): p. 549-58.

Lemstrom, K.B., Bruning, J.H., Bruggeman, C.A., et al., Cytomegalovirus infection-enhanced allograft arteriosclerosis is prevented by DHPG prophylaxis in the rat. Circulation, 1994. 90(4): p. 1969-78.

Liu, L., Hu, H., Ji, H., Murdin, A.D., Pierce, G.N. and Zhong, G., Chlamydia pneumoniae infection significantly exacerbates aortic atherosclerosis in an LDLR-/- mouse model within six months. Mo Cell Biochem, 2000. 215(1-2): p. 123-8.

Lopez, C., Simmons, R.L., Mauer, S.M., Najarian, J.S., Good, R.A. and Gentry, S., Association of renal allograft rejection with virus infections. Am J Med, 1974. 56(3): p. 280-9.

Lotz, G., Simon, S., Patonai, A., Detection of Chlamydia pneumoniae in liver transplant patients with chronic allograft rejection. Transplantation, 2004. 77(10): p. 1522-8.

Mayr, M., Kiechl, S., Mandall, M.A., Willeit, J., Wick, G. and Xu, Q., Increased risk of therosclerosis is confined to CagA-positive Helicobacter pylori strains: prospective results from the Bruneck study. Stroke, 2003. 34(3): p. 610-5.

Mennander, A., Tiisala, S., Halttunen, J., Yilmaz, S., Paavonen, T. and Hayry, P., Chronic rejection in rat aortic allografts. An experimental model for transplant arteriosclerosis. Arterioscler Thromb, 1991. 11(3): p. 671-80.

Mitusch, R., Luedemann, J., Wood, W.G., Asymptomatic carotid atherosclerosis is associated with circulating chlamydia pneumoniae DNA in younger normotensive subjects in a general population survey. Arterioscler Thromb Vasc Biol, 2005. 25(2): p. 386-91.

O'Grady, J.G., Alexander, G.J., Sutherland, S., et al., Cytomegalovirus infection and donor/ recipient HLA antigens: interdependent co-factors in pathogenesis of vanishing bile-duct syndrome after liver transplantation. Lancet, 1988. 2(8606): p. 302-5.

Paul, L.C., Chronic rejection of organ allografts: magnitude of the problem. Transplant Proc, 1993. 25(2): p. 2024-5.

Pethig, K., Heublein, B., Wahlers, T. and Haverich, A., Mechanism of luminal narrowing in cardiac allograft vasculopathy: inadequate vascular remodeling rather than intimal hyperplasia is the major predictor of coronary artery stenosis. Working Group on Cardiac Allograft Vasculopathy. Am Heart J, 1998. 135(4): p. 628-33.

Pieniazek, P., Stepien, E., Sadowski, J., Impact of Chlamydia pneumoniae infection on survival rate after heart transplantation. Med Sci Monit, 2003. 9(2): p. CR67-72.

Potena, L., Grigioni, F., Ortolani, P., et al., Relevance of cytomegalovirus infection and coronaryartery remodeling in the first year after heart transplantation: a prospective three-dimensional intravascular ultrasound study. Transplantation, 2003. 75(6): p. 839-43.

Saikku, P., Leinonen, M., Mattila, K., et al., Serological evidence of an association of a nove Chlamydia, TWAR, with chronic coronary heart disease and acute myocardial infarction. Lancet, 1988. 2(8618): p. 983-6.

Saikku, P., Leinonen, M., Tenkanen, L., et al., Chronic Chlamydia pneumoniae infection as a risk factor for coronary heart disease in the Helsinki Heart Study. Ann Intern Med, 1992. 116(4): p. 273-8.

Sorlie, P.D., Nieto, F.J., Adam, E., Folsom, A.R., Shahar, E. and Massing, M., A prospective study of cytomegalovirus, herpes simplex virus 1 , and coronary heart disease: the atherosclerosis risk in communities (ARIC) study. Arch Intern Med, 2000. 160(13): p. 2027-32.
Subramanian, A.K., Quinn, T.C., Kickler, T.S., Kasper, E.K. and Tucker, P.C., Correlation of chlamydia pneumoniae infection and severity of accelerated graft arteriosclerosis after cardiac transplantation. Transplantation, 2002. 73(5): p. 761-4.

Tesi, R.J., Elkhammas, E.A., Henry, M.L., Davies, E.A., Salazar, A. and Ferguson, R.M., Acute rejection episodes: best predictor of long-term primary cadaveric renal transplant survival. Transplant Proc, 1993. 25(1 Pt 2): p. 901-2.

Tondella, M.L., Talkington, D.F., Holloway, B.P., et al., Development and evaluation of real-time PCR-based fluorescence assays for detection of Chlamydia pneumoniae. J Clin Microbiol, 2002. 40(2): p. $575-83$.

Vliegen, I., Stassen, F., Grauls, G., Blok, R., Bruggeman, C., MCMV infection increases early T-lymphocyte influx in atherosclerotic lesions in apoE knockout mice. J Clin Virol, 2002. 25 Suppl 2: p. S159-71.

Wimmer, M.L., Sandmann-Strupp, R., Saikku, P. and Haberl, R.L., Association of chlamydial infection with cerebrovascular disease. Stroke, 1996. 27(12): p. 2207-10.

Winters, G.L., Kendall, T.J., Radio, S.J., et al., Posttransplant obesity and hyperlipidemia: major predictors of severity of coronary arteriopathy in failed human heart allografts. J Heart Transplant, 1990. 9(4): p. 364-71.

Wittwer, T., Pethig, K., Heublein, B., et al., Impact of chronic infection with chlamydia pneumoniae on incidence of cardiac allograft vasculopathy. Transplantation, 2000. 69(9): p. 1962-4.

Zhu, J., Quyyumi, A.A., Norman, J.E., Costello, R., Csako, G. and Epstein, S.E., The possible role of hepatitis A virus in the pathogenesis of atherosclerosis. J Infect Dis, 2000. 182(6): p. 1583-7. 


\section{Chapter 6}

Adenoviral activin $\mathrm{A}$ expression prevents vein graft intimal hyperplasia in a rat model 


\section{Abstract}

Autologus vein grafts are commonly used for coronary artery bypass grafting and infrainguinal bypass procedures. Although initially a successful procedure long term patency rates are limited due to proliferation and migration of smooth muscle cells leading to the formation of a neointima occluding the lumen. Gene therapy aiming at preventing smooth muscle cell proliferation responsible for intimal hyperplasia has been a subject of many studies although none of them have seemed to be entirely successful. Activin A, a member of the transforming growth factor- $B$ super family, does enhance the expression level of SMC-specific alpha-actin markers, indicating that it promotes the contractile phenotype of these cells. Maintaining the contractile SMC phenotype would represent a novel strategy to prevent intimal hyperplasia as seen in venous graft failure.

Epigastric vein-to-common femoral artery interposition grafts were placed in rats. Two experimental groups ( $\mathrm{n}=10$ animals/group) were used. In the Activin A group adenoviral activin $\mathrm{A}\left(1 \times 10^{9}\right.$ Plaque Forming Units) was i.v. injected immediately after grafting. Animals in the control group were injected with a solution containing an empty Adenoviral vector $\left(1 \times 10^{9}\right.$ Plaque Forming Units). All animals were sacrificed three weeks after surgery and the grafts were harvested for morphometrical and immunohistochemical analysis.

Activin A overexpression immediately after surgery resulted in a significant decrease in intimal cross-sectional area and percentage stenosis as compared to the control group. BrdU staining indicated a much lower proliferation rate of the smooth muscle cells in the experimental group treated with activin A as compared to the control group.

We here show for the first time evidence of the ability of activin A to diminish vein graft failure in a rat model of epigastric to common femoral artery vein grafting, implying a novel strategy to prevent intimal hyperplasia as seen in venous graft failure.

\section{Introduction}

Over the last forty years autologus saphenous vein grafts have become common practice for coronary artery bypass grafting (CABG). Apart from its use in CABG, saphenous vein grafts are also used in infrainguinal bypass procedures in patient with critical limb ischemia. Although the initial results of these procedures are successful, the symptoms tend to recur due to degeneration and occlusion of the graft giving rise to $15-30 \%$ graft failure within one year and up to $50 \%$ of all grafts being occluded 10 years after surgery. Usually, early thrombosis occurs within the first month after implantation and is thought to be responsible for $20 \%$ of all failed grafts. Subsequently, intimal hyperplasia $(\mathrm{IH})$, defined as the accumulation of smooth muscle cells (SMC) and extracellular matrix in the intimal component of the vein, is the major disease process in the venous graft within the first year. This process of graft occlusion involves the migration of medial vascular smooth muscle cells to the lumen of the graft were they transform into a more synthetic phenotype. Then, these cells will start proliferating as well as secreting extra-cellular matrix proteins. These processes will ultimately result in the formation of a neointima. It has been strongly suggested that $\mathrm{IH}$ is associated with extensive endothelial denudation and destruction of venous grafts, resembling the response to injury as seen after PTCA often leading to restenosis of the denuded artery (Logerfo 1983).

Gene therapy aiming to prevent processes contributing to $\mathrm{IH}$, like smooth muscle cell proliferation, has been a subject of many studies. Nonetheless, none of the approaches attempted so far gave acceptable results. A novel mechanism to reduce $\mathrm{H}$ may be provided by the protein Activin A.

Activin $A$ belongs to the transforming growth factor- $B$ super family and was initially identified as a protein that induced the release of follicle-stimulating hormone by pituitary cells (Ling 1986, Vale 1986). Next, it has been demonstrated that the protein is involved in growth and differentiation of various cell types including endothelial cells, macrophages and SMC (MCCarthy 1993, Kozaki 1997, Kojima 1993). In separate studies, activin A has been shown to be expressed in atherosclerotic lesions of hyperlipidaemic rabbits as well as in human atherosclerotic lesions (Inoue 1994). In addition, enhanced activin expression was observed in the rat carotid artery after balloon injury Pawlowski (1997).

Even though activin A has been shown to inhibit the growth of endothelial cells, its effect on SMC proliferation is more controversial. Although some demonstrated that activin A enhances rat SMC DNA synthesis, others found no effect of activin A on 
rat SMC growth (Kojima 1993, Nakaoka 1997). The latter is supported by findings of Engelse and colleagues, who demonstrated that activin A augments the expression level of SMC-specific markers, indicating that it promotes the contractile phenotype of these cells (Engelse 1999).

Maintaining the contractile SMC phenotype would represent a novel strategy to prevent intimal hyperplasia as seen in venous graft failure. In this study we show the ability of activin $A$ to prevent venous graft failure in an experimental animal model.

\section{Materials and Methods}

\section{Animal conditions and vein grafting procedure}

Male inbred specific pathogen free (SPF) male Lewis (LEW) rats were obtained form the Department of Experimental Animal service of the University of Maastricht, the Netherlands. Experiments were carried out on animals aged 12 weeks weighing 250350 gram. Housing and care of the animals, and all the procedures used in this study were approved by the Ethical Committee for the Use of Experimental Animals of the institution, and are in accordance with the Guide for the Care and the Use of Laboratory Animals, published by the US National Institute of Health (NIH Publication No. 85-23, revised 1985). Rats were fed standard rat chow and tap water at libitum. All surgical procedures were performed under general anesthesia and using sterile techniques. Epigastric vein-to-common femoral artery interposition grafts were placed in rats by the use of a method similar to that described earlier by Hoch et al. (Hoch 1994). In brief each animal was anesthetized with an intraperitoneal (i.p.) injection of sodium pentobarbital $(60 \mathrm{mg} / \mathrm{kg}$ ). An $8 \mathrm{~mm}$ segment of relaxed ipsilateral epigastric vein was carefully harvested, gently irrigated with heparinized saline solution $(100 \mathrm{U} / \mathrm{ml})$, and placed as reverse interposition graft into a segmental $3 \mathrm{~mm}$ defect of the common femoral artery with 8 to 10 interrupted sutures of 11-0 nylon (Ethicon). The entire procedure was carried out with standard microsurgical techniques. The total ischemic time was kept to less than 30 min. Patency was verified by visual inspection.

\section{Experimental design}

An activin A-expressing adenovirus (Ad.activin) as well as an adenoviral construct carrying no insert (Ad.mock) were kindly provided by Dr. Paul Quax, (Gaubius Laboratory, TNO-PG, Leiden, the Netherlands). For further details regarding construction see Engelse et al. (Engelse 2002). Two experimental groups ( $\mathrm{n}=10$ animals/group) were used. Ad.activin $\left(1 \times 10^{9} \mathrm{PFU}\right)$ was i.v. injected immediately after grafting. Controls were injected with Ad. mock $\left(1 \times 10^{9} \mathrm{PFU}\right)$.

\section{Histological and morphometrical procedures}

Three weeks after surgery, rats were anaesthetized, the chest and abdominal cavities were opened and a catheter was inserted into the apex of the heart. Vessels were initially flushed with physiological salt solution and then perfusion fixed with 3,7\% formaldehyde in phosphate-buffered saline, pH 7.4, at physiological pressure (100 $\mathrm{mmHg}$ ). Vein grafts were removed and fixed overnight in the same fixative and routinely processed for paraffin embedding. Cross-sections $(4 \mu \mathrm{m})$ were taken for morphometrical analysis and haematoxylin-eosin or Lawson stained (average of three cross-sections per graft). Intimal and medial areas were quantified using a computer assisted morphometry system (analySIS ${ }^{\circledR}$, Soft Imaging System $\mathrm{GmbH}$, Muenster, Germany). The cross-sectional area of the media was defined as the area surrounded by the external and internal elastic lamina. The neointimal cross-sectional area was defined by the area surrounded by the internal elastic lamina and the arterial lumen. Percentage stenosis was defined as the percentage of cross-sectional area surrounded by the internal elastic lamina covered by neointima. Final scores were given as mean \pm SEM.

\section{Immunohistochemistry}

Paraffin-embedded sections $(4 \mu \mathrm{m})$, taken from vein grafts three weeks after surgery, were routinely processed and stained with the two-layer indirect immunoperoxidase technique using monoclonal antibodies (mAb). BrdU was injected intraperitoneally one day before sacrifice.

The following mAbs were used in this study: anti-a smooth muscle actin (ASMA, Sigma, Missouri, USA); and anti-BrdU (Sigma, Missouri, USA). To visualize smooth muscle cells, sections were pre-incubated with $2 \%$ bovine serum albumin (BSA) in phosphate-buffered saline (PBS) for $15 \mathrm{~min}$ at room temperature and treated with antigen retrieval buffer. To reveal cell proliferation sections were pretreated with $3 \%$ $\mathrm{H}_{2} \mathrm{O}_{2}$ in PBS for 15 min at $37^{\circ} \mathrm{C}$, followed by $\mathrm{HCl} 2 \mathrm{~N}$ for $30 \mathrm{~min}$ at $37^{\circ} \mathrm{C}$ and $0.4 \%$ pepsin in $0.01 \mathrm{~N} \mathrm{HCl}$ for $30 \mathrm{~min}$ at $37^{\circ} \mathrm{C}$. Monoclonals were diluted (ASMA 1/1500, anti-BrdU $1 / 500)$ in PBS and applied to the slides for $60 \mathrm{~min}$ at $37^{\circ} \mathrm{C}$. After three wash steps with PBS for 5 min, a biotinylated goat anti-mouse secondary antibody (1/1200, DAKO Glostrup Denmark) was applied for $30 \mathrm{~min}$ at room temperature. Finally, sections 
were incubated with alkaline phosphatase-coupled streptavidin ( $A B C$ reagent, Vector Laboratories), followed by immunodetection using fast red as a substrate. Finally, sections were counterstained with haematoxylin to visualize nuclei. Then, the presence of positive cells was analyzed by microscopy and scored semi-quantitatively by an observer blinded to the experimental groups. Representative cross-sections of the graft were analyzed and amount of proliferation was indicated by zero $\quad<10$ positive signals per section), $\oplus$ (10-50 positive signals per section), $\oplus \oplus$ (50-100 positive signals per section), $\oplus \oplus \oplus$ (>100 positive signals per section).

\section{Statistical analysis}

Morphometrical data and cell count numbers are expressed as mean \pm S.E.M. Values were compared using the Mann-Whitney $U$ test and $p<0.05$ was considered as statistically significant.

\section{Results}

\section{Animals and grafts}

None of the animals had apparent clinical signs of illness during the follow-up period. Starting body weight ranged from $250 \mathrm{~g}$ to $350 \mathrm{~g}$; at the end of the experiments animal weight ranged from $300 \mathrm{~g}$ to $375 \mathrm{~g}$. The overall graft patency rate was $90 \%$. Failures seemed related to early thrombosis. There were no significant differences in body weights or graft patency between the experimental groups (data not shown). There were no structural anomalies at the anastomotic regions of the grafts. The gross appearance of the veins and adjoining arteries was normal.

\section{Activin A prevents neo intimal hyperplasia}

Three weeks after bypass grafting all veins developed an increase in medial thickness $(10 \pm 2 \mu \mathrm{m}$ none grafted control vs. $36 \pm 3 \mu \mathrm{m}$ grafted control group) and showed neointimal thickening as compared to non-grafted controls. Activin A administration immediately after vein grafting resulted in a significant decrease in intimal crosssectional area and percentage stenosis at three weeks after surgery as compared to the control group (figure 1 ).
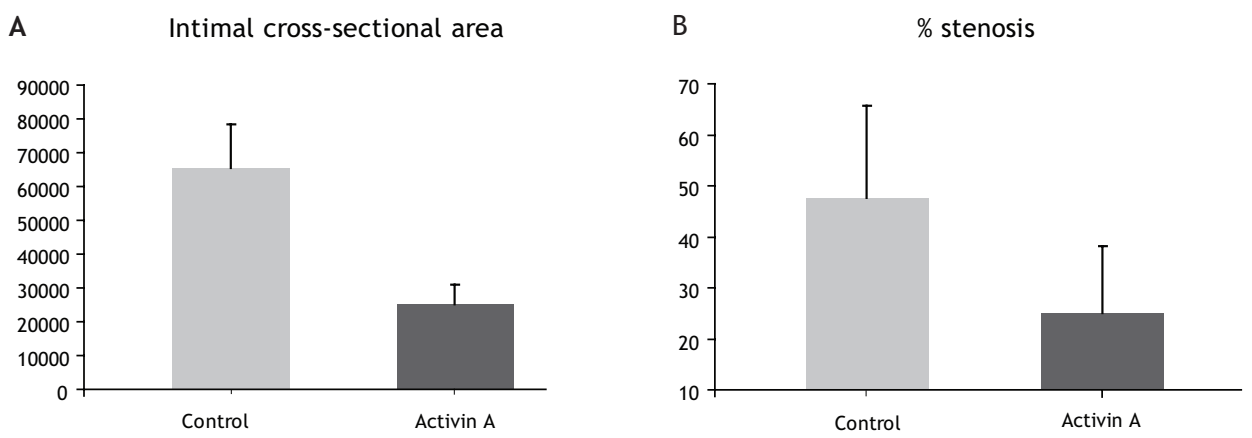

Figure1 | Effect of activin A administration on intimal cross-sectional area (A) and percentage stenosis (B) three weeks after vein grafting. ${ }^{*} P<0.05$ (values compared with control)
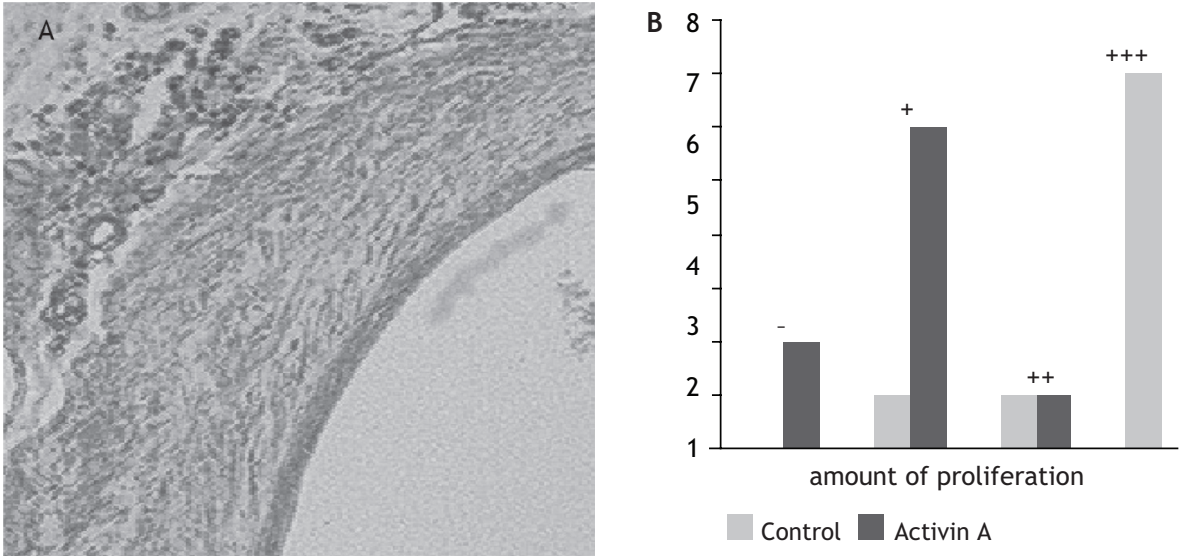

Figure 2 | (A) Alpha-actin smooth muscle cell staining of cross-section of the vein graft three weeks after surgery, activin A group. (B). Semiquantative analysis of proliferation measured by BrdU staining. Bars stand for number of sections representing indicated amount of proliferation. (see page 171 for color picture)

\section{ASMA and BrdU staining}

Alpha-actin smooth muscle cell staining revealed that the medial and neointimal layer in both activin A-treated and control rats predominantly consisted of smooth muscle cells (figure 2A). Furthermore, the result of the BrdU staining indicated a significantly lower proliferation rate of the smooth muscle cells in de experimental group treated 
with activin $A$ as compared to the non-treated control group suggesting that the overexpression of activin A prevents excessive proliferation of smooth muscle cells and in that way intimal hyperplasia (figure 2B).

\section{Discussion}

Although used for several decades, autologous saphenous vein grafts have a reduced long term patency as compared to arterial revascularisation with internal thoracic artery grafts. Nonetheless, as saphenous veins are usually more accessible than arterial segments, the availability of an easy to apply intervention to improve the long-term patency rates of vein grafts would be a major advance for cardiac and vascular surgery and its patients. Saphenous graft failure can be considered as a trimodel disease. Early graft failure occurs within the first months after surgery and is predominantly caused by thrombotic events often due to mechanical trauma during vein harvesting. Late graft failure tends to occur after several years and is caused by accelerated atherosclerosis. These causes may be treated with currently available antiplatelet and lipid lowering drug therapy which has been proven to be successful in several clinical studies (Christenson 2001, Paz 1993). Intermediate failure of saphenous vein grafts is due to neointimal hyperplasia which is most prominent in the first year after surgery but can occur up to three years after CABG (Barboriak 1978). Excessive proliferation and migration of several vascular cell types (e.g. vascular smooth muscle cells, endothelial cells, myofibroblasts) are important components in vascular remodeling and associated pathologies, including angiogenesis, atherosclerosis, and restenosis following percutaneous translumina coronary angioplasty (PTCA) (Schwartz 1990, Ross 1993, Schwartz 1997). In this study we show for the first time evidence of the ability of activin A to diminish excessive SMC hyperplasia in a rat model of epigastric to common femoral artery vein grafting.

Along with transforming growth factor (TGF)- $B$ and bone morphogenetic protein, activin $A$ is a member of the TGF-B super family (Chen 2002). Although initially identified as a protein that induces the release of follicle-stimulating hormone by pituitary cells, recent studies suggest that this cytokine is also involved in atherogenesis. For example, it has been revealed that activin $\mathrm{A}$ promotes plaque stability by regulating the expression of scavenger receptor mRNA, thereby inhibiting foam cell formation, or by inducing a contractile, non-proliferative smooth muscle cell phenotype in culture (Engelse 1999).
This latter effect of activin A might be of importance as a new therapeutic strategy towards enhanced long term patency rates in venous grafts. After all, the process of vein graft occlusion involves the transition of vascular smooth muscle cells from a contractile to a more synthetic phenotype, a phenotype which is characterized by proliferation and secretion of various extra-cellular matrix proteins ultimately resulting in the formation of a neointima. Thus, maintaining VSMC in a more contractile phenotype by over-expressing activin A might be an attractive novel strategy to prevent intimal hyperplasia as seen in venous graft failure.

Indeed, we were able to demonstrate that in the vein grafts of rats, injected with an activin A expressing adenovirus, smooth muscle cell proliferation was significantly diminished. Furthermore, and more importantly, intimal cross-section area and $\%$-stenosis were significantly reduced in activin A treated rats. These data suggest that activin A plays a role in controlling smooth muscle cell (de-)differentiation and proliferation, which is in accordance with data published earlier. In the rat carotid injury model, activin A expression increased already a few hours after injury and activin A immunoreactivity could be found in the developing neointimal (Pawlowski 1997). Also, enhanced expression of activin A strongly reduced the formation of a neointima in cultured human saphenous vein segments or in mice with cuffed femoral arteries (Engelse 2002)

\section{Therapeutic potential}

Taken together, our results suggest that activin A might be an attractive candidate for new therapeutic avenues to prevent vein graft failure. Administration of activin in the early period after surgery might be a useful treatment to prevent neointimal formation and subsequent graft failure. Nevertheless, there might be some drawbacks in this strategy. Despite the reported beneficial effects in cardiovascular disease, recent studies provided compelling evidence for important roles of activin in inflammation, tissue repair and fibrosis (Werner 2006). In particular, the findings that activin A may promote liver, kidney and lung fibrosis when abundantly present, suggests that we should consider some restraint with respect to the therapeutic applicability of the protein.

\section{Limitations of the study}

It is generally assumed that the major target for adenoviruses is the hepatic tissue. This results in high expression mRNA levels and protein in the liver as well as enhanced plasma concentration. Although Engelse et al. demonstrated that the adenovirus used 
in the present study had indeed these characteristics in mice, we didn't examine the presence of the protein in either plasma or liver tissue (Engelse 2002). Therefore, the evidence that the observed effect can be fully attributed to enhanced activin A levels is circumstantial. Furthermore, additional experiments are required before the observed effects can be entirely accredited to an increased production of activin. For example, simultaneous injections with follistatin, which sequesters activin $A$ and thus inhibits its biological activity, should prevent the beneficial effects of activin A on intima hyperplasia.

In conclusion, we here show for the first time evidence for the ability of activin A to diminish vein graft failure in a rat model of epigastric to common femoral artery vein grafting. However, due to the possible side effects of high activin concentrations, in particular in tissue fibrosis, additional studies are required to further determine the therapeutic potential of this protein.

\section{References}

Barboriak JJ, Pintar K, Van Horn DL, Batayias GE, Korns ME. Pathologic findings in the aortocoronary vein grafts. A scanning electron microscope study. Atherosclerosis. 1978;29(1):69-80.

Chen YG, Lui HM, Lin SL, Lee JM, Ying SY. Regulation of cell proliferation, apoptosis, and carcinogenesis by activin. Exp Biol Med (Maywood). 2002;227(2):75-87.

Christenson JT. Preoperative lipid control with simvastatin reduces the risk for graft failure already 1 year after myocardial revascularization. Cardiovasc Surg. 2001;9(1):33-43.

Engelse MA, Neele JM, van Achterberg TA, van Aken BE, van Schaik RH, Pannekoek H, de Vries CJ. Human activin-A is expressed in the atherosclerotic lesion and promotes the contractile phenotype of smooth muscle cells. Circ Res. 1999;85(10):931-9.

Engelse MA, Lardenoye JH, Neele JM, Grimbergen JM, De Vries MR, Lamfers ML, Pannekoek H, Quax PH, De Vries CJ. Adenoviral activin a expression prevents intimal hyperplasia in human and murine blood vessels by maintaining the contractile smooth muscle cell phenotype. Circ Res. 2002;90(10):1128-34

Hoch JR, Stark VK, Hullett DA, Turnipseed WD. Vein graft intimal hyperplasia: leukocytes and cytokine gene expression. Surgery. 1994;116(2):463-70; discussion 470-1.

Inoue S, Orimo A, Hosoi T, Ikegami A, Kozaki K, Ouchi Y, Nomura S, Muramatsu M, Orimo H. Demonstration of activin-A in arteriosclerotic lesions. Biochem. Biophys. Res. Commun. 1994;205:441-8

Kojima I, Mogami H., Kawamura N., Yasuda H., Shibata H. Modulation of growth of vascular SMC by activin A. Exp. Cell Res 1993;206:152-6.

Kozaki K, Akishita M, Eto M, Yoshizumi M, Toba K, Inoue S, Ishikawa M, Hashimoto M, Kodama $T$, Yamada N, Orimo H, Ouchi Y. Role of activin-A and follistatin in foam cell formation of THP-1 macrophages. Arterioscler. Thromb. Vasc. Biol. 1997;17:2389-94.
Ling N, Ying SY, Ueno N, Shimasaki S, Esch F, Hotta M, Guillemin R. Pituitary FSH is released by a heterodimer of the beta-subunits from the two forms of inhibin. Nature 1986;321:779-82.

LoGerfo FW, Quist WC, Cantelmo NL, Haudenschild CC. Integrity of vein grafts as a function of initial intimal and medial preservation. Circulation. 1983;68(3 Pt 2):11117-24.

McCarthy S.A., Bicknell R. Inhibition of vascular EC's growth by activin-A. J. Biol. Chem. 1993;268:23 66-71.

Nakaoka T, Gonda K, Ogita T, Otawara-Hamamoto Y, Okabe F, Kira Y, Harii K, Miyazono K, Takuwa $Y$, Fujita $T$. Inhibition of rat vascular smooth muscle proliferation in vitro and in vivo by bone morphogenetic protein-2. J Clin Invest. 1997;100(11):2824-32.

Pawlowski JE, Taylor DS, Valentine M, Hail ME, Ferrer P, Kowala MC, Molloy CJ. Stimulation of activin A expression in rat aortic SMC's by thrombin and angiotensin II correlates with neointima formation in vivo. J. Clin. Invest. 1997;100(3):639-48.

Paz MA, Lupon J, Bosch X, Pomar JL, Sanz G. Predictors of early saphenous vein aortocoronary bypass graft occlusion. The GESIC Study Group. Ann Thorac Surg. 1993;56(5):1101-6.

Ross R. The pathogenesis of atherosclerosis: a perspective for the 1990s. Nature. 1993 29;362(6423):801-9.

Schwartz RS, Murphy JG, Edwards WD, Camrud AR, Vliestra RE, Holmes DR. Restenosis after balloon angioplasty. A practical proliferative model in porcine coronary arteries. Circulation. 1990;82(6):2190-200.

Schwartz SM. Smooth muscle migration in atherosclerosis and restenosis. J Clin Invest. 1997; 100(11 Suppl):S87-9.

Vale W, Rivier J, Vaughan J, McClintock R, Corrigan A, Woo W, Karr D, Spiess J. Purification and characterization of an FSH releasing protein from porcine ovarian follicular fluid. Nature 1986;321:776-9.

Werner S, Alzheimer C. Roles of activin in tissue repair, fibrosis, and inflammatory disease. Cytokine Growth Factor Rev. 2006;17(3):157-71. 


\section{Chapter 7}

General discussion 


\section{General discussion}

Evidence linking ubiquitous viruses, like members of the human herpes virus family, to cardiovascular diseases has been mounting since the late 1970's observation that an avian herpes virus is able to initiate and aggravate atherosclerosis in chickens (Fabricant 1978). Since this original observation, multiple pathogens have been linked to coronary and peripheral artery disease as well as myocardial infarction and solid organ transplant dysfunction (Ellis 1997, Mattila 1998, Rubin 2001).

Next to the herpes virus cytomegalovirus (CMV), whose role in cardiovascular disease is fairly established, Chlamydia pneumoniae is the best characterized microorganism associated with cardiovascular diseases. This association was initially described by Saikku et al. (Saikku 1988) in the late 1980's and since then confirmed by many others (recently reviewed by Watson and Alp) (Watson 2008).

Apart from their suggested contribution to "naïve" atherosclerosis, seroepidemiological evidence also points towards a role for CMV and C. pneumoniae in other cardiovascular complications, like restenosis, venous graft failure or transplantation arteriosclerosis, which to predominantly result from surgical interventions. As intimal hyperplasia, which is considered to be the major determining factor in limiting the long term success rate of these interventions, is a general factor in all these different pathologies, it may be speculated that pathogens stimulate the processes underlying the formation of a neointima. Nonetheless, a causal relationship between these microorganisms and intima hyperplasia is still a matter of debate. Moreover, animal models shedding light on a more causal relationship between these two pathogens and intimal hyperplasia, if any, are scarce and do not all point in the same direction. Therefore, one of the main objectives of the present thesis was to elucidate and unravel the mechanisms of interplay between $C$. pneumoniae, CMV and intimal hyperplasia. Additionally, we tried a novel approach to diminishing intimal hyperplasia as seen in vein graft failure.

\section{CMV aggravates restenosis and venous graft failure}

Data presented in this thesis confirm the hypothesis that CMV is able to aggravate both restenosis and venous bypass failure and offers additional insights in the relationship between CMV infection and intimal hyperplasia (chapter 2 and 3 ).

Regarding restenosis, this process can be considered as a tri-phase disease consisting of: (1) proliferation of SMC's in the media, (2) migration of SMC's from the media to luminal surface and (3) proliferation of SMC's in the neointima. To study the effect of CMV on this process, we used a rat model of photochemicallyinduced endothelial injury to mimic thrombus formation and SMC's proliferation as seen after balloon angioplasty (chapter 2). Inspired by previous findings which showed an enhanced susceptibility of proliferating SMC's for CMV (Persoons 1997), we infected the animals at two different time points, i.e. prior to the stage when medial SMC proliferation is maximal or preceding the phase of maximal proliferation in the intima. Our data indicated that proliferating SMC are indeed predominantly susceptible for CMV infection and that the effect of CMV on these cells is primarily responsible for the observed effect of the virus on the process of restenosis. When rats were infected immediately after injury, medial but not neointimal cross-sectional areas were significantly increased in infected rats. Alternatively, infection prior to the second wave of proliferation enhanced the neointimal but not the medial area suggesting that CMV infection indeed primarily affects SMC cell proliferation. This is supported by the results concerning cellularity of the different layers which revealed that the increase in cross-sectional area was due to smooth muscle cell hyperplasia instead of hypertrophy. Whether this effect is due to a direct effect of the virus on the vessel wall or to an indirect effect through activation of the immune system following infection remains to be established. We addressed this question to some extent by determining the presence of CMV DNA in the injured vessel at various time points post infection. Only limited amounts of CMV DNA could be detected in the injured vessel. In contrast, high amounts were found in liver, spleen and salivary gland indicating that the infection procedure had been successful. These findings are in accordance with earlier results by Zhou et al., who also demonstrated an increased neointimal response in the rat carotid artery following balloon injury without significant amounts of virus present in the vessel wall and suggest that immune activation following CMV infection may be more important than direct effects of the virus (Zhou 1999, 2000). This will be discussed in more detail later in this section.

Taken into account the effects of CMV infection on the process of restenosis we hypothesized that CMV might also aggravate intimal hyperplasia in other vascular pathologies like venous bypass failure. Although this hypothesis is supported by some sero-epidemiological studies, experimental data demonstrating a causal relationship between CMV infection and venous bypass graft failure are lacking (Westphal 2006, Ibrahim 2005). We addressed this issue in chapter 3 in which we used the well-defined rat epigastric vein-to-common femoral artery graft model to investigate to possible role of $C M V$ in venous graft failure. This model is characterized by a marked increase in the medial cross-sectional area of the venous wall when compared to a naïve veins 
(Hoch 1994). Also in our hands a pronounced neointimal thickening was observed in all grafted veins at three weeks after surgery. Moreover, CMV infection immediately after vein grafting resulted in a significant increase in intimal cross-sectional area, medial cross-sectional area and medial wall thickness further supporting the hypothesis that CMV affects intimal hyperplasia

\section{C. pneumoniae infections affects venous bypass failure, but not} transplant arteriosclerosis

So, in both models we were able to demonstrate that CMV enhances the formation of a neoinitima. The issue we addressed next was whether $C$. pneumoniae was likewise able to affect this process. Previously, it has been shown that this obligate intracellular micro-organism, like CMV, is able to enhance or even initiate plaque formation in (atherosclerotic) animal models (Ezzahiri 2002). Yet, apart from some sero-epidemiological studies, little is known on the possible effects of $C$. pneumoniae on intima hyperplasia (Rupp 2005, Bartels 200). In chapter 4 we present for the first time direct experimental evidence for a role of $C$. pneumoniae in the process of venous graft failure. Using the epigastric vein-to-common femoral artery interposition graft rat model we demonstrated that $C$. pneumoniae administration immediately after vein grafting resulted in a significant increase in medial cross-sectional area, wall thickness and total wall area at three weeks after surgery as compared to the control group. Interestingly, and in accordance with our observations in the CMV experiments, $C$. pneumoniae infections also induced smooth muscle hyperplasia but not hypertrophy or edema as the total number of cells $/ \mu \mathrm{m}^{2}$ in the graft remained constant. In line with this is the recent observation that $C$. pneumoniae infection promotes a proliferative phenotype in the vasculature which makes $C$. pneumoniae also a likely risk factor for vein graft failure (Rupp 2005, Hirono 2003).

Remarkably however, and in contrast to our expectations, our results do not point towards an effect of $C$. pneumoniae on chronic transplant dysfunction. Previously, it has been demonstrated convincingly by us and by others that CMV is well capable to affect the viability of solid organ transplants in a negative way (for review see Streblow 2007). Likewise, it has been shown that CMV enhances transplant arteriosclerosis in a rat aortic allograft model (Bruning 1994, Lemström 1993). We used this latter model to study the effect of $C$. pneumoniae on transplant arteriosclerosis. However, no clear effects of $C$. pneumoniae on either myointimal hyperplasia or vascular inflammation were observed despite the fact that the infection had been successful and $C$. pneumoniae DNA copies could even be demonstrated in some grafts. Thus, although $C$. pneumoniae infection did augment the formation of the neointima in vein grafts, no effects were observed in arterial grafts. The reason for this discrepancy is still unclear.

\section{Molecular mechanisms involved in pathogen-associated enhancement of intima hyperplasia}

Previously, various molecular mechanisms have been associated with infection-related enhancement of neointima formation. Nevertheless, most of these mechanisms have been established in isolated cells or other in vitro models. Yet, in our intact rat models only very limited amounts of either CMV or C.pneumoniae DNA copies could be detected in both arterial and venous grafts. This may limit the importance of previously reported direct effects of $\mathrm{CMV}$ or $C$. pneumoniae on vascular cells. In contrast, indirect immune-related mechanisms may be more important, which is in agreement with findings by Vliegen et al., who demonstrated in a mouse model of atherosclerosis that injection of non-infectious (UV-inactivated) virus was able to increase atherosclerotic lesion size (Vliegen 2005). Indeed, CMV-induced immune activation may also contribute to the process of restenosis as shown by the ability of CMV to increase intimal hyperplasia in the absence of detectable virus at the site of injury. This is supported by the observation in in-vitro infected cell cultures that up-regulation of adhesion molecules occurs on the surface of non-infected neighbouring cells (Dengler 2000). The same phenomenon is seen in response to supernatant from infected cultures, suggesting a paracrine mechanism of activation. In addition, infection induces production of pro-inflammatory cytokines such as IL-12, IL-18, TNF- $\alpha$ and IFN- $\gamma$ by several cell-types including monocytes, SMC and endothelial cells. Although the exact role of IL-12 and IL-18 in the formation of a neointima has to be established, it is well known that these cytokines play a crucial role in activating NK- and T-cells with subsequent production of IFN-Y (Smith 1992, Woodroffe 1993, Whitman 2002). This will ultimately result in activation of macrophages which play an important role in aggravating vein graft intimal hyperplasia as was demonstrated earlier by Hoch et al. (Hoch 1999). Furthermore, additional support for a role for IL-18 comes from studies demonstrating that IL-18 affects smooth muscle cell proliferation and, most importantly, neutralization of IL-18 reduces restenosis in a rat carotid artery balloon model (Maffia 2006). Additionally, infections in patients with coronary disease are associated with increased serum concentrations of IL-6, a pro-inflammatory cytokine which has been implicated in the development of vascular diseases with high levels of IL-6 expression observed in atherosclerotic lesions of venous bypass grafts (Almeida 1994, Gredmark 2007). 
Together with direct effects induced by presence of microbes in the vascular wall and indirect effects involving systemic cytokine induction, autoimmunity may contribute to the aggravated intimal hyperplasia after infection. For example, antibodies directed against CMV modulate the expression of genes coding for molecules involved in activation and apoptosis of endothelial cells (Lunardi 2007). Also, inactivated virus is able to induce T cell influx and increase plaque formation in mouse model of atherosclerosis (Vliegen 2005). A persistent $C$. pneumoniae infection is accompanied by an increased production of chlamydial Heat Shock Protein 60 (cHSP60), which may induce antigenic mimicry (Mayr 1999). Also, persistent production of CHSP60 may result in chronic immune stimulation in the vascular wall and the release of local and systemic cascades of inflammatory cytokines (Kol 1999). Alternatively, host-derived HSP60 may also play a role in neointima formation. HSP60 is expressed in the normal vessel wall and can be up-regulated under stressed conditions such as infection. Autoantibodies directed against expressed HSP60 may cause endothelial cell lysis (Schett 1995). Furthermore, it has been demonstrated that HSP60 is a potent inducer of SMC proliferation (de Graaf 2006, Sasu 2001). Similar effects have been attributed to C-reactive protein (CRP) (Kuji 2007). In Chapter 4, we addressed such a possible role for HSP60 and CRP in our venous bypass graft model. Although we were able to demonstrate the presence of both CRP and HSP60 in venous graft, difference between experimental and control groups never reached statistical significance.

In summary, we were able to show a persistent effect of infection on neointima formation in the models we used. As only limited amounts of either viral or bacterial DNA could be detected in either arterial or venous grafts questions whether microbes affect the process at a local levels and points towards a role for systemic immune activation. Nonetheless the hypothesis that infection-induced activation of the immune reaction is responsible for aggravating restenosis and venous bypass failure as seen in our studies remains to be established and further research is required challenging this hypothesis.

\section{Treatment}

\section{The synthetic malononitrilamide FK778}

Since it is known that CMV infection plays a role in intimal hyperplasia it would be interesting to have a drug able to prevent not only intimal hyperplasia, but also inhibit the aggravating effects of CMV infections on this process. Previous studies reported that the immunosuppressive drug FK778, similar to the active metabolite of leflunomide but with a clinically relevant shorter serum half-life, exerts antiviral activity against CMV (Evers 2005, Zeng 2005). Furthermore, besides being immunosuppressive and antiviral, vasculoprotective properties have also been attributed to FK778. More precisely, it has been shown that FK778 is able to inhibit SMC proliferation. In various experimental models it has been demonstrated that FK778 effectively attenuates vascular responses to injury by diminishing neointima formation and fibrointimal hyperplasia, perhaps through inhibition of the receptor tyrosine kinase activity in vascular SMC or their progenitors (Jahnke 2005, Pan 2003). All this inspired us to study the therapeutic potential of the immunosuppressive/ anti-proliferate drug FK778 in preventing intimal hyperplasia with or without a concomitant CMV infection. We demonstrated that FK778 is able to partially prevent intimal hyperplasia in a venous bypass graft in non-infected animals, while the drug was also able to reverse the additional effect of a concomitant CMV infection on intimal hyperplasia (chapter 3). Unfortunately, the effect of FK778 on CMV dissemination was not established in this study. Therefore, additional studies are required to determine in more detail whether the effect of FK778 was predominantly due to its anti-proliferative effect or to its antiviral effect. Nevertheless, from these results and recent data from other animals studies as well as clinical trials it appears that FK778 is a promising therapeutic to prevent acute allograft rejection and vascular remodelling after mechanical intimal injury.

\section{Activin A prevents vein graft failure}

Intimal hyperplasia due to SMC proliferation is considered to be the main reason of graft failure. Therefore, gene therapy aiming at the prevention of SMC proliferation could potentially increase graft patency rates. Based on the observation that it modulates smooth muscle cell and macrophage proliferation and differentiation, it has been suggested that enhanced expression of activin $A$, a member of the transforming growth factor- $B$ super family, might be a potential therapeutic avenue to treat vascular pathologies characterized by prominent smooth muscle proliferation (Engelse 1999). Indeed, in a femoral artery cuff model the formation of a smooth muscle cell-rich neointima was dramatically reduced in mice that were injected with adenoviral vehicles encoding activin A (Ad.activin A) (Engelse 2002). In chapter 6 we used a similar approach to study whether overexepression of activin A prevents intima hyperplasia in the epigastric vein-to-common femoral artery interposition graft. 
Ad.activin A administration immediately after vein grafting resulted in a significant decrease in intimal cross-sectional area and percentage stenosis as compared to the control group. Alpha-actin smooth muscle cell staining revealed that the medial and neointimal layer predominantly consisted of smooth muscle cells. Furthermore, the result of BrdU staining indicated a significantly lower proliferation rate of the smooth muscle cells in de experimental group treated with activin A. Thus, in accordance with previously published data, our results suggest that activin A counteracts neointima formation and might accordingly help to maintain the integrity of venous bypass grafts. Nevertheless, although the role of activin A in diminishing intimal hyperplasia seems promising, care should be taken in clinical use as many other functions have been attributed to activin, including its involvement in apoptosis, metabolism, homeostasis, immune response, wound repair and endocrine function (Chen 2006, Sulyok 2005).

\section{Concluding remarks and perspectives}

Intimal hyperplasia is considered to be the major determining factor limiting long term success after PTCA, venous bypass grafting and solid organ transplantation. In this thesis we provide data that although the underlying cause may be multifactorial, infections with $C$. pneumoniae and CMV certainly aggravate intimal hyperplasia in experimental animal models of restenosis and venous graft failure. In contrast to the established relation between CMV and transplantation arteriosclerosis, our data suggest that $C$. pneumoniae infection may be of minor importance for the severity of transplantation arteriosclerosis as seen in the rat aortic allograft model.

Furthermore we were able to demonstrate the $C$. pneumoniae and $\mathrm{CMV}$ infection are able to stimulate SMC proliferation in vivo. Importantly, these induced effects even occur when there are only low amounts of pathogen present in the vessel wall, suggesting that inflammatory and immune responses to infections are more important in exaggerating the response to vascular injury than the pathogen itself. However further studies are required to unravel these exact underlying mechanisms.

Additionally we proved the potential effect of a new immunosuppressive, antiviral and anti-proliferative agent FK778 to prevent intimal hyperplasia and its ability to diminish the CMV induced effects rendering it a possible therapeutic candidate in the field of transplantation. In this thesis we also demonstrated gene therapy aiming at preventing intimal hyperplasia to be effective in reducing intimal hyperplasia as seen in venous graft failure.
To conclude we and others demonstrated a causal role for infections in cardiovascular pathologies initiated by intimal hyperplasia and suggest that therapies aimed against these pathogens may diminish disease progression, unfortunately evidence arising from sero-epidemiologic and experimental studies still largely have to be proven in clinical trials.

\section{References}

Almeida GD, Porada CD, St Jeor S, Ascensao JL. Human cytomegalovirus alters interleukin-6 production by endothelial cells. Blood 1994;83:370-6.

Bartels, C., Maas, M., Bein, G., Brill, N., Bechtel, J.F., Leyh, R., Sievers, H.H., Association of serology with the endovascular presence of Chlamydia pneumoniae and cytomegalovirus in coronary artery and vein graft disease. Circulation. $2000 \mathrm{Jan}$ 18;101(2):137-41.

Bruning JH, Persoons M, Lemström K, Stals FS, De Clercq E, Bruggeman CA. Enhancement of transplantation-associated atherosclerosis by $\mathrm{CMV}$, which can be prevented by antiviral therapy in the form of HPMPC. Transpl Int. 1994;7 Suppl 1:S365-70.

Chen YG, Wang Q, Lin SL, Chang CD, Chung J, and Ying SY. Activin Signaling and its Role in Regulation of Cell Proliferation, Apoptosis and Carcinogenesis. Exp Biol Med. 2006; 231: 534-544.

Dengler TJ, Raftery MJ, Werle M, Zimmermann R, Schönrich G. Cytomegalovirus infection of vascular cells induces expression of pro-inflammatory adhesion molecules by paracrine action of secreted interleukin-1beta. Transplantation. 2000 Mar 27;69(6):1160-8.

Ellis RW. Infection and coronary heart disease. J Med Microbiol. 1997 Jul;46(7):535-9.

Engelse MA, Neele JM, van Achterberg TA, van Aken BE, van Schaik RH, Pannekoek H, de Vries CJ. Human activin- $A$ is expressed in the atherosclerotic lesion and promotes the contractile phenotype of smooth muscle cells. Circ Res. 1999 Nov 12;85(10):931-9.

Engelse MA, Lardenoye JH, Neele JM, et al. Adenoviral activin a expression prevents intimal hyperplasia in human and murine blood vessels by maintaining the contractile smooth muscle cell phenotype. Circ Res. 2002 May 31;90(10):1128-34.

Evers DL, Wang X, Huong SM, Andreoni KA, Huang ES. Inhibition of human cytomegalovirus signaling and replication by the immunosuppressant FK778. Antiviral Res. 2005 Jan;65(1):1-12

Ezzahiri R, Nelissen-Vrancken HJ, Kurvers HA, Stassen FR, Vliegen I, Grauls GE, van Pul MM, Kitslaar PJ, Bruggeman CA. Chlamydophila pneumoniae (Chlamydia pneumoniae) accelerates the formatio of complex atherosclerotic lesions in Apo E3-Leiden mice. Cardiovasc Res. 2002 Nov;56(2):269-76.

Fabricant CG, Fabricant J, Litrenta MM, Minick CR. Virus-induced atherosclerosis. J Exp Med. 1978 Jul 1;148(1):335-40

de Graaf R, Kloppenburg G, Kitslaar PJ, Bruggeman CA, Stassen F. Human heat shock protein 60 stimulates vascular smooth muscle cell proliferation through Toll-like receptors 2 and 4. Microbes Infect. 2006 Jun;8(7):1859-65.

Gredmark S, Jonasson L, Van Gosliga D, Ernerudh J, Söderberg-Nauclér C. Active cytomegalovirus replication in patients with coronary disease. Scand Cardiovasc J. 2007 Aug; 41 (4):230-4.

Hirono, S., Dibrov, E., Hurtado, C., Kostenuk, A., Ducas, R., Pierce, G.N., Chlamydia pneumoniae 
stimulates proliferation of vascular smooth muscle cells through induction of endogenous heat shock protein 60. Circ Res. 2003 Oct 17;93(8):710-6.

Hoch JR, Stark VK, Hullett DA, Turnipseed WD. Vein graft intimal hyperplasia: leukocytes and cytokine gene expression. Surgery. 1994 Aug;116(2):463-70

Hoch JR, Stark VK, van Rooijen N, Kim JL, Nutt MP, Warner TF. Macrophage depletion alters vein graft intimal hyperplasia. Surgery. 1999 Aug; 126(2):428-37.

Ibrahim Al, Obeid MT, Jouma MJ, Moasis GA, Al-Richane WL, Kindermann I, Boehm M, Roemer K, Mueller-Lantzsch N, Gärtner BC. Detection of herpes simplex virus, cytomegalovirus and EpsteinBarr virus DNA in atherosclerotic plaques and in unaffected bypass grafts. J Clin Virol. 2005 Jan;32(1):29-32

Jahnke T, Schafer FK, Bolte H, et al. 2005 Dr. Gary J. Becker Young Investigator Award: periprocedural oral administration of the leftunomide analogue $\mathrm{F} 778$ inhibits neointima formation a double-injury rat model of restenosis. J Vasc Interv Radiol. 2005; 16: 903-10.

Kol A, Bourcier T, Lichtman AH, Libby P. Chlamydial and human heat shock protein $60 \mathrm{~s}$ activate human vascular endothelium, smooth muscle cells, and macrophages. J Clin Invest. 1999 Feb;103(4):571-7.

Kuji T, Masaki T, Li L, Cheung AK. Expression of C-reactive protein in myointimal hyperplasia in a porcine arteriovenous graft model. Nephrol Dial Transplant. 2007 Sep;22(9):2469-75.

Lemström KB, Bruning JH, Bruggeman CA, Lautenschlager IT, Häyry PJ. Cytomegalovirus infection enhances smooth muscle cell proliferation and intimal thickening of rat aortic allografts. J Clin Invest. 1993 Aug; $92(2): 549-58$

Lunardi C, Dolcino M, Peterlana D, Bason C, Navone R, Tamassia N, Tinazzi E, Beri R, Corroche R, Puccetti A. Endothelial cells' activation and apoptosis induced by a subset of antibodies agains human cytomegalovirus: relevance to the pathogenesis of atherosclerosis. PLOS ONE. 2007 May 30;2(5):e473.

Maffia P, Grassia G, Di Meglio P, Carnuccio R, Berrino L, Garside P, Ianaro A, Ialenti A. Neutralization of interleukin-18 inhibits neointimal formation in a rat model of vascular injury. Circulation. 2006 Aug 1;114(5):430-7.

Mattila KJ, Valtonen VV, Nieminen MS, Asikainen S. Role of infection as a risk factor for atherosclerosis, myocardial infarction, and stroke. Clin Infect Dis. 1998 Mar;26(3):719-34.

Mayr M, Metzler B, Kiechl S, Willeit J, Schett G, Xu Q, Wick G. Endothelial cytotoxicity mediated by serum antibodies to heat shock proteins of Escherichia coli and Chlamydia pneumoniae: immune reactions to heat shock proteins as a possible link between infection and atherosclerosis. Circulation. 1999 Mar 30:99(12):1560-6.

Pan F, Ebbs A, Wynn C et al. FK778, a powerful new immunosuppressant, effectively reduce functional and histological changes of chronic rejection in rat renal allografts. Transplantation. 2003; 75:1110-4.

Persoons MC, Daemen MJ, van Kleef EM, Grauls GE, Wijers E, Bruggeman CA. Neointimal smooth muscle cell phenotype is important in its susceptibility to cytomegalovirus (CMV) infection: a study in rat. Cardiovasc Res. 1997 Nov; 36(2):282-8

Rubin RH. Cytomegalovirus in solid organ transplantation. Transpl Infect Dis. 2001;3 Suppl 2:1-5.

Rupp, J., Hellwig-Burgel, T., Wobbe, V., Seitzer, U., Brandt, E., Maass, M., Chlamydia pneumoniae infection promotes a proliferative phenotype in the vasculature through Egr-1 activation in vitro and in vivo. Proc. Natl. Acad. Sci. U.S.A. 2005 Mar 1;102(9):3447-52
Saikku P, Leinonen M, Mattila K, Ekman MR, Nieminen MS, Mäkelä PH, Huttunen JK, Valtonen V. Serological evidence of an association of a novel Chlamydia, TWAR, with chronic coronary heart disease and acute myocardial infarction. Lancet. 1988 Oct 29;2(8618):983-6.

Sasu S, LaVerda D, Qureshi N, Golenbock DT, Beasley D. Chlamydia pneumoniae and chlamydial heat shock protein 60 stimulate proliferation of human vascular smooth muscle cells via tollke receptor 4 and 44/p42 mitogen-activated protein kinase activation. Circ Res. 2001 Aus $3 ; 89(3): 244-50$

Schett G, Xu Q, Amberger A, Van der Zee R, Recheis H, Willeit J, Wick G. Autoantibodies agains heat shock protein 60 mediate endothelial cytotoxicity. J Clin Invest. 1995 Dec;96(6):2569-77.

Smith PD, Saini SS, Raffeld M, Manischewitz JF, Wahl SM. Cytomegalovirus induction of tumor necrosis factor-alpha by human monocytes and mucosal macrophages. J Clin Invest 1992;90:1642-8.

Streblow DN, Orloff SL, Nelson JA. Acceleration of allograft failure by cytomegalovirus. Curr Opin Immunol. 2007 Oct;19(5):577-82.

Sulyok S, 20 M, Alzheimer C, Werner S. Activin: an important regulator of wound repair, fibrosis, and neuroprotection. Molecular and Cellular Endocrinology. 2005; 225: 126-132.

Vliegen I, Herngreen SB, Grauls GE, Bruggeman CA, Stassen FR. Mouse cytomegalovirus antigenic immune stimulation is sufficient to aggravate atherosclerosis in hypercholesterolemic mice. Atherosclerosis. $2005 \mathrm{Jul} ; 181(1): 39-44$.

Watson C, Alp NJ. Role of Chlamydia pneumoniae in atherosclerosis. Clin Sci (Lond). 2008 Apr;114(8):509-31.

Westphal M, Lautenschlager I, Backhaus C, Loginov R, Kundt G, Oberender H, Stamm C, Steinhoff Cytomegalovirus and proliferative signals in the vascular wall of CABG patients. Thorac Cardiovas Surg. 2006 Jun;54(4):219-26.

Whitman SC, Ravisankar P, Daugherty A. Interleukin-18 enhances atherosclerosis in apolipoprotein $E(-/-)$ mice through release of interferon-gamma. Circ Res. 2002 Feb 8;90(2):E34-8.

Woodroffe SB, Garnett HM, Danis VA. Interleukin-1 production and celactivation response to ytomegalovirus infection of vascular endothelial cells. Arch Virol 1993;133:295-308.

Zeng H, Waldman WJ, Yin DP, Knight DA, Shen J, Ma L, Meister GT, Chong AS, Williams JW. echanistic study of malononitrileamide FK778 in cardiac transplantation and CMV infection in ats. Transplantation. 2005 Jan 15;79(1):17-22.

Zhou YF, Shou M, Guetta E, Guzman R, Unger EF, Yu ZX, Zhang J, Finkel T, Epstein SE. Cytomegalovirus of rats increases the neointimal response to vascular injury without consistent evidence of direct infection of the vascular wall. Circulation, 1999. 100(14): p. 1569-75.

Zhou YF, Shou M, Harrell RF, Yu ZX, Unger EF, Epstein SE. Chronic non-vascular cytomegalovirus infection: effects on the neointimal response to experimental vascular injury. Cardiovasc Res. 2000 Mar;45(4):1019-25. 


\section{Summary}

Intimal hyperplasia is considered to be the major determining factor limiting long term success after PTCA, venous bypass grafting and solid organ transplantation. Although the underlying cause is generally considered to be multifactorial, infections with C. pneumoniae and cytomegalovirus (CMV) have been proposed to be associated with intimal hyperplasia, especially in stimulating an already going process.

Yet, sero-epidemiological studies demonstrating an association between $C$. pneumoniae or $\mathrm{CMV}$ and restenosis, venous graft failure and transplant arteriosclerosis show conflicting results. Moreover, the number of studies in which animal models have been used in order to investigate a more causal relationship between these two pathogens and intimal hyperplasia are scarce and results do not point in the same direction, thereby generating the need for additional research. In this thesis we tested the hypothesis that infections with $C$. pneumoniae and CMV affect the process of intimal hyperplasia and aimed to unravel the underlying mechanisms. For this purpose several animal models were used.

First we studied the effect of CMV infection on restenosis (Chapter 2). Using a well defined animal model of photochemically-induced endothelial denudation leading to intimal hyperplasia, a relationship was detected between the time point of CMV infection and its effect on SMC proliferation either in the media or in the neointima. When rats were infected immediately after injury a significant increase was observed on medial but not on neointimal cross sectional area. On the other hand, when rats were infected fourteen days after the initial injury, a significant increase was observed in the neointimal area. Also, the mean number of smooth muscle cells per $\mu \mathrm{m}^{2}$ in both cell layers was unchanged despite an increase in crosssectional area, which implies that CMV stimulated smooth muscle cell proliferation but not hypertrophy. Furthermore, these vascular effects were observed with only a few DNA copies of virus being present in the vascular wall as demonstrated by real time PCR. This suggests that indirect factors like inflammatory and immunemediated responses to $\mathrm{CMV}$ infection are more important in aggravating the response than direct vascular injury by the virus itself.

Thus, inspired by the observation that CMV aggravated intimal hyperplasia as seen in the process of restenosis, we hypothesized that similar effects might occur in intimal hyperplasia leading to venous bypass failure. In a study using an epigastric vein-to-common femoral artery interposition graft model, we evaluated the effect of CMV infection on intimal hyperplasia. Additionally we studied the potential effect of a new immunosuppressive, anti-viral and anti-proliferative agent FK778 to prevent intimal hyperplasia and its ability to diminish the CMV induced effects (Chapter 3 ). The results of this study revealed that CMV infection induced a significant increase in intimal cross-sectional area, medial cross-sectional area and medial wall thickness of the vein grafts, while this effect was diminished by administration of FK778. Moreover, FK778 treatment alone resulted in a significant decrease in neointimal area and stenosis rate vs. the control group but had no effect on medial crosssectional area or medial thickness. Interestingly, no significant differences in T-cell or macrophage influx observed. Likewise, cell counts revealed no significant differences in number of cells $/ \mu \mathrm{m}^{2}$ between groups. Overall, these data suggested a role of $\mathrm{CMV}$ in venous graft failure as well as a role for the new immunosuppressive drug FK778 in the prevention of not only CMV-mediated vein graft intimal hyperplasia, but intima hyperplasia in general.

Next, we examined whether $C$. pneumoniae had an effect on venous bypass failure (Chapter 4). C. pneumoniae is an obligate intracellular Gram-negative bacterium which, like CMV, has frequently been associated with atherosclerosis. Using the epigastric vein-to-common femoral artery interposition graft rat model we were able to demonstrate that $C$. pneumoniae infection immediately after vein grafting resulted in a significant increase in medial cross-sectional area, wall thickness and total wall area. As with CMV, the mean number of cells $/ \mu \mathrm{m}^{2}$ was not altered indicating that also in the case of $C$. pneumoniae the increase in area was caused by an increase in total cell number and not by cellular hypertrophy. This implicates that C. pneumoniae infection stimulated smooth muscle cell proliferation resulting in a significant increase in intimal hyperplasia hereby aggravating venous graft failure. We also tried to unravel the underlying mechanisms which may be responsible for this effect of $C$. pneumoniae. In vitro studies previously delineated an increased secretion of C-reactive protein (CRP) and heat shock protein 60 (HSP60) after infection of SMC with $C$. pneumoniae. These secreted proteins in turn may stimulate SMC proliferation. In our in vivo study we tried to confirm such relationship between C. pneumoniae, intimal hyperplasia, and presence of CRP and HSP60 in the venous graft. Also, the number of T-cells and macrophages were determined in the graft at 3 weeks after surgery. Nonetheless, no significant differences in T-cell or macrophage influx were detected. Likewise, although positive immunostaining for both CRP and 
HSP60 could be detected, no differences were found between groups. Thus, we were unable to confirm that either CRP or HSP60 plays a prominent role in the effects of $C$. pneumoniae on venous graft failure. Indicating that $C$. pneumoniae stimulates smooth muscle cell proliferation thereby aggravating intimal hyperplasia in venous grafts by hereunto unknown molecular mechanisms.

Given the well established relationship between CMV and transplant arteriosclerosis we hypothesized that $C$. pneumoniae may also play a role in this process. To study this hypothesis we used the rat allograft model of orthotopic abdominal aorta transplantations (Chapter 5). Orthotopic abdominal aorta transplantations were performed with $\mathrm{BN}$ rats as donors and Lewis rats as recipients. Rats were sacrificed one or eight weeks after surgery to assess the presence of $C$. pneumoniae DNA, monocytes/macrophages and T-cells in the graft. Eight weeks after surgery grafts were also processed for morphometrical examination. One week after transplantation, the peri-vascular influx of inflammatory cells in the graft was not affected by $C$. pneumoniae infection. Furthermore, only limited numbers of $C$. pneumoniae DNA copies were found in the graft one week after transplantation. In addition, C. pneumoniae did not alter the severity of myointimal hyperplasia eight weeks after surgery. $C$. pneumoniae DNA was not present in the grafts at eight weeks after surgery. These data suggest that, in contrast to earlier observation with CMV, C. pneumoniae infection does not influence the influx of inflammatory cells or the severity of transplantation arteriosclerosis in the rat aortic allograft model.

Although with currently available pharmacotherapy a lot of cardiovascular diseases may be prevented and/or treated, some forms of cardiovascular disease are still difficult to prevent and/or treat. And despite some drawbacks in some early clinical trials, gene therapy is still accepted as being attractive and may open new ways for treatment and prevention. In our study we applied gene therapy in order to prevent intimal hyperplasia (chapter 6). Activin A is a member of the transforming growth factor-b superfamily and able to promote the contractile phenotype of smooth muscle cells. Maintaining the contractile SMC phenotype by adenoviral activin A overexpression could prevent intimal hyperplasia and would represent a novel strategy to prevent venous graft failure. To examine the potential therapeutic of activin A in preventing venous graft failure we used the epigastric vein-to-common femoral artery interposition graft model in the rat. One group of rats was injected immediately after surgery with an adenoviral construct carrying the activin $\mathrm{A}$ gene resulting in an systemic over-expression of liver derived activin A. The other group was injected with an adenovirus carrying no insert. All animals were sacrificed three weeks after surgery and the grafts were harvested for morphometrical and immunohistochemical analysis for the presence of SMC. The amount of SMC proliferation was quantified using BrdU staining. Adenoviral activin A over-expression resulted in a significant decrease in intimal cross-sectional area and percentage stenosis as compared to the control group, Moreover, BrdU staining identified lower proliferation rates of the smooth muscle cells in the group treated with activin $A$ indicating that overexpression of activin A may promote the contractile phenotype of these cells. This study shows for the first time evidence that activin A can diminish vein graft failure in a rat model supporting a novel strategy to prevent intimal hyperplasia.

In summary, in this thesis we provide supporting evidence that, besides multiple other factors, C. pneumoniae and CMV affect intimal hyperplasia in experimental animal models of restenosis and venous graft failure. On the other hand, in contrast to the established relation between CMV and transplant arteriosclerosis, our data suggest that $C$. pneumoniae is of no importance in the latter pathology. Furthermore, we were able to demonstrate the $C$. pneumoniae and $C M V$ infections are able to stimulate SMC proliferation in vivo. Importantly, these infection-induced effects even occur when there are only low amounts of pathogen present in the vessel wall, suggesting that inflammatory and immune responses to micro-organisms are more important in exaggerating the response to vascular injury than the presence of pathogens itself. Nevertheless, additional studies are still needed to further elucidate the underlying mechanisms. Additionally we demonstrated that the new immunosuppressive, anti-viral and anti-proliferative agent FK778 may be useful in preventing intimal hyperplasia, rendering it a possible therapeutic candidate in the field of transplantation. Finally, we also demonstrated the feasibility of gene therapy in preventing intimal hyperplasia, as adenovirus-mediated overexpression of activin A significantly reduced intimal hyperplasia in our rat model of venous graft failure. 
Samenvatting 


\section{Samenvatting}

Intima hyperplasie wordt beschouwd als de belangrijkste factor verantwoordelijk voor het limiteren van het lange termijn succes van PTCA, plaatsing van een veneuze bypass en orgaan transplantatie. Naast een groot aantal andere oorzaken welke gedurende de laatste decennia ontdekt zijn, wordt gesuggereerd dat bepaalde microorganismen, en met name cytomegalovirus (CMV) en Chlamydia pneumoniae, een rol spelen bij de verergering van intima hyperplasie. Echter, alhoewel verscheidene sero-epidemiologische studies een associatie beschrijven tussen $C$. pneumoniae en CMV enerzijds en restenose, veneuze bypass falen en transplantatie arteriosclerose anderzijds, zijn de resultaten niet eenduidend. Daarnaast zijn er slechts enkele dierexperimentele studies gepubliceerd waarin gekeken is naar een meer oorzakelijk verband tussen deze twee pathogenen en intima hyperplasia. Ook hier zijn de resultaten niet conclusief en zijn verdere studies noodzakelijk om meer duidelijkheid te krijgen omtrent de rol van micro-organismen binnen deze aandoening(-en). In deze thesis hebben we getracht met behulp van verschillende diermodellen de rol die $C$. pneumoniae en CMV spelen in intima hyperplasie te verhelderen en de onderliggende mechanismen te bestuderen.

Onderwerp van de eerste studie (Hoofdstuk 2) was de hypothese dat CMV infectie in staat is de mate van restenose te verergeren. In deze dierexperimentele studie werd in de grote beenslagader van de rat endotheelschade geïnduceerd wat vervolgens resulteerde in intima hyperplasie. Vervolgens werd het effect van een CMV infectie op de gladde spiercel proliferatie in de intima en media bestudeerd. Opmerkelijk was dat met name het moment van infecteren in belangrijke mate het effect van de infectie bepaalde. Wanneer ratten onmiddellijk na de ingreep werden geïnfecteerd werd er een significante toename gezien van de media oppervlakte maar niet van de intima oppervlakte. Anderzijds werd er een significante toename van alleen de intima oppervlakte gezien wanneer de ratten veertien dagen na de initiële endotheel beschadiging geïnfecteerd werden. In beide situaties bleef het totale aantal gladde spiercellen per $\mu \mathrm{m}^{2}$ in de vaatwand wel ongewijzigd hetgeen impliceert dat CMV de vermeerdering ("proliferatie") van gladde spiercellen stimuleert maar niet de groei qua grootte ("hypertrofie"). Opvallend was dat deze vasculaire effecten werden waargenomen terwijl er maar enkele CMV DNA kopieën in de vaatwand konden worden aangetoond ondanks het feit dat gebruik gemaakt werd van een bijzonder gevoelige detectiemethode (real time PCR). Dit suggereert dat indirecte factoren zoals ontsteking en immuungemediëerde processen gericht tegen CMV belangrijker zijn voor het verergeren van de vaatwandschade dan de directe lokale aanwezigheid van het virus zelf.

Geïnspireerd door de waarneming dat CMV intima hyperplasie verergert bij restenose ontstond de hypothese dat soortgelijke effecten wellicht ook een rol zouden kunnen spelen bij intima hyperplasie leidend tot het falen van een veneuze bypass. Gebruikmakend van een model waarbij we een stukje van een vene plaatsten in de beenslagader van de rat hebben we het effect van CMV infectie op intima hyperplasie in een veneuze bypass bestudeerd. Daarnaast hebben we gekeken in hoeverre een nieuw medicijn (FK778), waarvan de werking verondersteld wordt 3-voudig te zijn (onderdrukking van het immuunsysteem, antiviraal en remming van de vermeerdering van gladde spiercellen in de vaatwand), in staat was om intima hyperplasie te voorkomen en de door CMV geïnduceerde effecten te verminderen (Hoofdstuk 3). Resultaten van deze studie gaven aan dat infecties met CMV leiden tot een significante toename van intima oppervlakte, media oppervlakte en media dikte hetgeen grotendeels tenietgedaan werd door behandeling met FK778. Behandeling met enkel FK778 gaf reeds een significante vermindering van de intima oppervlakte maar had geen effect op media oppervlakte en media dikte. Opmerkelijk was dat er geen verschil in de hoeveelheid T-cellen of macrofagen in de vaatwand werd gezien. Ook werden er geen significante verschillen tussen de groepen gevonden met betrekking tot het aantal cellen per $\mu \mathrm{m}^{2}$ vaatwandoppervlakte. Op basis van deze resultaten kan geconcludeerd worden dat CMV mogelijk ook een rol speelt bij het falen van een veneuze bypass. Daarnaast tonen ze aan dat FK778 een veelbelovend nieuw middel kan zijn bij het voorkomen intima hyperplasie in het algemeen.

Vervolgens hebben we gekeken of $C$. pneumoniae het falen van een veneuze bypass kan beïnvloeden (Hoofdstuk 4). C. pneumoniae is een intracellulaire Gramnegatieve bacterie die evenals CMV frequent geassocieerd wordt met atherosclerose. Gebruikmakend van het eerder beschreven ratmodel, waarbij een klein stukje vene in de grote beenslagader werd gehecht, konden we aantonen dat een infectie met C. pneumoniae onmiddellijk na de operatie resulteerde in een significante toename van media oppervlakte, totale vaatwand oppervlakte en vaatwand dikte. Ook in deze experimenten bleef het totale aantal cellen per $\mu \mathrm{m}^{2}$ ongewijzigd. Dit wijst erop dat ook in het geval van C. pneumoniae de toename in oppervlakte veroorzaakt wordt door een toename van het aantal cellen (hyperplasie) en niet door een toename van 
de celgrootte (hypertrofie). We hebben ook gekeken naar mogelijke mechanismen waardoor $C$. pneumoniae het falen van een veneuze bypass kan beïnvloeden. Eerdere in vitro studies wezen op een toegenomen productie ven het zogenaamde $\mathrm{C}$-reactive proteïne (CRP) en heat shock proteïne 60 (HSP60) na infectie van gladde spiercellen met $C$. pneumoniae. Deze eiwitten kunnen op zichzelf gladde spiercel proliferatie stimuleren. In onze in vivo studie hebben we geprobeerd om deze mogelijke relatie tussen C. pneumoniae, intima hyperplasie en aanwezigheid van CRP of HSP60 in de veneuze bypass aan te tonen. Tevens hebben we gekeken naar de aanwezigheid van T-cellen en macrofagen in the veneuze bypass drie weken na de ingreep. Hierbij werden echter geen significante verschillen gevonden in het aantal T-cellen of macrofagen. Evenmin werden er verschillen gevonden tussen de groepen wat betreft de aanwezigheid van CRP of HSP60, ondanks het feit dat er aanwijzingen gevonden werden dat beide eiwitten daadwerkelijk aanwezig waren in de vaatwand. Derhalve hebben we in vivo niet kunnen bevestigen dat CRP danwel HSP60 een prominente rol speelt bij de effecten van $C$. pneumoniae op veneuze bypass falen. Concluderend kunnen we zeggen dat $C$. pneumoniae de poliferatie van gladde spiercellen stimuleert wat vervolgens kan bijdragen aan het falen van een veneuze bypass door tot nu toe onbekende moleculaire mechanismen.

In het licht van deze resultaten en gebaseerd op de bekende relatie tussen CMV en transplantatie arteriosclerose is de hypothese ontstaan dat C. pneumoniae ook bij deze vasculaire aandoening wel eens een rol zou kunnen spelen. Om dit te bestuderen hebben we gebruik gemaakt van een diermodel waarbij een stukje van de aorta ('graft") van een donor rat getransplanteerd werd naar een ontvanger. (Hoofdstuk 5). Aorta transplantaties werden verricht met Brown Norway ratten als donor en Lewis ratten als ontvanger, waarbij als gevolg van weefselincompatibiliteit na enige tijd in de getransplanteerde graft intima hyperplasia zal ontstaan. Deze ratten werden op een of acht weken na de operaties ge-euthaniseerd waarna er werd gekeken naar de aanwezigheid van C. pneumoniae DNA, monocyten/macrofagen en T-cellen in de graft. Tevens werden de grafts acht weken na transplantatie verwerkt voor morfometrisch onderzoek. Een week na transplantatie was er geen effect van C. pneumoniae infectie op de perivasculaire aanwezigheid van ontstekingscellen. Daarnaast werd er slechts een geringe hoeveelheid $C$. pneumoniae DNA kopieën terug gevonden in de graft een week na transplantatie. Evenmin had een $C$. pneumoniae infectie een effect op de ernst van myointimale hyperplasie acht weken na chirurgie. C. pneumoniae DNA was op dat moment niet meer aanwezig in de grafts. Deze data suggereren dat in tegenstelling tot $\mathrm{CMV}, \mathrm{C}$. pneumoniae infectie geen invloed heeft op de instroom van ontstekingscellen in de graft noch op de ernst van transplantatie arteriosclerose in het rat aorta transplantatie model.

Alhoewel er met de huidige beschikbare medicijnen reeds vele cardiovasculaire aandoeningen voorkomen of behandeld kunnen worden, zijn er nog altijd verschillende "therapie-resistente" hart- en vaataandoeningen. Gen therapie wordt ondanks wat tegenslagen in vroegere klinische studies nog altijd beschouwd als een nieuwe en aantrekkelijke therapeutische strategie in behandeling en preventie van ziekten. In onze studie hebben we dan ook gentherapie gebruikt om intima hyperplasie te voorkomen (Hoofdstuk 6). Activin A is lid van de transforming growth factor-b superfamilie en is in staat om gladde spiercellen in een gedifferentieerd, contractiel fenotype te houden. Het voorkomen van intima hyperplasie middels het voorkomen van gladde spiercel de-differentiatie zou een nieuwe methode kunnen zijn om veneuze bypass falen te verhinderen. Om het therapeutisch vermogen van activin $A$ te testen hebben we gebruik gemaakt van het eerder genoemde rat model waarbij we een stukje vene plaatsten in de beenslagader. Eén groep ratten werd direct na de operatie geïnjecteerd met een adenoviraal construct welke het activin A gen met zich meedroeg. Dit resulteert in systemische overexpressie van het in de lever gemaakte activin A. De andere groep werd geïnjecteerd met een adenovirus zonder construct. Alle dieren werden drie weken na chirurgie ge-euthaniseerd en grafts werden verwerkt voor morfometrisch onderzoek en immunohistochemische kleuringen voor de aanwezigheid van gladde spiercellen. De mate van gladde spiercel proliferatie werd bepaald door BrdU kleuring. Adenovirale over-expressie van activin A resulteerde in een significante afname van intima oppervlakte en percentage stenose ten opzichte van de controle groep. Tevens toonde BrdU kleuring aan dat de mate van gladde spiercel proliferatie lager was in de met activin A behandelde groep, hetgeen er op wijst dat activin A in staat is gladde spiercellen in hun contractiele fase te houden. Deze studie toont dan ook voor het eerst aan dat gen therapie met activin A een mogelijke nieuwe strategie kan zijn om intima hyperplasie en veneuze graft falen te verminderen.

Samenvattend hebben we in deze thesis aangetoond dat, naast meerdere andere factoren, C. pneumoniae en CMV een rol spelen bij intima hyperplasie in experimentele diermodellen van restenose en veneuze graft falen. Aan de ander kant geven onze data, in tegenstelling tot de bekende relatie tussen CMV en transplantatie 
Chapter 7

arteriosclerose, geen bewijs voor een link tussen $C$. pneumoniae en deze pathologie. Daarnaast hebben we aangetoond dat $C$. pneumoniae en CMV infecties in staat zijn gladde spiercel proliferatie te stimuleren in vivo. Belangrijk hierbij is dat de infectie geïnduceerde effecten optreden terwijl er slechts geringe hoeveelheden pathogenen in de vaatwand aanwezig zijn. Dit suggereert dat onstekings en immunologische reacties gericht tegen de micro-organismen belangrijker zijn voor het stimuleren van intima hyperplasie dan de lokale aanwezigheid van het pathogeen zelf. Aanvullende studies naar de mogelijke onderliggende mechanismen zijn echter nog noodzakelijk.

Tevens hebben we aangetoond dat het nieuwe immunosuppressieve, antivirale en antiproliferatieve medicijn FK778 functioneel is in het voorkomen van intima hyperplasie, hetgeen het een aantrekkelijke kandidaat maakt voor gebruik op het gebied van transplantatie. Tot slotte hebben we aangetoond dat gen therapie met activin A werkt ter vermindering van intima hyperplasie in ons rat model van veneuze graft falen. 


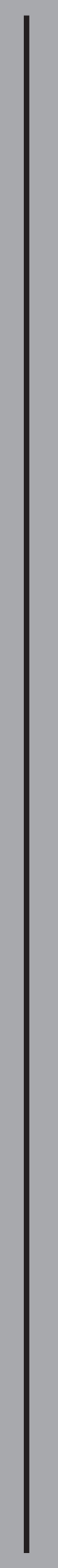

Dankbetuigingen 


\section{Dankwoord}

Als tweede jaars geneeskunde student begon ik destijds idealistisch aan mijn onderzoek. Nu vele frustraties maar ook zeker leerzame ervaringen later is dit proefschrift met doorzetten en volharding eindelijk tot stand gekomen. Vele mensen hebben bijgedragen aan de inhoud en voltooing hiervan waarvoor mijn oprechte dank. Graag wil ik enkele personen in het bijzonder bedanken zonder wie er zeker geen proefschrift was geweest.

Prof. Dr. Cathrien Bruggeman. Als $\mathrm{U}$ in mij niet enig potentieel gezien had toen ik als tweede jaars geneeskunde student bij $\mathrm{U}$ op de stoep stond met mijn onderzoeks idee over HIV en ozontherapie (achteraf niet eens zo gek nu ze spoelingsvloeistof voor dialyse steriliseren met ozon) zou er van een wetenschappelijke carrière waarschijnlijk geen sprake geweest zijn. Alhoewel het uiteindelijke onderzoeks onderwerp iets totaal anders werd, was $\mathrm{U}$ gedurende de vele jaren verantwoordelijk voor het richting geven aan dit proefschrift. Waarbij $U$ naast wetenschappelijke inbreng altijd aandacht had voor een persoonlijke noot. Met name in de beginfase toen ik eindeloos gefrustreerd was door het Maastrichtse onderwijssysteem, is dit zeer behulpzaam geweest voor mij.

Dr. Frank Stassen. Als mijn directe begeleider ben je een bepalende factor geweest voor de inhoud van dit proefschrift. Je hebt mij de beginselen bijgebracht om een fatsoenlijke proefopzet te maken en mij geleerd een wetenschappelijk artikel te schrijven. Alhoewel we het niet altijd eens waren over de snelheid waarmee zaken werden gedaan, ben ik wel altijd bijzonder tevreden geweest met het uiteindelijke resultaat. Met name de vlotte leesbaarheid en het correcte Engels hebben vast menig publicatie bevorderd.

Gert, Is er iets wat je mij niet geleerd hebt? Als geneeskunde student was ik praktisch totaal niet onderlegt in iets wat met labarotorium technieken te maken had. $\mathrm{Jij}$ hebt mij met enthousiasme en het nodige geduld alles geleerd. Alhoewel je altijd bang was dat ik de totale voorraad CMV en Chlamydia pneumoniae zou gebruiken voor mijn experimenten is het allemaal nog beheersbaar gebleken. Zonder jouw faciliterende kennis en ervaring was er geen soepel draaiend lab geweest en geen proefschrift. Helaas is jouw allergie voor ratten en muizen besmettelijk gebleken !!
Selma je hebt mij geleerd hoe ik een Taqman run moest doen, daarnaast ben ik je dank verschuldigd voor de hulp die ik van je kreeg voor de DNA en RNA isolaties. Rick alhoewel onze relatie nog het meest leek op wederzijds parasitisme hebben jou stormvloed aan ideeën en mijn praktische vaardigheden in een relatief korte periode geleid tot een veelvoud aan gezamelijke artikelen.

Last but not laest lijkt me dit de juiste plek om mijn ouders te bedanken. Na vele jaren ben óók ik tot het inzicht gekomen dat de switch van Leuven naar Maastricht de juiste was. Zonder jullie indirecte en directe steun was dit proefschift nooit ontstaan. 


\section{About the author}


Chapter 7

\section{Curriculum Vitae}

Geoffrey Theodorus Lourens Kloppenburg werd geboren op 9 augustus 1979 te Oss. In 1997 deed hij eindexamen VWO aan het Augustinianum te Eindhoven. In datzelfde jaar begon hij met de studie Geneeskunde, initiëel aan de Katholieke Universiteit van Leuven, later vanaf september 1999 aan de Universteit van Maastricht.

Vanaf februari tot september 2000 was hij verbonden als student-assistent aan de Capaciteitsgroep Farmacologie/Toxicologie sectie Humane Toxicologie van de Universiteit Maastricht onder begeleiding van Dr. R. van Haaften met als onderzoeks onderwerp: Vitamine $\mathrm{E}$ anti-oxidant en pro-oxidant werking.

In september 2000 begon hij als student-assistent bij de Capaciteitsgroep Medische Microbiologie, Academisch Ziekenhuis Maastricht waar hij onder begeleiding van Dr. F. Stassen en Prof. C. Bruggeman onderzoek verrichte naar het effect van cytomegalovirus infectie op restenose en veneus graft falen. Later werd gestart met het onderzoek naar de relatie tussen Chlamydia pneumoniae, veneus graft falen en transplantation arteriosclerose. In 2003 ontving hij het "Dr. E Dekker stipedium” voor een onderzoeksperiode in het Transplantatie Laboratorium van het Universitair Ziekenhuis van Helsinki te Finland onder begeleiding van Dr. I Lautenschlager. Voor zijn onderzoekswerk ontving hij in 2004 vanuit het Cardiovascular Research Institute Maastricht (CARIM) een "Prof. dr. Kootstra Fellowship" als talentvolle aspirant promovendus.

In 2006 behaalde hij het artsendiploma en werkte vervolgens als AGNIO cardiothoracale chirurgie in het St. Antonius ziekenhuis te Nieuwegein waar hij medio 2009 start met de opleiding tot cardiothoracaal chirurg. 
List of scientific papers 


\section{List of scientific papers}

Botta L., Kloppenburg G., Yilmaz A. Intramural Hematoma of a Cryopreserved Aortic. Homograft. Thorac Cardiov Surg 2008; 56: 1-3.

Kloppenburg G., de Graaf R., Grauls G., Bruggeman C., Stassen F. Chlamydia pneumoniae aggravates vein graft intimal hyperplasia in a rat model. BMC Microbiol. 2007 Dec 6;7:111.

Kloppenburg G., de Graaf R., Herngreen S., Bruggeman C., Stassen F. Cytomegalovirus aggravates intimal hyperplasia in rats by stimulating smooth muscle cell proliferation. Microbes Infect. 2005 Feb;7(2):164-70.

de Graaf R., Kloppenburg G., Kitselaar P., Bruggeman C., Stassen F. Human heat shock protein 60 stimulates vascular smooth muscle cell proliferation through toll like receptor 2 and 4. Microbes Infect. 2006 Jun;8(7):1859-65.

de Graaf R., Kloppenburg G., Tintu A., Rouwet E., Kitslaar P., van Hooff J., Bruggeman C., Stassen F. The new immunosuppressive agent FK778 attenuates neointima formation in an experimental bypass model. Vascul Pharmacol. 2008 Nov

Sonker U., Kloppenburg G., Knoop E., Seldenrijk C., Morshuis W. Emergency surgery for acute mitral valve obstruction resulting from hemorrhage within a left atria myxoma. Ann Thorac Surg. 2009 Feb;87(2):636-638.

Kloppenburg G., Maessen J.G. Streptococcus endocarditis after tongue piercing. J Heart Valve Dis. 2007 May;16(3):328-30.

Kloppenburg G., Graeler H., Bruggeman C., Stassen F. Chlamydia Pneumonia infection is not associated with chronic transplant dysfunction in a rat aortic allograft model. Transplant Proc. 2007;39(1):261-7.

Kloppenburg G., Grauls G., Bruggeman C, Stassen F. Adenoviral Activin A Expression Prevents Vein Graft Intimal Hyperplasia in a Rat Model. Interact Cardiovasc Thorac Surg. 2008 Oct 14.
Kloppenburg G., Sonker U., Schepens M. Intra-aortic balloon pump related thrombus in the proximal descending thoracic aorta with peripheral emboli. Accepted for publication Journal of Invasive Cardiology.

Yilmaz A., Rehman A., Sonker U., Kloppenburg G. Minimal access aortic valve replacement using minimal extracorporeal circulation system. Accepted for publication in Annals of thoracic surgery.

Botta L., Kloppenburg G., Yilmaz A. Prosthetic Valve Endocarditis Presenting With Severe Anemia: Report of a Case. Accepted for publication in Chirurgia.

Massi F., Muretti M., Salvati A., Kloppenburg G., van Boven W. Internal mammary artery anastomosed on a stented coronary artery after stent incision. Submitted.

Kloppenburg G., de Graaf R., Bruggeman C.A., Stassen F. FK778 inhibits cytomegalovirus enhanced venous graft failure in a rat model. Submitted.

de Graaf R., Kloppenburg G., Tintu A., Kitselaar P., Bruggeman C., Stassen F. NAC attenuates hyperoxia induced smooth muscle cell proliferation and neointima in a venous bypass model. Submitted. 
Color figures 

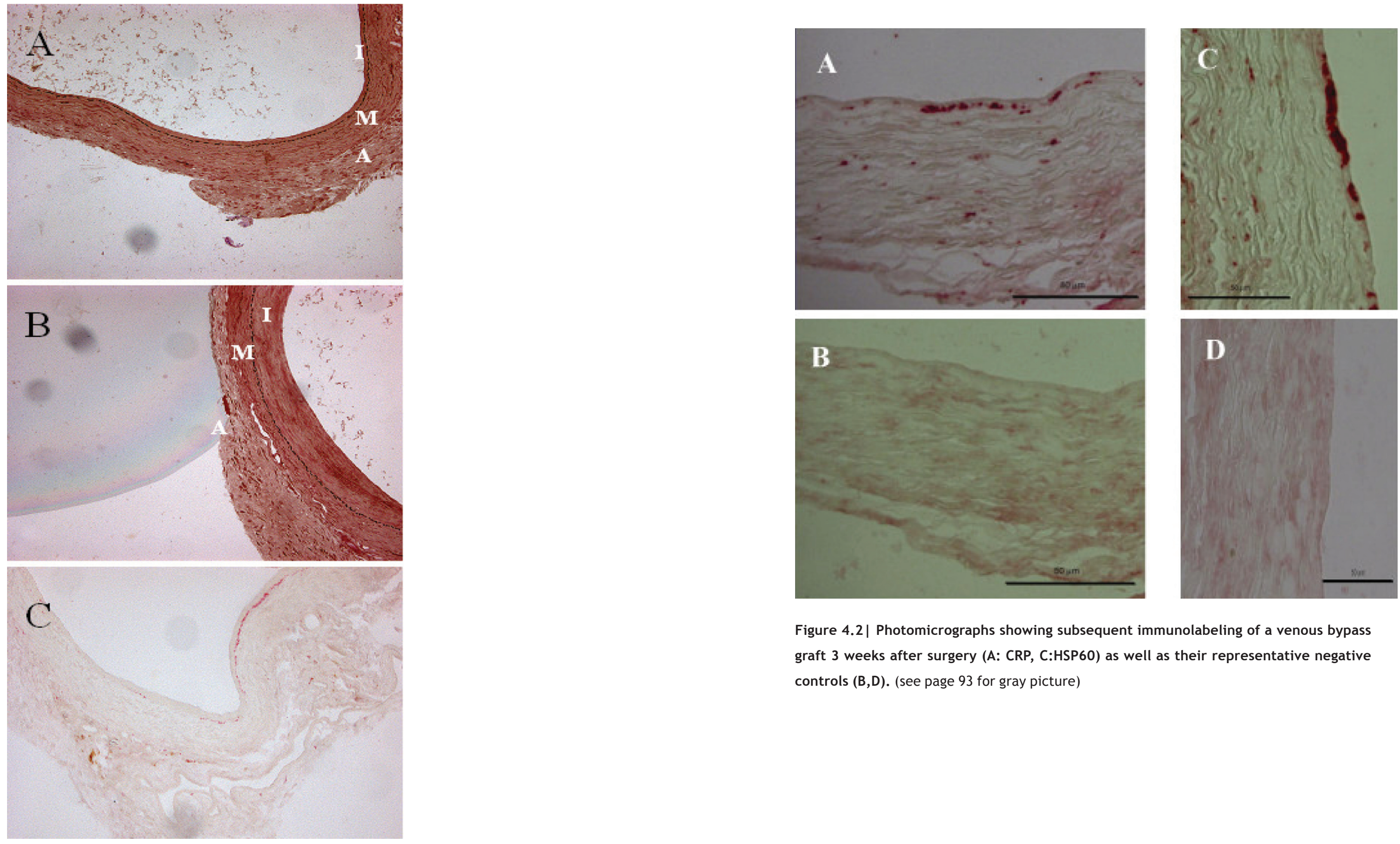

Figure 4.2 Photomicrographs showing subsequent immunolabeling of a venous bypass graft 3 weeks after surgery (A: CRP, C:HSP60) as well as their representative negative controls (B,D). (see page 93 for gray picture)

Figure 3.2 | Showing typical examples of venous grafts cross-sections 21 days after grafting. A) Lawson staining venous graft control group, B) Lawson staining venous graft CMV infected group, C) ED-1 monocyte macrophage staining. I = Intima, $M=$ Media, $A=$ Adventitia. (see page 


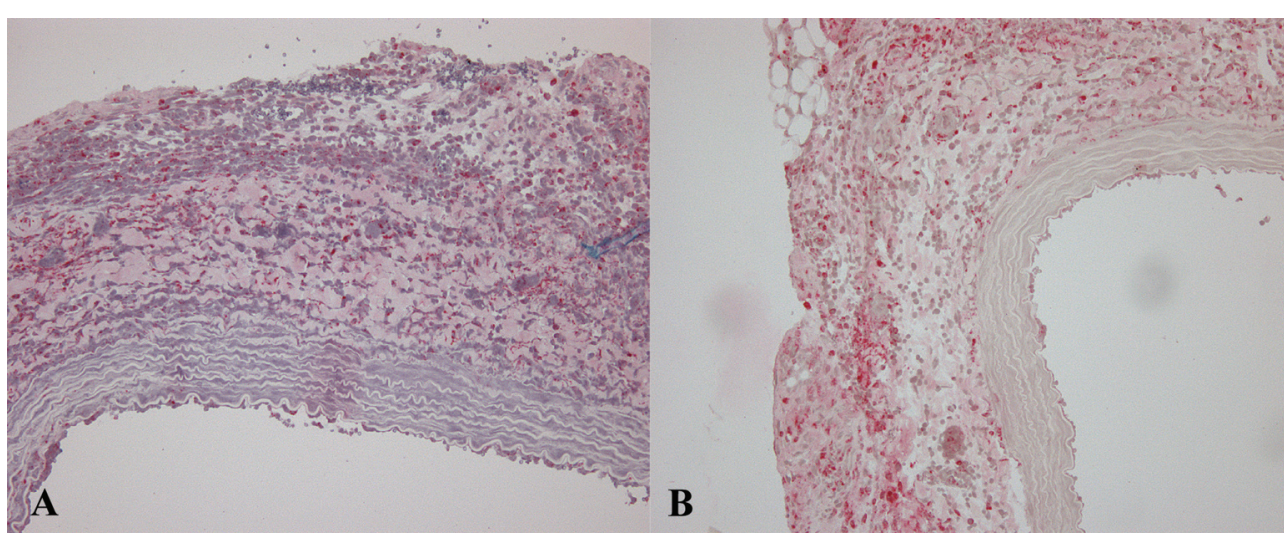

Figure 5.1 | Photomicrographs of rat aortic allograft 1 week after transplantation. ED-1 immunoperoxidase staining against monocytes/macrophages. A) Allogeneic group with C. pneumoniae infection 24 hours after transplantation. B) Allogeneic control group. No statistical significant differences were observed. (see page 105 for gray picture)

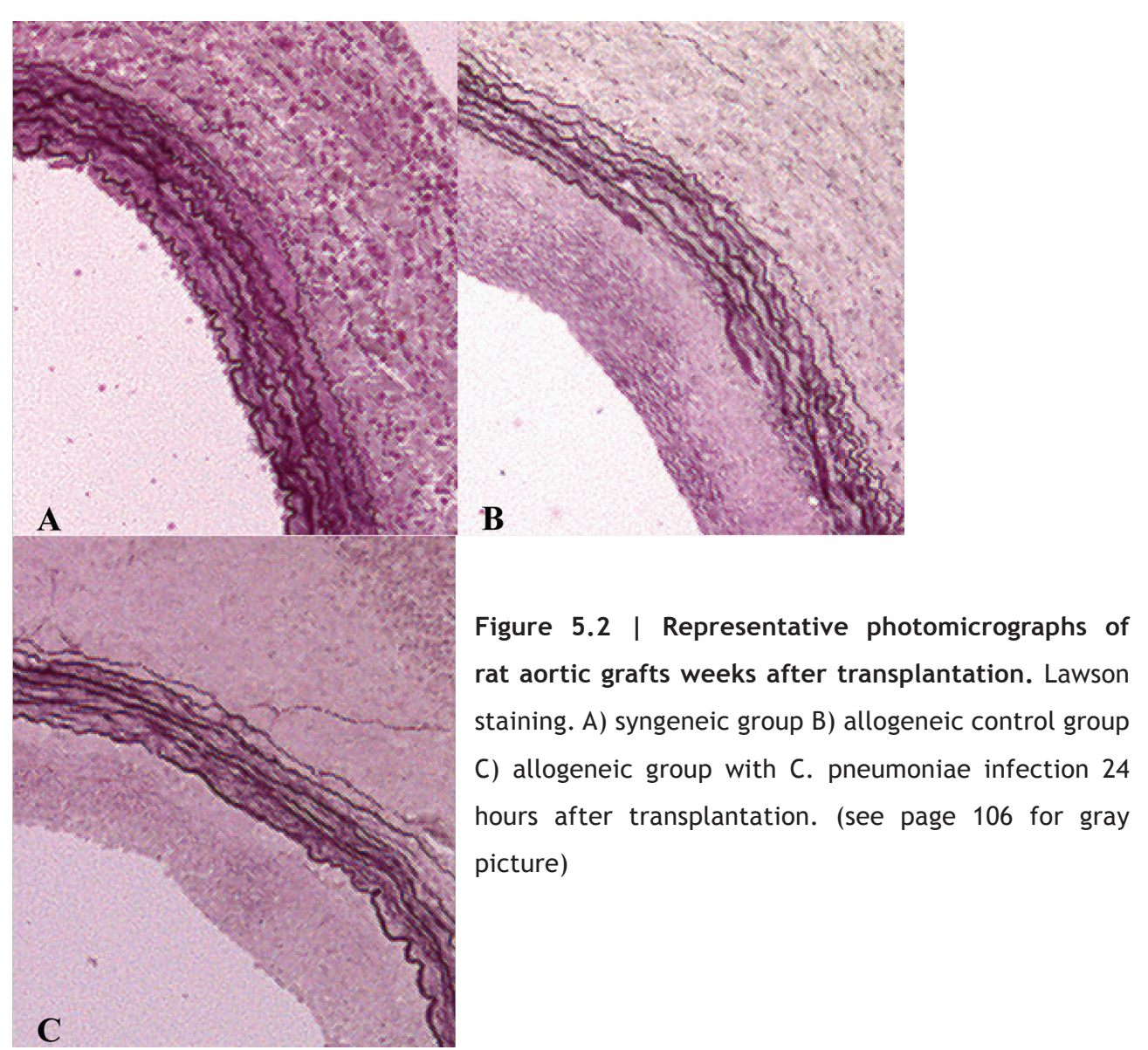

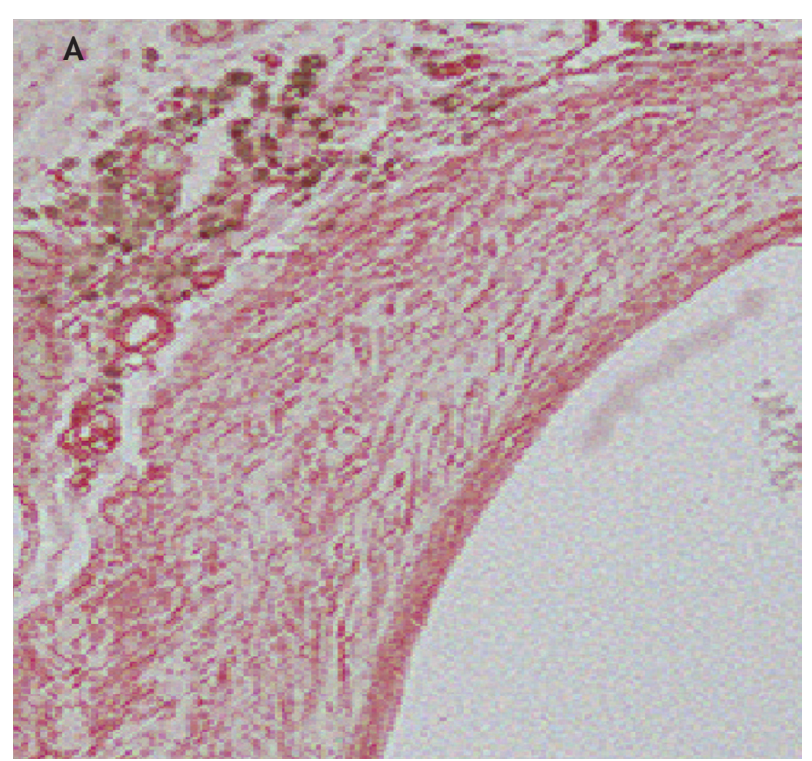

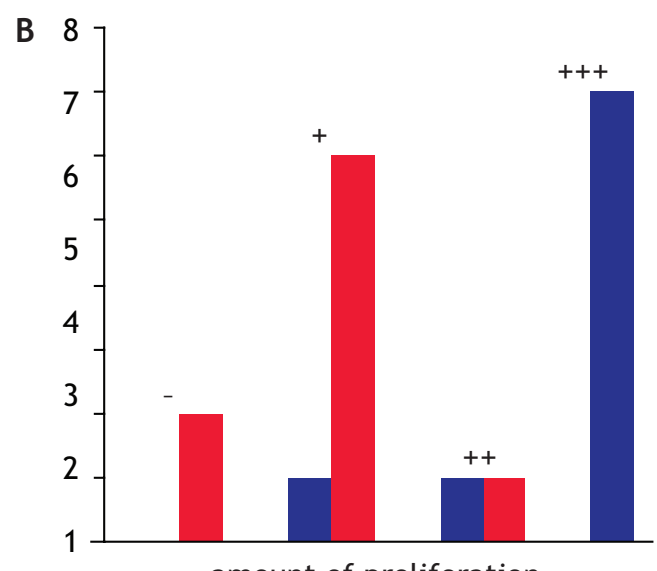

amount of proliferation

Control Activin A

Figure 6.2 | (A) Alpha-actin smooth muscle cell staining of cross-section of the vein graft three weeks after surgery, activin A group. (B). Semiquantative analysis of proliferation measured by BrdU staining. Bars stand for number of sections representing indicated amount of proliferation. (see page 121 for gray picture) 


